University of Louisville

ThinkIR: The University of Louisville's Institutional Repository

Electronic Theses and Dissertations

$12-2014$

\title{
A discourse on entrepreneurial identity : three essays.
}

Krishna P. Poudel

University of Louisville

Follow this and additional works at: https://ir.library.louisville.edu/etd

Part of the Entrepreneurial and Small Business Operations Commons

\section{Recommended Citation}

Poudel, Krishna P., "A discourse on entrepreneurial identity : three essays." (2014). Electronic Theses and Dissertations. Paper 1757.

https://doi.org/10.18297/etd/1757

This Doctoral Dissertation is brought to you for free and open access by ThinkIR: The University of Louisville's Institutional Repository. It has been accepted for inclusion in Electronic Theses and Dissertations by an authorized administrator of ThinkIR: The University of Louisville's Institutional Repository. This title appears here courtesy of the author, who has retained all other copyrights. For more information, please contact thinkir@louisville.edu. 


\title{
A DISCOURSE ON ENTREPRENEURIAL IDENTITY: THREE ESSAYS
}

\author{
By \\ Krishna P. Poudel \\ B.A., Tribhuvan University, Nepal, 2000 \\ M.A., Tribhuvan University, Nepal, 2002 \\ M.P.A., Cornell University, USA, 2007

\begin{abstract}
A Dissertation
Submitted to the Faculty of the

College of Business of the University of Louisville

in Partial Fulfillment of the Requirements

for the Degree of
\end{abstract}

Doctor of Philosophy

Entrepreneurship

University of Louisville

Louisville, Kentucky

December 2014 
Copyright 2014 by Krishna P. Poudel

All rights reserved 



\section{A DISCOURSE ON ENTREPRENEURIAL IDENTITY: THREE ESSAYS}

By

Krishna P. Poudel

B.A., Tribhuvan University, Nepal, 2000

M.A., Tribhuvan University, Nepal, 2002

M.P.A., Cornell University, USA, 2007

\section{A Dissertation Approved on}

December 1, 2014

by the following Dissertation Committee:

Dr. Bruce Kemelgor (Dissertation Co-chair)

Dr. Sherry Thatcher (Dissertation Co-chair)

Dr. Howard Aldrich

Dr. David Dubofsky

Dr. Subhash Lonial 


\section{DEDICATION}

This dissertation is dedicated to my parents

Mrs. Purn Kala Devi Poudel

and

the late Mr. Dansi N. Poudel

who were my first teachers, who provided me an unparalleled upbringing and education beyond their means, and who always supported and loved me unconditionally. I would not be who I am without you. I also dedicate this to my loving and caring sister

Laxmi Sharma

who was always there to support me through the thick and thin of life. 


\section{ACKNOWLEDGEMENTS}

I had some vague idea of what it would take to be a research scholar but I did not know the real ordeals, the commitment, and the help I would need from so many helping hands to mold me into one. This journey of a scholar would not have begun and the dissertation would not have been completed without this circle of people. I am very fortunate to have them in my life.

I must start by thanking my mentors and dissertation co-chairs, Dr. Sherry Thatcher and Dr. Bruce Kemelgor. First, thank you for going out of your way to make sure this dissertation happened. I owe my confidence, achievements, and future promise as a scholar to your mentorship. Dr. Thatcher, I must, additionally, thank you for making me challenge myself when I needed to, telling me what I needed to hear but was not prepared to, and trusting me as a scholar in so many projects. I also cannot forget the fine morning I came to your office with the idea of "intrinsic prospection of identity." Thank you for trusting the idea as well as your help in collecting the data for the dissertation. Dr. Kemelgor, our research on reward structure and my first research presentation in front of world-class scholars, at the Babson Conference, instilled in me the confidence that I was cut out to be a scholar. Thank you for trusting a first-year $\mathrm{PhD}$ student. I am indebted to both of you.

I am very grateful to my committee members, Dr. Howard Aldrich, Dr. David Dubofsky, and Dr. Subhash Lonial for their very important support and guidance on this 
dissertation. Moreover, I know you attended to my dissertation putting your other projects behind. Thank you so much for going the extra mile. Dr. Lonial, I must take the opportunity to thank you for the guidance and support you provided me while at Louisville. You have been an equally important and exceptionally supportive mentor to me. I would like to thank Dr. James Fiet for the support he provided throughout as well. I must express my gratitude to Dr. Melissa Baucus for her caring support throughout my stay at Louisville and beyond. Dr. Baucus, your emails came as light when I was in some dark places during this PhD saga. Thank you for not letting me falter. I am also grateful to all other internal and external faculty at the University of Louisville for shaping me into an academic. We became a cohort by a stroke of randomness but we became friends and brothers, confiding and sharing in each other's pains and pleasures, by choice. Thank you Dr. John Mueller and Dr. Christopher Crawford for being such a wonderful cohort. I should not forget to thank Dr. Sharon Kerrick and Daniel Johnsen for their help in the data collection as well as the survey respondents. I am very grateful to Tammy $\mathrm{H}$. Green at Management Department. Tammy, you have been more than a staff and you have taken care of our needs like a friend cum sister, always wearing that contagious smile.

Finally, I must express my endless gratitude to my parents Dansi N. Poudel and Purn Kala Devi Poudel. This dissertation, and the degree, is the direct result of your unprecedented support, love, and care. You gave me opportunities far beyond what your means could afford. You always inspired me to walk on the path of compassion, courage and honesty. That is what sustained me throughout this academic career. I am indebted to you more than you will ever know. I am also grateful to my sister, Laxmi Sharma. You were there by my side in the ups and downs of my career helping me even when you 
were in need of help. It would not have been possible without you. This note will be incomplete without some of my friends who were always there for me. Thank you Saurav Pudasaini, Krishna Dhakal, Nibha Shrestha, and Dr. Paloma Yannakakis. 


\section{ABSTRACT \\ A DISCOURSE ON ENTREPRENEURIAL IDENTITY: THREE ESSAYS \\ Krishna P. Poudel}

December 1, 2014

My dissertation provides theoretical insights on individual level entrepreneurial identity in three inter-related essays, drawing on multiple theories and disciplines. In the first essay, I advance a dual-process model of identity development, contributing to the debates in the broad identity literature. I articulate that the intrinsic prospection of identity is another fundamental process of identity formation, besides the social construction of identity, the prevalent notion in the literature. I propose a comprehensive conceptual framework of entrepreneurial identity. On the basis of this conceptual framework, I explain that there are within-group and between-group variations in the entrepreneurial identity of different types of entrepreneurs - innovators, imitators, and self-employed professionals. In the second essay, I develop and validate an entrepreneurial identity scale with socially constructed and intrinsically prospected identity dimensions. I theorize on the antecedents of entrepreneurial identity, and empirically test a conceptual model. Particularly, I investigate the influence of career related attitudes, personality characteristics, and family background on entrepreneurial identity. In the final essay, I argue that entrepreneurial identity is a missing link in the nascent entrepreneurship literature. Although the centrality of entrepreneurial intentions and entrepreneurial self-efficacy in predicting an individual's transition to an 
entrepreneurial career is well established, we do not adequately know what contributes to entrepreneurial intentions and entrepreneurial self-efficacy. To that end, I investigate the impacts of entrepreneurial identity on entrepreneurial intentions and entrepreneurial selfefficacy in a sample of potential entrepreneurs. Therefore, the third essay fills that critical gap. 


\section{TABLE OF CONTENTS}

\section{PAGE}

ACKNOWLEDGEMENTS ...........................................................

ABSTRACT ...........................................................................

LIST OF TABLES......................................................................

LIST OF FIGURES...................................................................

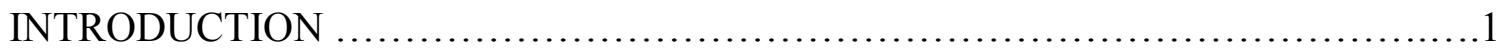

Research Questions \& Motivation...........................................

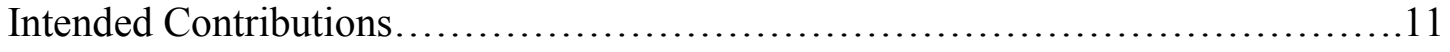

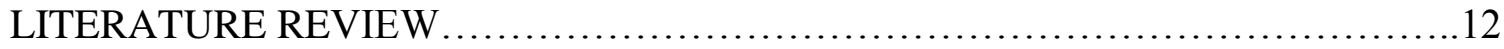

Concepts and Definitions.....................................................

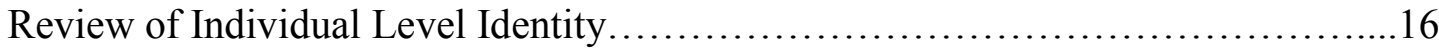

The developmental and dynamic nature of identity/career

identity ...................................................................

The antecedents of identity at the individual level..........................20

The consequences of identity at the individual level.........................25

Review of Entrepreneurial Identity Specific Literature.............................35

Collective/organizational level entrepreneurial identity.......................36

Individual level entrepreneurial identity.................................. 40

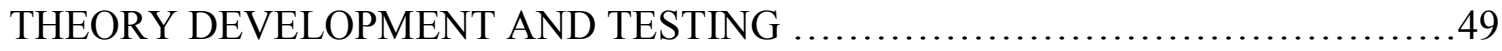


Understanding Individual Level Entrepreneurial Identity: Identity Development, Complexity, and Variations across Entrepreneur Types (Essay

\#1).

Identity development: The case for a dual-process .49

The differences and similarities between intrinsically prospected identity and socially constructed identity.

The conceptualization of entrepreneurial identity and its potential

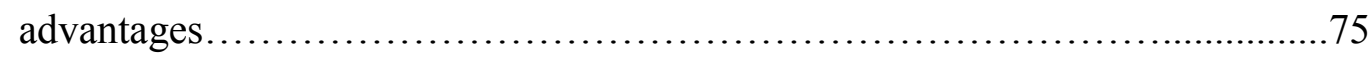

Entrepreneurial identity across entrepreneur types $\ldots \ldots \ldots \ldots \ldots \ldots \ldots \ldots \ldots . \ldots 7$

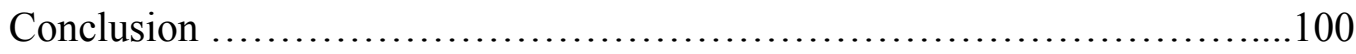

Exploring the Determinants of Individual level Entrepreneurial Identity (Essay

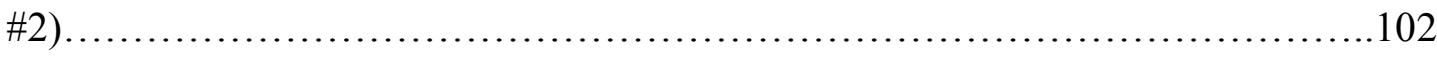

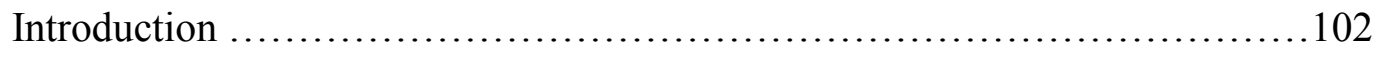

Job meaningfulness and entrepreneurial identity........................ 107

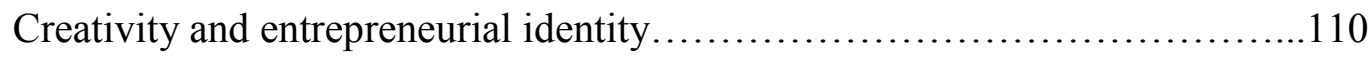

Family background and entrepreneurial identity $\ldots \ldots \ldots \ldots \ldots \ldots \ldots \ldots \ldots \ldots \ldots \ldots \ldots \ldots$

Personality characteristics and entrepreneurial identity $\ldots \ldots \ldots \ldots \ldots \ldots \ldots \ldots 114$

Method......................................................... 122

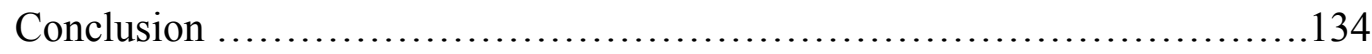

Entrepreneurial Identity: The Missing Link in Nascent Entrepreneurship (Essay \#

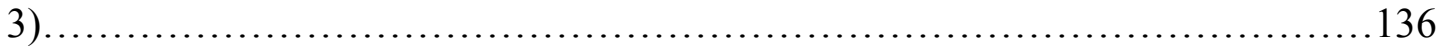

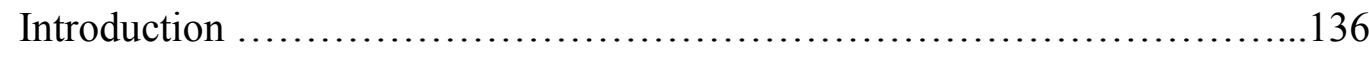

Entrepreneurial identity and entrepreneurial intentions ....................139 
Entrepreneurial identity and entrepreneurial self-efficacy................. 143

Method ............................................................... 148

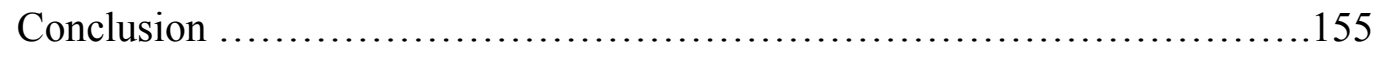

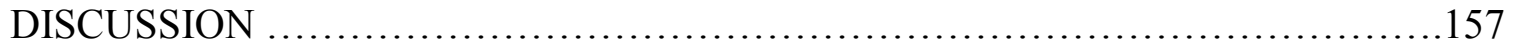

REFERENCES....................................................... 174

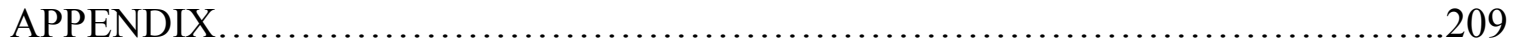

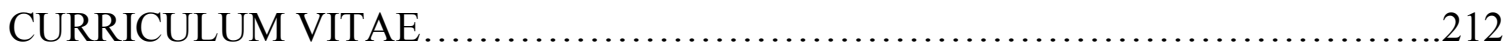




\section{LIST OF TABLES}

TABLE

PAGE

1. The Distinctions between IPI and SCI.

63

2. Descriptive Statistics, Zero-Order Correlations, AVE, SCR and Cronbach's

Alpha

3. Fit Statistics for Theorized Measurement Models, Constrained Measurement Models for Testing Psychometric Properties and Robustness Check, and Theorized Structural Model. .

4. Descriptive Statistics, Zero-Order Correlations, AVE, SCR and Cronbach's Alpha.

5. Fit Statistics for Theorized Measurement Models, Constrained Measurement Models for Testing Psychometric Properties and Robustness Check, and Theorized Structural Model. 


\section{LIST OF FIGURES}

FIGURE

PAGE

1. Conceptualization of Entrepreneurial Identity as a Superordinate Identity.....63

2. Constituents of Entrepreneurial Identity (EI) across Entrepreneur Types......89

3. A Theoretical Framework of the Determinants of Entrepreneurial Identity....................................................... 106

4. SEM Results for the Determinants of Entrepreneurial Identity.............133

5. An Entrepreneurial Identity Centered Model of Nascent Entrepreneurship..............................................139

6. SEM Results for the Entrepreneurial Identity Centered Model of Nascent Entrepreneurship.............................................154 


\section{INTRODUCTION}

Individual identity is a highly researched interdisciplinary area, including the contributions from various disciplines of management, organization science, social psychology, and vocational psychology, among others (Alvesson, 2010; Ashforth \&

Mael, 1989; Clark, Gioia, Ketchen, \& Thomas, 2010; Cooper \& Thatcher, 2010; Creed, Dejordy \& Lok, 2010; Dutton, Dukerich, \& Harquail, 1994; Dutton, Roberts, \& Bednar, 2011; Hogg \& Terry, 2000; Johnson \& Lord, 2010; Shepherd \& Haynie, 2009; Thatcher \& Zhu, 2006). Although "identity" as a research construct was conceptualized by management scholars decades ago (e.g., March \& Simon, 1958) and started gaining solid traction in the broader management literature in the late 1980s and early 1990s (Ashforth, Harrison \& Corley, 2008), it remained an un-researched topic in the entrepreneurship field until the turn of $21^{\text {st }}$ century. Personal attributes of entrepreneurs constituted one of the initial streams of entrepreneurship research and individual level entrepreneurship research has always been one of the dominant themes of inquiry throughout the development of the entrepreneurship discipline (cf. Grégoire et al., 2006 for a review). Against this backdrop, the paucity of research on the identity of potential and active entrepreneurs is somewhat surprising. In recognition of this gap, researchers have made explicit calls for research on entrepreneurial identity (cf. Ireland \& Webb, 2007). Responding to this call for, and the opportunity of, the development of theories on 
entrepreneurial identity, the last few years witnessed an initial development of both individual-level and organizational-level entrepreneurial identity literatures (Farmer, Yao, \& Kung-McIntyre, 2011; Fauchart \& Gruber, 2011; Hoang \& Gimeno, 2010; Miller \& Le Breton-Miller, 2011; Mitchell \& Shepherd, 2010; Milton, 2008; Moss, Short, Payne, \& Lumpkin, 2010; Murneiks \& Mosakoski, 2007; Navis \& Glynn, 2010; Navis \& Glynn, 2011; Shepherd \& Haynie, 2009b).

The preliminary work on entrepreneurial identity at different levels of analysis is dominated by conceptual and qualitative works (Hoang \& Gimeno, 2010; Mitchell \& Shepherd, 2010; Shepherd \& Haynie, 2009b; Fauchart \& Gruber, 2011; Navis \& Glynn, 2010) with a few exceptions (e.g., Farmer et al., 2011; Murneiks, 2007¹). Some of these early theoretical studies on individual level entrepreneurial identity ${ }^{2}$ center on role identities and they link role identity with entrepreneurial passion (Cardon et al., 2009; Hoang and Gimeno, 2010; Murneiks, 2007). Drawing on "role identity theory", Cardon et al. (2009) propose three entrepreneurial role identities-inventor role identity, founder role identity, and developer role identity-to advance the argument of entrepreneurial passion. These role identities provide some understanding of the transitional identities of entrepreneurs (e.g., from paid-employment to self-employment) and assist us in comprehending the distinctions of an entrepreneurial identity from other forms of role

\footnotetext{
${ }^{1}$ Unpublished doctoral dissertation.

${ }^{2}$ In this dissertation the term "entrepreneurial identity" refers to the identity at the individual level. The term "individual level entrepreneurial identity" is used when emphasizing the level. Entrepreneurial identity at other levels is always preceded by an appropriate adjective, e.g., organizational level entrepreneurial identity.
} 
identities (Cardon et al., 2009; Hoang \& Gimeno, 2010). However, as Fauchart \& Gruber (2011) observe, they discount the social context of entrepreneurial identity - such as the heterogeneous social motivations that shape individual attitudes and behaviors. In contrast, other authors (Fauchart \& Gruber, 2011) exclusively invoke the social identity theory lens (Tajfel \& Turner, 1979) to develop an entrepreneurial identity typology (Darwinian, Communitarian, and Missionary identities). Although these conceptual studies have contributed tremendously to the literature, as Murneiks (2007) observed, they have only scratched the surface of the entrepreneurial identity construct. We still do not know much about how these social identities and role identities of entrepreneurs fit together. Moreover, we do not know about the role of personal identity of entrepreneurs on their overall self-concept.

A personal identity captures the idiosyncratic aspects of an individual's selfconcept (Ashforth, Harrison, \& Corley, 2008; Brickson, 2000; Postmes \& Jetten, 2006). In this research, I contend that entrepreneurial identity concepts that do not take into account the idiosyncratic aspects miss the true essence of entrepreneurial identity. Relatedly, one of the influential theories in the entrepreneurship field, the effectuation theory (cf. Sarasvathy, 2001), assumes personal identity as the starting point of the entrepreneurial process. In addition, a great volume of the entrepreneurship research that originates in economics, finance, and strategic management academic traditions regards entrepreneurship as a career/occupational choice (Parker, 2009; Wilson, Kickul \& Marlino, 2007). Scholars have argued that an occupational identity is a major component of the self-definition of an individual (Ashforth \& Kreiner, 1999). Therefore, I argue that conceptualizing an entrepreneurial identity as a role identity or a social identity alone 
does not adequately capture the identity that characterizes a person's career and occupation either. In fact, a precise, congruent definition of entrepreneurial identity in the literature is also lacking. Therefore, before I proceed to lay out the gaps in the literature on entrepreneurial identity and articulate how I address them in this dissertation, it is necessary to conceptualize entrepreneurial identity (a thorough conceptualization follows in later sections). I refer to entrepreneurial identity as a perception of self-concept among active or potential entrepreneurs of 'who they are' and 'who they want to be' as an entrepreneur which is simultaneously reflected in their role identities, social identities, career identity and personal identity.

There are several gaps in the literature on entrepreneurial identity. My theoretical ambition and empirical exploration in this dissertation is based on these gaps that I identify. First, researchers have considered entrepreneurship as a process of social construction where identities and organizations are co-produced over time (Downing, 2005). Similarly, others have argued that, in many respects, entrepreneurship is an “identity construction process" (Ireland \& Webb, 2007). From the seminal identity literature, which is enriched and informed by multiple social sciences, we know that an identity is a dynamic entity and comes to exist through a developmental process (Erikson, 1959, 1968; Goodman, 1960; Tiedeman, 1961). However, we do not yet have much theoretical understanding of the dynamics of entrepreneurial identity formation and development. Particularly, we do not know whether social construction is the only process of entrepreneurial identity formation or whether entrepreneurial identity is also the function of other processes. Relatedly, we also do not know if the entrepreneurial identity of certain types of entrepreneurs (for instance, an inventor who founds an 
enterprise based on radical innovations) is similar to, or different from, the entrepreneurial identity of other types of entrepreneurs (for instance, a law professional who founds a new company and hires professional employees). I address these gaps in Essay \#1. Drawing on existing works (e.g., Alvesson, 2010), I propose a dual-process identity development framework which includes intrinsic prospection and social construction of identity development; these will be defined and explained in later sections. I compare and contrast the intrinsic prospection and the social construction of identity. I conceptualize and explore the complex, hierarchical nature of entrepreneurial identity as well. Based on the identity development processes of intrinsic prospection and social construction, I theorize on the commonalities and distinctions of the entrepreneurial identity across three entrepreneur types: innovators, imitators, and selfemployed professionals. Note that understanding the possible impact and imprinting of an entrepreneurial identity on the organizational emergence processes, strategies, organizational successes, and organizational forms (Cardon et al., 2009; Drori, Honing, \& Sheaffer, 2009; Fauchart \& Gruber, 2011; Hoang \& Gimeno, 2010; Miller \& BretonMiller, 2011) requires a deeper theoretical inquiry and wide-ranging empirical investigations because of the complex nature of the multiple identities of entrepreneurs (cf. Shepherd \& Haynie, 2009b).

Second, the pioneering research on entrepreneurial identity has emphasized the critical importance of entrepreneurial identity in understanding entrepreneurial motivations and entrepreneurial passion as well as entrepreneurial behaviors (Cardon et al., 2009; Murneiks, 2007; Murnieks \& Mosakowski, 2007). However, we have a limited understanding of the factors that contribute to entrepreneurial identity formation to begin 
with. To my knowledge, only Farmer et al. (2011) have empirically investigated this question so far. These authors show evidence that the congruence between one's selfdefinition and the perceived entrepreneurial role-definition enhances the entrepreneurial identity aspiration. However, the research in the broad literature on identity has identified some predictors of identity. Broadly, contextual antecedents (e.g., Dukerich, Golden, \& Shortell 2002; Dutton et al., 1994; Gonzalez \& Denisi, 2009; Mael \& Ashforth, 1992) as well as demographic and personal attribute related antecedents (e.g., Anteby 2008; Diemer \& Blustein, 2006; Jackson \& Neville, 1998) have been examined. In this light, in Essay \# 2, I address these voids by looking at contextual and personal attribute related factors that might influence entrepreneurial identity. Specifically, I investigate the roles of family background, personality characteristics (extraversion and imagination), and attitude towards career-related rewards (value attached to job meaningfulness and creativity) on entrepreneurial identity.

Finally, entrepreneurship literature suggests that an entrepreneurial intention is a significant predictor of entrepreneurship (Souitaris et al., 2007). Since the intention for a particular career, a distinct role, or a specific behavior is likely to be influenced by the self-concept of individuals (Andersen \& Chen, 2002; Gelfand et al., 2006; Gore, Cross, \& Kanagawa, 2009), exploring the impact of entrepreneurial identity on entrepreneurial intentions is critical. Similarly, self-efficacy (the task-specific self-confidence) has been associated with actual task performance in both entrepreneurship and nonentrepreneurship contexts (Baum, 1994; Shane et al., 2003). The degree to which individuals engage in certain actions and behaviors is contingent on their sense of ability to successfully engage in those actions and behaviors (Wilson et al., 2007). Relatedly, the 
corresponding identities of those particular actions and behaviors (in this case, entrepreneurial actions and behaviors) might dictate the self-efficacy related with those particular actions and behaviors. However, we do not know much about the influence of entrepreneurial identity on entrepreneurial intentions and entrepreneurial self-efficacy. In Essay \#3, I address this void in the literature.

In summary, to address the gaps in the literature, I investigate the entrepreneurial identity development processes, the nature and structure of entrepreneurial identity, and the commonalities and distinctions of entrepreneurial identity among three different types of entrepreneurs in the conceptual essay (\# 1). I derive propositions to that end. I explore the antecedents and consequences of entrepreneurial identity in a sample of potential entrepreneurs in the empirical essays (\# 2 and 3), respectively.

It is important to address these voids in the literature on entrepreneurial identity for multiple reasons. First, the criticism of the early research on entrepreneurship that attempted to exclusively explain entrepreneurial behaviors and start-up activities with personality characteristics is largely valid (cf., Grégoire et al., 2006, Gartner, 1988). However, researchers have now made a strong case that "human agency" and related cognitive, affective, and motivational factors as well as personality characteristics are important in explaining entrepreneurship (Cardon et al., 2009; Markman, Balkin, \& Baron, 2002; Markman \& Baron, 2003; Shane, Locke \& Collins, 2003; Zhao, Seibert, \& Lumpkin, 2010). The research on entrepreneurial identity will thus inform the ongoing debate on the determinants of entrepreneurship. Second, exploring the entrepreneurial identity among potential entrepreneurs holds significant theoretical as well as practical interest. One important premise of this dissertation is that the entrepreneurial identity 
construct is a cognitive construct applicable to both active entrepreneurs and potential entrepreneurs who are currently in paid-employment. In fact, considerable evidence shows that most entrepreneurs switch to an entrepreneurship career from paidemployment or other careers in established organizations (Nanda \& Sørensen, 2010; Obschonka, Goethner, Silbereisen, \& Cantner, 2012; Parker, 2009). The investigation of the entrepreneurial identity of potential entrepreneurs may allow us to broaden our understanding on "why, how, when, and to what consequence" certain individuals, and not others, engage in the rather arduous, and often risky, process of entrepreneurship (Shane \& Venkataraman, 2000). We know that $66 \%$ of new ventures fail within six years (Timmons, 1994; Zacharakis, Meyer, \& De Castro, 1999). The entrepreneurial identity of potential entrepreneurs might be a strong marker of whether they will actually engage in enterprise start-up activities - which is one of the most pressing questions in entrepreneurship research. Finally, the inquiries on entrepreneurial identity will also have pragmatic and theoretical implications on the person-organization fit debate and the career choice issues (Antoncic \& Hisrich, 2001; Parker, 2009). For instance, employees with a strong entrepreneurial identity might be more motivated to work in a start-up venture or in an existing corporate organization that has a reputation of being entrepreneurial, rather than in a traditional corporate organization.

The rest of the dissertation, presented in an essay format, is organized as follows. In the remaining parts of the introduction, I outline specific research questions regarding the gaps identified above and furnish the motivations behind these research questions. I also articulate the contributions of this dissertation. In section 2, I review the general literature on identity which focuses on individual level identity as well as the literature on 
entrepreneurial identity. I organize the general literature on identity in the following subsections: concepts and definitions; the developmental and dynamic nature of a career identity; the antecedents of an identity at the individual level; and the consequences of an identity at the individual level. Then, I review the entrepreneurial identity literature at both the organizational level and individual level. Theory development and empirical testing comprises section 3 in which I develop relevant propositions and hypotheses in three inter-related essays. I present the results of empirical analyses for each essay separately and draw conclusions. In the final section, the discussion section, I discuss on the dialogues that I initiated and contributed to in the context of the main-stream identity literature as well as the entrepreneurial identity literature. I identify avenues for further theoretical and empirical research on entrepreneurial identity. I also articulate the implications of my dissertation research and findings for practice, policy, and entrepreneurship education in a holistic manner.

\section{Research Questions \& Motivation}

How do social identities, role identities, personal identity and the career identity of an entrepreneur - or of a potential entrepreneur, for that matter - fit together? What are the underlying processes of entrepreneurial identity formation? Do these processes explain the commonalities and distinctions of entrepreneurial identity among entrepreneur types? I investigate these specific research questions in Essay \# 1. The rationale behind the three stated questions is twofold. First, given the complex nature of entrepreneurial behaviors, the corresponding identity of entrepreneurs may be a complex identity. In order to understand the direct influence or implications of entrepreneurial 
identity, we need to understand the construct at a deeper level. Second, we have theory and empirical evidence to suggest that entrepreneurs have a diverse set of motivations for firm founding, and as such, they are not a homogenous group of actors (cf. Davidsson, 2006). Therefore, the identity they hold may have certain commonalities as well as certain distinctions. Take, for instance, the two entrepreneurs mentioned earlier. On the one hand, they might share a common self-image. On the other hand, simultaneously, they may differ substantially in their self-concept. The exploration of the entrepreneurial identity development processes and the understanding of the complexity of entrepreneurial identity may illuminate the commonalities and the distinctions of selfconcept across these entrepreneurs.

The questions theorized upon and empirically tested in the second essay revolve around the antecedents of entrepreneurial identity. Particularly, I ask what contextual, attitudinal and personality trait factors are likely to shape entrepreneurial identity and whether they influence the socially constructed entrepreneurial identity and the intrinsically prospected entrepreneurial identity differentially. The rationale is that identifying the antecedents and the magnitudes of their impact on the focal construct, entrepreneurial identity, is a logical, preliminary step on the investigation of an underresearched/un-researched phenomenon.

Finally, what are the consequences of entrepreneurial identity of potential entrepreneurs, particularly, on their entrepreneurial self-efficacy and entrepreneurial intentions? Because entrepreneurial intentions and entrepreneurial self-efficacy both have been linked to entrepreneurial actions, it is necessary to understand the precursors of these variables. 


\section{Intended Contributions}

The intended contributions of this research are as follows. First, by theorizing and testing the models of entrepreneurial identity at the individual level, I contribute to the foundational work on entrepreneurial identity. Second, by making a case for a dualprocess of identity development, I contribute to the mainstream identity literature that cuts across disciplines - such as management, organizational behavior, and applied psychology, among others. Third, the examination of entrepreneurial identity with a career approach, and the insights generated therein, also contributes to career literature. Fourth, by connecting entrepreneurial identity with entrepreneurial intentions and entrepreneurial self-efficacy, and by empirically testing the models in a sample of potential entrepreneurs, this research contributes to the nascent entrepreneurship literature. Fifth, entrepreneurship scholars have called for contributions that can inform conversations of broader management discipline and other disciplines (Busenitz et al., 2003). Because of the interdisciplinary nature of "identity" and the particular contribution of Essay \# 1, I expect to contribute to that interdisciplinary dialogue. Finally, because I investigate the impact of entrepreneurial identity on entrepreneurial intentions and entrepreneurial self-efficacy which are linked to entrepreneurial actions (cf. Souitaris et al., 2007; Wilson et al., 2007), it has practical implications for practitioners, policy makers, and educators. 


\section{LITERATURE REVIEW}

\section{Concepts and Definitions}

The identity literature unanimously suggests that multiple identities are situated within an individual (cf. Feldman, 1979; Markus \& Nurius, 1986; Pratt \& Foreman, 2000; Stryker \& Serpe, 1982; Tajfel \& Turner, 1979). These multiple identities can be broadly described as personal identities, role identities and social identities (Ashforth, Harrison, \& Corley, 2008; Brickson, 2000; Postmes \& Jetten, 2006). Originating and conceptualized in social identity theory (SIT) and social categorization theory (SIC), a social identity refers to the self that individuals perceive because of their affiliation with, ascription to, or belongingness to a certain social institution (e.g., an organization) or a group/unit or a status or a class (e.g., race) (Ashforth et al., 2008; Brickson, 2000; Clair, Beatty, \& Maclean, 2005; Haslam, \& Reicher, 2006; Haslam \& Ellemers, 2005; Tajfel \& Turner, 1986). A personal identity refers to the self that individuals perceive owing to their unique and idiosyncratic aspects as individuals (such as their interests and values) (Brickson, 2000; Tajfel \& Turner, 1986). Based on structural identity theory and identity control theory (together, loosely called identity theory), scholars refer to a 'role identity' as the definition of self that individuals perceive based on a certain role they play in a particular context (Ashforth et al., 2008; Brewer \& Gardner, 1996; Brickson, 2000; Stryker \& Burke, 2000). 
To avoid any possible terminology confusion, in this dissertation I define identity as the perception and definition of "the self" by an individual. Note that social identities can be conceived at different levels of analysis. For example, organizational identity can be an individual level identity, that is, to the extent that an individual perceives his or her self-image based on the affiliation to a certain organization (cf. Dutton, Dukerich, and Harquail, 1994). Organizational identity can also be what and how an organization perceives its self-image to be (in other words, the stakeholders' collective perception) (e.g., Navis \& Glynn, 2010). The social identity discussed in the context of this dissertation is at the individual level, unless otherwise explicitly stated.

Like motivation and personality characteristics, identity is a very fundamental, integral attribute of individuals that impacts their attitudes, actions, affects, intentions, and behaviors (Andersen \& Chen, 2002; Gelfand et al., 2006; Gore, et al., 2009; Mael \& Ashforth, 1992). Some researchers even boldly argue that identities are the only source of intentional efforts (cf. White 1992, p 236). On the other hand, the scope of identity is immensely broad as identities are comprehended at different levels of analysis and across various contexts: cultural, ethnic, gender, racial, national, vocational, and organizational contexts, among others. Since I aim to develop an individual level entrepreneurial identity theory and conduct corresponding empirical analyses, I review the general identity literature at the individual level.

There is also diversity among scholars in their definition of "identity, or identification" (cf. Mael \& Ashforth, 1992). Consistent with identity literature in the management research domain (Mael \& Ashforth, 1992), identities and identification in general, and career identity in particular, are referred to in this dissertation as 
perceptual/cognitive constructs. Career related behavioral, attitudinal, affective factors are considered potentially being either antecedents or consequences of career identity. Accordingly, an individual will only need to see him- or herself as psychologically (that is, cognitively and/or emotionally) connected with a certain career in order to have that particular career identification. An individual identifying with a certain career identity (or entrepreneurial identity) is likely to, but does not necessarily have to, demonstrate any behavior typical of that career. Note that a career identity is also inherently longitudinal because it involves "making sense of one's past and present and giving direction to one's future (although the relevance and importance of the past, present, and future tend to change over the life course)" (Fugate, Kinicki, \& Ashforth, 2004: p 20).

Similarly, the conceptualization of entrepreneurship, and who an entrepreneur is, for that reason, is also broad and sometimes fluid in the literature (Shane \& Venkataraman, 2000). Consistent with the economics, entrepreneurship, and career choice literatures (Douglas \& Shepherd, 2002; Dobrev \& Barnett, 2005; O’Neil \& Ucbasaran 2010; Parker, 2009) for the purposes of this dissertation, anyone who founds and/or owns and operates a business is referred to as an 'entrepreneur.' As previous research has indicated (cf. Davidsson, 2006), the motivation behind founding and/or owning and operating a business can be very diverse- from financial security to a lifestyle preference to the realization of a grand vision, and everything in between. The position of this dissertation is that, irrespective of the motivation, to some degree, engagement in entrepreneurial activities is a career choice (cf. Parker, 2009) because, like any other career, entrepreneurship is a sequence of related work experiences over time (Arthur, Khapova, \& Wilderom, 2005; Hoekstra, 2011). In fact, several researchers agree 
that entrepreneurship is a career choice and have conducted research taking that approach (cf. Chen, Greene \& Crick, 1998; Douglas \& Shepherd, 2002; Dobrev \& Barnett, 2005; Markman, Balkin, \& Baron, 2002; Eddleston \& Powell, 2008). Researchers even argue that career development is, in part, the interactive progression of internal career identity (Hoekstra, 2011). Therefore, I take a career choice approach to entrepreneurial identity. It forms the basis of my theory development in that I argue that career identity is one of the basic building blocks of the entrepreneurial identity concept.

The remainder of the review is divided into two main parts with several subsections. In the first part, I review the general identity literature at the individual level with a particular focus on the developmental and dynamic nature of career identity, the construction of/antecedents of individual level identity, and the consequences of individual level identity in general. The purpose of this rather broad review is twofold. First, although the theory and empirical analysis of this dissertation centers on entrepreneurial identity, the new concepts developed in the theory essay (\#1) draws fundamentally on the broad literature on identity and has immediate implications for the identity theories/research domain in general. Second, the entrepreneurial identity literature is in its early period of development, and therefore, does not provide enough insight, evidence, and conversations required for the theoretical and conceptual grounding of this dissertation. The second part of the review looks at the entrepreneurial identity literature both at the individual and collective levels. Although the focus of the review is on the individual level, reviewing the collective level entrepreneurial identity is likely to facilitate the understanding of individual level entrepreneurial identity as well. 


\section{Review of Individual Level Identity}

\section{The developmental and dynamic nature of identity/career identity}

Scholars from various academic traditions have argued, furnished evidence, and provided insight on the dynamic and developmental nature of identity in general, and that of the career identity in particular. In this section of the review, I draw on these multiple traditions.

\section{The insights from the various denominations of psychology and}

interdisciplinary sciences. The career aspect of an individual's identity developed in the psychology literature quite early and the pioneering theorists (Erikson, 1959, 1968; Tiedeman, 1961) considered work and career choices as central to an individual's selfdefinition (cf. Waterman \& Waterman, 1976). These theorists laid the foundations of the developmental and dynamic nature of identity. For instance, Tiedeman (1961) theorized that the vocational identity of individuals goes through a period of anticipation to a period of implementation and finally to a period of adjustment. Similarly, early researchers conceptualized identity in terms of crisis and commitment, assuming the dynamic and developmental nature of occupational identity, which they categorized into four different identity statuses and empirically investigated (Erickson 1959, 1968; Marcia, 1966, Schmitt-Rodermnud, \& Vondracek, 1999). According to this scheme, there are four occupational identity statuses: identity achievement, identity moratorium, identity foreclosure, and identity diffusion. Individuals "achieve a vocational identity" when they have been through a period of crisis and formed a comparatively stable career commitment. However, if they have not committed to any vocation and are not actively 
seeking to do so, their career identity will be in identity diffusion status (Waterman \& Waterman, 1976). When one commits to a particular career/work without considering other careers seriously, her/his career identity is regarded to be in "identity foreclosure status." Further, if the individual is in a crisis situation and trying to arrive at a career choice among certain alternatives, it is considered as being in "identity moratorium status."

Gouldner (1957) introduced the concept of a manifest social identity (the identity that is considered to be relevant by other group members in a given setting) and a latent social identity (the identity that is considered to be irrelevant, inappropriate to consider, or illegitimate to take into account by a group's members in a given setting or social context). For example, a female entrepreneur may possess a manifest social identity with the organization she creates. Simultaneously, she may be a feminist/activist who holds a strong gender identity that is latent. Gouldner argued that social scientists often unjustifiably overlook the latent identities. He makes the point that latent identities and roles are significant since they influence manifest identities. These influences can often create disequilibrium in the manifest roles/identities. It might create enough conflict to impair the individual's conformity to the expectations, behaviors, and obligations of the manifest roles/identities. He suggests that "people playing different manifest roles may be performing similar latent roles and, conversely, those performing the same manifest role may be playing different latent roles" (p, 286). To sum up, the duality of an identity as "manifest and latent" and the counterinfluences of manifest and latent identity essentially suggest that career identity is dynamic in nature. 
Researchers in identity literature have talked about an identity in terms of a "dynamic self" and proposed that an identity is a dynamic entity with possible and provisional self-images (Ibarra, 1999; Markus \& Wurf, 1997; Markus and Nurius 1986) (cf. Clark et al., 2010: p 399 for the discussion). Similarly, the concept of "identity work" inevitably suggests that identity is anything but static in nature because this notion refers to "people being engaged in forming, repairing, maintaining, strengthening or revising the constructions that are productive of a sense of coherence and distinctiveness" (Alvesson, 2010: p 201).

Other contemporary dialogues in different literatures emphasize the role of human agency on various human activities and behaviors (Giddens, 1991) - including the role of "agency and control" on identity (cf. Alvesson, 2010). Although an individual's degree of awareness and/or effort towards identity development is likely to vary, the agency and the sense of control in identity formation imply that identity is dynamic. More importantly, Giddens (1991) and other scholars (Alvesson \& Willmott, 2002) conceptualize identity as a reflexively organized narrative which the individual arrives at by engaging in various competing discourses and experiences. They further note that "self-identity is continuity across time and space as interpreted reflexively by the agent." Career identity, as a prominent identity of individuals, arguably would require the participation of the agent in various competing or aligning discourses. That means, as per the conceptualization proposed by Giddens and other prominent scholars, that a career identity should be dynamic and developmental.

The insights from career sciences. Researchers in career sciences explicitly theorize identity as a developmental concept. They argue that identity development 
requires an exploration of a variety of roles and behaviors (Brown, Glastetter-Fender, \& Shelton, 2000; Cheek \& Jones, 2001; Marcia et al., 1993). The assertion is that career identity is critically, and essentially, exploratory in nature (cf. Brooks, Cornelius, Greenfield, \& Joseph, 1995). Conceivably, the identity formed through an exploratory process must be dynamic and developmental. Similarly, other classical researchers have also alluded to the dynamic and developmental nature of career identity with concepts such as identity flexibility (referred to as "the deliberate and informed comparison of one's present identity commitment with other possibilities") (cf. Grote \& Raeder, 2009; Whitebourne 1986, p 164). Taken together, this research domain also clearly suggests a dynamic and developmental career identity.

The insights from organizational and management sciences. Management and organizational research, which largely regards identities as tools of control and regulation, also views identities (such as an organizational identity) as incrementally adaptive and changeable in the long run (Albert \& Whetten, 1985; Dutton \& Dukerich, 1991; Brown \& Starkey, 2000). Recently organizational researchers have articulated various approaches of work-related identity research (e.g., career identities), which includes "the developmental perspective of identity" as one of the major approaches (Dutton, Roberts, \& Bednar 2010). As these authors suggest, the developmental approach to identity entails focusing on the change of identity over time and thus assumes the dynamic nature of identity ( $\mathrm{p} 271)$.

In summary, from this review, we understand that identity research across disciplines agrees that career identity is dynamic and developmental. We know the following: a career identity is central to an individual's self-concept; certain identities 
might be salient/manifest or latent depending on contexts; identity development includes exploratory processes; human agency and control play a role in identity development; and individuals hold an identity after engaging in competing and converging discourses about the self. These insights on the dynamic and developmental nature of an identity in general, and the career identity in particular, provide logical traction for the development of my theory. Particularly, as explained in the upcoming sections, these insights inform "the dual-process identity development framework" that I articulate as well as the comprehensive conceptualization of entrepreneurial identity.

\section{The antecedents of identity at the individual level}

Identifying the factors that shape the identity of an individual has been one of the fundamental questions of identity literature (Ashforth et al., 2008). Identification is conceptualized as the process of embedding an individual in a relevant identity (Ashforth et al., 2008: p 326). Thus, the review will take into consideration the antecedents and consequences of identity and identification to the extent that they are relevant to the focus of the dissertation, that is, to career and organizational identities. The antecedents of identity and identification are organized under three broad categories below- some antecedents belong to multiple categories.

The contextual antecedents of identity. In an organizational context, Brickson (2000) proposed that the personal, relational and collective identity orientations of individuals are the function of contextual factors such as organizational structures, task structures and reward structures. Empirically, Mael \& Ashforth (1992) found the following contextual factors to be related to organizational identification-the existence of 
a mentor, organizational distinctiveness, organizational prestige, and intraorganizational competition. Similarly, other studies also documented that the diversity climate in the organization, the attractiveness of the organization, and the prestige of the organization influenced organizational identification (Dukerich, Golden, \& Shortell 2002; Dutton et al., 1994; Gonzalez \& Denisi, 2009). In the context of organizational boundary-spanning, Bartel (2001) established that when there is a favorable intergroup comparison (in engagement with clients), it enhances the collective self-esteem of the employees, and thereby leads to stronger organizational identification. Epitropaki (2013) found that a psychological contract breach in the employee-organization relationship results in a negative influence on organizational identification. Olkkonen \& Lipponen (2006) looked at the influence of various types of justice on different identity targets in an organization. They found that organization-focused distributive justice and procedural justice were related to employees' identification with the organization. On the other hand, supervisorfocused interactional justice was related to work-unit identification.

In a qualitative study conducted in a service firm, Alvesson and Kärreman (2007) found that the human resource management system (i.e., practices and activities) shapes the organizational identity at the organizational level as well as at the individual level. This study also concludes that the human resource management system "works as a major linking mechanism between organizational identity and individual identity regulation" (p. 719). Bartels et al. (2007) argued for the importance and influence of internal communication climate and the perceived external prestige of the organization on the members' multiple organizational identities. They also showed that the employees' identification with the lower level unit of the organization influences their identification 
with higher level units. Jones \& Volpe (2011) documented that contextual organizational factors, such as organizational distinctiveness, as well as organizationally affiliated members' social networks (particularly network size), impact organizational identification. Farmer, Tierney, \& Kung-McIntyre's (2003) study demonstrated that an exposure to a culture of creativity, an individual's own perception of her/his past creative behaviors, and the perceived co-worker role expectations for creativity positively impact the creative role identity, which, in turn, gives rise to creative performance. In a qualitative study, Chreim et al. (2007) demonstrated a complex, dynamic influence of institutional factors, organizational factors, and individual factors on the reconstruction of professional role identity among physicians. Their findings indicate that "agentic reconstruction of professional role identity is enabled and constrained by an institutional environment" (p 1515). Delmestri (2006) also found an intricate, concerted impact of various local, national, and transnational institutional factors (such as cultures, rules and regulations, norms, and ideas on personality) on the formation of the multiple identities of middle-level managers.

The demographic, attitude, personality trait, and motivation related antecedents

of identity. Disparate categories of antecedents related with the attributes of an individual have been investigated in the context of career-related identities. For example, Waterman \& Waterman (1976) presented the case that education and the nature of motivation (intrinsic or extrinsic) impact career selection and thereby vocational identity. They empirically found an association to that effect. Jackson \& Neville (1998) looked at the factors that shaped the vocational identity for the African American students in a university with predominantly white students. This research indicated that the 
internalization of racial identity and other demographic factors had bearings on students' vocational identity. However, the influence was differential for males and females. Investigating the selective use of various desired identities as organizational control instruments in an aeronautic plant, Anteby (2008) found that managerial leniency enhanced workers' occupational identity. Diemer \& Blustein (2006) examined the role of critical consciousness (the ability of individuals to assess and overcome socio-political barriers) as a predictor of career development among urban adolescents. The results showed that those with a higher level of critical consciousness had greater clarity regarding their career identity. Similarly, Dobrow and colleagues (cf. Dobrow et al., 2012; Dobrow \& Higgins, 2005) documented that development networks ${ }^{3}$ had a bearing on the clarity of professional identity.

The study of Johnson, Morgeson, \& Hekman (2012) asserted that cognitive identification and affective identification are distinct forms of social identification in organizational contexts which are differentially affected by personality characteristics. Specifically, extraversion was found to influence affective identification and neuroticism was found to be related with cognitive identification. Examining the participants in a business incubator, Kornberger \& Brown (2007) argued that the notion of ethics is a meaningful, discursive resource for constructing both personal and collective identities. They found that people indeed drew on the notion of ethics for identity construction.

\footnotetext{
3 "Groups of people who take an active interest in and action toward advancing a protégé's career." (Dobrow et al., 2011)
} 
The behavioral antecedents of identity. While identity researchers theorize an identity as the precursor of behaviors, in a majority of the studies, some researchers looked at the behavioral antecedents of identity as well. In a multi-method study, examining how the giving behavior (giving back by the employees) impacts their affective commitment to the organization, researchers (Grant, Dutton, \& Rosso, 2008) found that this commitment is enhanced through the augmentation of personal prosocial identity and organizational prosocial identity. In other words, a behavioral antecedent influences identity which, in turn, affects commitment. Some researchers have studied the nature of the relationship between leadership behavior and its impact on the followers' identity in an organizational context. For instance, Conger, Kanungo, \& Menon (2000) found that the strength of an employee's collective identity is positively influence by the charismatic leadership behavior of her/his managers. Similarly, other studies have demonstrated the influence of leadership role, especially that of transformational leadership on organizational identification (Epitropaki, 2013; Epitropaki \& Martin, 2005).

To summarize, the review of this general literature on the antecedents of identity offers the following insights for the present research. We understand that various types of identities (personal, role, and social identities) are influenced by different types of contextual factors at different levels. Factors related with different aspects of an organization are found to impact both the organizational and professional identity of individuals. This informs the conceptualization of entrepreneurial identity as well as the theorizing of contextual determinants of entrepreneurial identity in the present dissertation. While we have some understanding that reward structures have a bearing on 
identities, we do not know much about how an individual's attitude towards these organizational rewards impact identity in particular. Therefore, to some extent, I contribute to fill this gap in the broad identity literature by developing theory and empirically testing the influence of career-related attitudes on entrepreneurial identity.

Similarly, this review documents that demographic and personal attribute related factors also have a bearing on identity and identification, which further provides a basis for personality characteristics and career attitude related antecedents of entrepreneurial identity theorized in Essay \# 2.

\section{The consequences of identity at the individual level}

Identity and psychological well-being. One of the widely researched consequences of identity is the psychological well-being of an individual. Briscoe et al. (2012) found that individuals with self-directed protean career attitude are more likely to develop identity awareness which, in turn, leads to psychological well-being for those individuals. Brook, Garcia, \& Fleming (2008) also looked at how various/multiple identities that an individual holds, as a part of their self-concept, influence their psychological well-being. More particularly, they look at the interactive influence of the importance of these identities in the person's general self-concept, the harmony among the identities, and the number of identities. They found that identities that were very important for them and that were in harmony (i.e., facilitated each other) lead to greater psychological well-being. In addition, this interactive effect on psychological well-being was stronger when harmonious identities were higher in number relative to when they were lower in number (i.e., a three-way interaction effect). However, the psychological 
well-being was lower when these highly important identities contradicted each other. Herrbach (2006) hypothesized that "organizational identification reflects the overall psychological relevance of one's membership in an organization; it is therefore correlated with experiencing both positive and negative affective states at work" (p 633).

Identity and commitment, cooperative intentions, and citizenship behaviors. An important researched outcome of an organizational/social identity is organizational support-in various forms and manifestations. Mael \& Ashforth (1992) found that organizational identification leads to both intentional and behavioral support for the organization. More particularly, their study revealed that the employees who demonstrated strong organizational identification were willing to recruit others for their organization, participated in various organizational functions, and even contributed financially to the organization. In two related field studies, Blader \& Tyler (2009) examined the role of social identity (work group being the target identity) on employees' engagement in extra-role behaviors. They not only found that social identity has a positive impact on extra-role behaviors but also demonstrated that it mediates the relationship between two predictors (procedural justice and economic outcomes judgment) and the extra-role behavior. Note that the social identity conceptualization usually adopted in organizational research is the cognitive sense of belonging to a social unit/institution/group. But researchers in other academic traditions conceptualize social identity as consisting of two additional dimensions also-respect (standing and acceptance within the group) and pride (the group's worth and status) (cf., Blader \& Tyler, 2009; Tyler \& Blader, 2001). Drawing on this multidimensional concept of the social identity framework, Boezeman \& Ellemers (2007) examined the impact of the pride and respect 
dimensions of social identity on the commitment and cooperative intent of volunteers of a volunteer organization. Their findings suggest that pride and respect indirectly impact the cooperative intent of the volunteers, with organizational commitment functioning as a mediator. Similarly, Bagozzi et al. (2012) documented that a consumer (a Ducati motorcycle owner in their study) identifies not only with an organization (Ducati the company) but also with various targets of social identity (friendship group, virtual community, the brand and the company itself) for that organization. The consumers achieved a satisfying self-definition through these identity targets which lead to positive outcomes for the organization, such as resilience to negative information about the organization and the social promotion of the organization. In a similar type of study conducted in the context of organization-client relationship (organizational boundary spanning), Bartel (2001) found that an enhanced organizational identity (due to boundary-spanning experiences of an organizational member) has work behavior consequences. She found that stronger organizational identification leads to higher interpersonal cooperation, work related efforts, and advocacy for the organization. Bavel and Cunningham conducted multiple experiments (2012) looking at how social identity impacts, and might provide a framework, for explaining personal memory. Their finding is that certain aspects of social identity shape social attention as well as personal memory.

In a seminal study that examined blood donor role identity, Callero (1985) found that role identity is not only a significant part of self-definition, but it also impacts feelings, behaviors, and cognitive functions. The finding suggested that the salience of a role identity is related with the following: the propensity to evaluate others in terms of that same identity; the development of interpersonal relationships in the context of that 
role identity (e.g., a blood donation); and others' expectations that the agents/individuals will engage in the behavior and action representative of that identity. In a similar contemporary study, the effect of volunteer-program attitudes on the intention to stay and organizational citizenship behaviors were found to be mediated by organizational identification (Jones, 2010). Looking at student identity, Burke \& Reitzes (1991), argue that an identity generates certain typical behavioral outcomes and that the strength of commitment to the focal identity plays the role of a moderator in this relationship. Particularly, they find that the relationship between the student identity and role performance (assessed on three associated behaviors) was higher for those individuals with a higher commitment to student identity.

Dukerich, Golden, \& Shortell (2002) conducted a longitudinal study among physicians to explore the influence of identity-related factors on their cooperation and organizational citizenship behaviors. The findings showed that the attractiveness of the construed self-image of the social unit (a particular health care system in this study) as well as the perceived attractiveness of the organizational identity of the system was related to the strength of organizational identity which, in turn, predicted cooperative behaviors and organizational citizenship behaviors. Finally, Johnson et al. (2012) looked at, and found evidence of, the differential influence of cognitive and affective identification on organizational commitment, organizational involvement, and organizational citizenship behaviors.

Identity and adjustment. Beyer \& Hannah (2002), in a longitudinal qualitative study, found that an employee's ongoing adjustment and assimilation in a new job/organization is, in part, influenced by the work-related personal identities of the 
employees. Relatedly, van Knippenberg, Martin, \& Tyler (2006) found that, during an organizational change, the employees who identified more with the organization focused on the change process (e.g., participation in change). On the other hand, those who identified less with the organization focused on the change outcomes (e.g., salary).

Identity and leadership. Identity scholars across various traditions have directly or indirectly theorized prototypical leadership (signifying collective/social identity) and the impact of such leadership. "Prototypical as compared to less prototypical leaders are seen as exemplifying the shared group or organizational identity, and as representing what defines the group and distinguishes it from other groups" (e.g., a US president seen as a 'real American' and the embodiment of American values) (Giessner \& van Knippenberg, 2008: p 16). These authors find that leadership prototypicality, due to the very fact of commonality of the identity with the followers, generates more positive/favorable evaluations of leadership effectiveness after the failures in achieving a maximal goal (ideally, that could be reached) but not the minimal goal (i.e. moderated by goal definition). In a similar study, using multiple experiments, Haslam \& Platow (2001) demonstrated that the leader's capacity to affirm the distinct social identity shared among his or her followers was a significant predictor of followership-particularly in generating the support for novel plans and the willingness to help realize the plans ( $p$ 1476). The study by Hirst, van Dick \& van Knippenberg (2009) documented that team identification positively influenced creative efforts, and eventually creative performance, both of which were positively moderated by the leaders' inspirational motivation, prototypicality (signifying shared identity), and the interaction between prototpyicality and inspirational motivation. 
Identity and job and/or career satisfaction. Aryee and Luk (1996) looked at the influence of family identity and work identity on career satisfaction in a sample of dualearning couples of Hong Kong. Their study found that the work identity of husbands enhanced their career satisfaction, while that influence, although positive, was not significant for the wives. On the other hand, this study found that their family identity did not have an impact on career satisfaction.

Identity/identification and turnover intentions/withdrawals. Scholars (Abrams, Ando, \& Hinkle, 1998) have found that organizational identification predicts turnover intentions in that the more an employee identifies with the organization, the less likely it is that she/he will leave the organization. Abramus' et al. (1998) comparative study in Japan \& Great Britain also showed that the impact of organizational identification was uniform across the two national contexts. Cole \& Bruch (2006) demonstrated an even more nuanced impact of identity and identification in turnover intentions. They looked at the differential impact of identity among high level officers, middle management, and occupation workers. Consistent with the findings of other studies, this study also found that identification and identity strength negatively influenced turnover intentions; the influence on different levels of organizational hierarchy varied, however. Relatedly, Das, Dharwadkar, \& Brandes (2008) investigated the impact of various identities and organizational identification on turnover and performance in an "international/globalized" business context. They found that when the workers of an international call-center have high national identity centrality, it resulted in higher turnover intentions. As per this study, the occupational identity and the organizational identity positively reinforced each other. Grube \& Paliavin (2000) conducted a 
comprehensive study looking at various antecedents of general role identity and specific role identity as well as work behaviors and turnover intentions as a function of these identities. They find that when a volunteer has a strong role identity, he/she is less likely to leave and more likely to devote a greater number of work hours to the focal organization. Some other studies have found similar effects. For instance, Rothbard \& Edwards, (2003) found a positive impact of the role identity on the time invested in that particular role. Finally, a meta-analysis (cf. Riketta, 2002 cited in Das et al., 2008) also found that when individuals strongly identify with an organization their intention to leave is low.

Some researchers examined the factors that contribute to recruitment withdrawal (why someone self-selects out of recruitment processes) (Griepentrog et al., 2012). They showed that organizational identification impacted withdrawal behaviors directly and through a mediating variable, the intention to pursue the job. The organizational identity also worked as a mediator in transmitting the effect of other predictors on withdrawal behaviors namely, person-organization fit, distinctiveness of the organization, and organizational prestige.

Identity and job performance. Das et al.'s (2008) study cited above also found that high national identity centrality resulted in poor performance outcomes and higher turnover intentions. In addition, national identity centrality, as a moderator, weakened the relationship between organizational identification and performance. That is, organizational identification produced better performance outcomes when national identity centrality was low. Lobel \& Clair (1992) reported that when employees' career identity salience was high, it enhanced their work efforts. Randel \& Jaussi (2003) 
provided evidence that individual performance in a cross-functional team setting was a function of the personal and social functional background identities of the team members.

Identity and decision making. Researchers in vocational psychology have argued and documented that the people with a higher awareness about their career identities face fewer difficulties while making career related decisions, have a lower rate of career uncertainty, and explore a broader range of occupational choices (Cheek \& Jones, 2001; Holland, Gottfredson, \& Power, 1980; Schmitt-Rodermund \& Vondracek, 1999; Vondracek et al.). In a very interesting study of how individuals make unethical decisions, Detert, Treviño, and Sweitzer (2008) argue that an individual's moral identity reduces his/her propensity for moral disengagement (the deactivation of moral selfregulation by an individual, cf. Bandura 1999), thereby reducing unethical decision making. Similarly, other studies (cf. Gino et al., 2011: p 193) have found that people with a strong moral identity try harder to be consistent with their moral compass and to make moral decisions. Also, Gino et al. (2011) found a moderating role of moral identity on the relationship between self-control depletion and unethical behaviors. In a series of experiments, LeBoeuf, Shafir \& Bayuk (2010) looked at identity conflicts and decision choices. Among others, one of the findings was that the relative salience of one identity over the other affects one's decision choices and the subsequent satisfaction with those choices. Similarly, other studies also demonstrated that moral identity has direct and conditional influences on moral behaviors (cf. Reynolds \& Ceranic, 2007).

The preceding overview on the consequences of individual identity in careerrelated and organizational contexts provides broad insights pertinent to the present research. The impact of individual level identity is indeed quite diverse and wide-ranging 
because it influences affect, cognition, intentionality, psychological well-being, decision making, and the behaviors of an individual. The finding that "when different identities are in harmony, they create a positive impact for the psychological well-being of individuals", offers fundamental insight for my argument in the upcoming section. On the basis of this finding, I theorize that when various micro-identities of entrepreneurial identity are in harmony, they are likely to create a better sense of coherence and stability for active and potential entrepreneurs. Moreover, this review also shows that an identity generates "typical behavioral outcomes" for that particular identity. In Essay \# 3, I theorize that entrepreneurial identity is a missing link in explaining entrepreneurial behaviors. I argue that entrepreneurial identity eventually leads to typical entrepreneurial behavioral outcomes through entrepreneurial self-efficacy and entrepreneurial intentions. The general finding that identity does lead to intentionality (of various forms, as this review suggested) provides basic validation for my argument that entrepreneurial identity leads to entrepreneurial intentions. The finding that identity has a bearing on decision making also provides a logical basis for the impact of entrepreneurial identity on entrepreneurial self-efficacy.

Various contingent effects of identity/identification. Many researchers have also looked at the various conditions and contingencies that come into play when predicting cognitive, affective, and behavioral consequences of identity. Farmer \& van Dyne (2010), integrate the concept of idealized and situated "selves" of individuals, arguing that the typical, expected behavioral outcomes of an identity will be conditioned by the role occupancy (e.g., tenure). Particularly, their study found that a "helping identity" and helping behaviors of employees and an "industrious work identity" and industrious work 
behaviors were moderated by two role occupancy variables, organizational tenure and work status (part-time vs full-time). Another study, by Farmer, Tierney, \& KungMcIntyre (2003) found that the influence of employees' creative role identity on creativity was moderated by their perceived organizational valuing of creativity. In a qualitative study, Golden-Biddle \& Rao (1997) explored a complex dynamics of interaction between the collective level organizational identity and individual identities. In particular, they found that the interaction shapes the expected and enacted roles of an organization's board of directors. In a configurational study ${ }^{4}$, Greenhaus and colleagues documented that the interactive effect of work identity and family identity with situational demand and sex influenced an individual's work behavior (operationalized in terms of work hours) (Greenhaus, Peng \& Allen, 2012). They found that elongated work hours were the function of weak situational demand for females, but not for males, because of the differential construal of work identity and family identity among male and female employees. Some other studies have looked at the interactive effects of organizational identity and work role identity on job satisfaction and citizenship behaviors (e.g., van Dick et al. 2008) as well.

Team faultline researchers have also looked at the conditioning effect of identity on team dynamics-particularly as it concerns conflicts and team outcomes. Jehn \& Bezrukova (2010) reported that a strong workgroup identity decreased the likelihood that the activated faultlines led to coalition formation and conflicts.

Mayer, Greenbaum, Shteynberg, \& Kuenzi (2009) documented evidence that when a central aspect of an individual's personal or social identity is violated, her/his

${ }^{4}$ Researchers use this term to refer to a three-way interaction term, or a contingent effect. 
perception of procedural and distributive justice does not improve even when the procedures are objectively fair.

Conducting experimental studies, Holmvall \& Bobocel (2008) reported that when individuals have an interdependent self-construal (that is, base their identity on their relationships with other people) they are likely to react positively to the negative outcomes which resulted from a procedural fairness issue. And the opposite was true for the people who construed their identity as independent; that is, they negatively reacted to such outcomes.

Although the present research does not specifically look at the interactive influences of entrepreneurial identity — both for the exploratory nature of the study and the 'scope and focus' manageability issues - the review on contingent effects of identity does have some theoretical application for the current research. For instance, the finding that the influence of identity on behavioral outcomes is contingent on role occupancy dictates that the present research should control for the tenure of potential entrepreneurs in their paid-employment while testing the impacts of entrepreneurial identity on entrepreneurial intentions.

\section{Review of Entrepreneurial Identity Specific Literature}

This section of the review focuses on the literature which in some form addresses/deals with an entrepreneurial identity, the identities of entrepreneurs (defined broadly), the identities of entrepreneurial ventures, or the entrepreneurial identity of any existing, traditional organizations. Although the focus of this dissertation is individual level entrepreneurial identity, I briefly review the literature on collective level 
entrepreneurial identity because the identities of entrepreneurs and their

ventures/organizations are likely to have interdependent relationships.

\section{Collective/organizational level entrepreneurial identity}

\section{Conceptualization of entrepreneurial identity at the collective level. A}

conceptual study by Downing (2005) provides a framework which looks at the formation and the development of organizations as individual and collective identity projects. Downing's central idea is that entrepreneurship is a collaborative social achievement, a socially constructed reality, although it might start with an entrepreneur's personal theories/visions - where individual and collective identities are simultaneously coproduced with institutions through narratives and other similar means. Navis \& Glynn (2011) conceptualize entrepreneurial identity in a broader sense, quoted below, as a constellation of claims. Their study specifies three entrepreneurial identity targets at three different levels:

We define the entrepreneurial identity as the constellation of claims around the founders, organization, and market opportunity of an entrepreneurial entity that gives meaning to questions of 'who we are' and 'what we do' (Navis \& Glynn, 2011: p 480).

The chief insight of this study is that authentic entrepreneurial identities serve as the touchstone of external investors' assessments on the plausibility of an entrepreneurial venture. In another study (Navis \& Glynn, 2010), examining the evolutionary landscape of a new market (of satellite radios), the authors look at the identity and legitimacy dynamics of new markets and entrepreneurial firms. The central idea of this work is the following: while new organizations first act in concert to establish the legitimacy of the "new market" by forming a common market identity, these firms shift their attention to 
their individual differentiation within the new market once the legitimation process of the new market precipitates.

\section{Entrepreneurial identity and resource acquisition by entrepreneurial firms.}

Owing to the liability of newness (Stinchcombe, 1965) and legitimacy issues (Aldrich \& Fiol, 1994), resource constraints are common for entrepreneurial firms. How entrepreneurial firms construct/develop their identity is found to be critical in legitimizing the new ventures/organizations and acquiring the needed resources. In a classic conceptual paper, researchers (Lounsbury \& Glynn, 2001) argue that an entrepreneurial identity serves as the basis on which various stakeholders base, judge, and confer legitimacy to the organization. That, in turn, allows these ventures to access new and better sources of capital and market opportunities. The general insight of this conceptual work is empirically corroborated to a large extent by the study of Martens, Jennings \& Jennings (2007).

Entrepreneurial identity and the survival of entrepreneurial firms. Relatedly, in an interesting longitudinal, ethnographic study, Drori, Honig, \& Sheaffer (2009) investigated the entrepreneurial identity formation, along with legitimacy, of an internet firm over the course of its life - from inception to death. They showed that various organizational scripts became the source of the organizational identity. Further, the conflicting organizational scripts/narratives as well as the misalignment of the identities of various actors of the organization created organizational conflicts, and eventually, were responsible for the organization's demise. 
Entrepreneurial identity and entrepreneurial orientation. A substantial amount of research has generally supported the idea that a firm's entrepreneurial orientation leads to superior performance outcomes (cf. Poudel, Carter \& Lonial, 2012). A study by Miller \& Le Breton-Miller (2011) investigated the connection between entrepreneurial identity and entrepreneurial orientation. Their major thesis is: conditional upon social contexts, role identities and social identities of owners and owner managers differentially impact the strategic orientations of their firms, and thereby, their business' success. Particularly, they documented that lone founders have a stronger entrepreneurial identity and accordingly pursue entrepreneurial orientation, thereby achieving higher success relative to founding or non-founding family owners or managers.

Identity in family businesses. Resorting to the notion of "identity confirmation," Milton (2008) argued that the business identity confirmation in family businesses works as a catalyst for the business performance. Specifically, as the author posits, the identity confirmation can function as a unique, hard-to-imitate resource that bestows the family firm with an advantage over non-family businesses. Shepherd \& Haynie (2009) examined the potential conflict of identity (between family identity and business identity) and the impact of such identity conflicts on entrepreneurial processes. These researchers argue that the differences about the potential entrepreneurial opportunities and how to go about them are likely to trigger, although not exclusively, such identity conflicts in family businesses. However, the authors suggest, the presence of a "family-business meta-

\footnotetext{
${ }^{5}$ Referred to as the condition in which personal and social contexts of an individual are consistent with one's identities (cf. Milton \& Westphal, 2005).
} 
identity" (a superordinate identity that harmonizes and controls the meaning of lower level identities - that is, family identity and business identity) is likely to mitigate the identity conflicts. Examining the nature of the boundary between a family identity and a business identity in family businesses, Sundaramurthy \& Kreiner (2008) advanced a continuum of identity integration argument. They theorized that the degree of such an integration of family and business identities manifests itself in observable factors such as: the association between the family and business image, ownership and governance structure, and the financial relationships with the family, among other factors. For example, when these identities are highly segmented, there will be limited cross-flow of finances between the family and the business. On the other hand, in the case of high integration, a free flow of finances between the two is likely. In a related paper, Zellweger and colleagues (Zellweger, Nason, Nordqvist, \& Brush, 2013) conceptually examined why family businesses are particularly inclined to pursue non-family centered non-financial goals. Invoking organizational identity theory, they assert that it is the need for and the significance of synergy between organizational identity and family identity that motivates them to achieve a better organizational reputation through such nonfinancial goals.

In conclusion, this overview of collective level entrepreneurial identity literature offers some critical insights for individual level entrepreneurial identity theory development. This literature tells us that authenticity in the entrepreneurial identity of a new organization/venture has immediate implications for its survival, strategic orientation, as well as on the assessment of the venture by external stakeholders. The literature also informs us that the harmony or conflict of identities among various 
stakeholders of an entrepreneurial firm has a bearing on its survival. Note that it is not difficult to see the individual level parallel to these findings. Particularly, it is conceivable that the authenticity of entrepreneurial identity, either in an active or potential entrepreneur, might have a bearing on their probability of engagement in startup activities and the eventual success of their startups.

\section{Individual level entrepreneurial identity}

The small body of existing literature in entrepreneurship research has conceptualized individual level entrepreneurial identity either as a role identity or a social identity or as a career identity, each with disparate research questions and interests. Therefore, this review is organized based on the conceptualization of entrepreneurial identity.

Entrepreneurial identity as a distinct concept. As the authors claim (and largely corroborated during the present research), the Murnieks \& Mosakowski (2007) study laid the foundation for the entrepreneurial identity conversation (particularly at the individual level) in the entrepreneurship field. They emphasized that understanding entrepreneurial identity is critical for understanding entrepreneurial motivations, entrepreneurial behaviors, and entrepreneurial processes. The major contribution of this study is that it provides theoretical underpinning and empirically tests the question of whether a distinct entrepreneurial role and entrepreneurial identity exists. This work posits that "certain individuals hold salient entrepreneurial identities, which motivate them to act as entrepreneurs" (p 1). Shepherd \& Haynie's (2009b) conceptual paper is another work that explicitly theorizes about entrepreneurial identity. Their study focuses on the "identity management" predicated on the fact that entrepreneurs might have other salient identities 
besides an entrepreneurial identity, which they collectively refer to as non-work identity. The major insight is that entrepreneurial identity satisfies the "distinctiveness" need of an individual which might come at the cost of another need of equal significance, "the belongingness need." For psychological health, they argue, the need of distinctiveness and the need of belongingness must be balanced which entrepreneurs can accomplish by employing identity management strategies. By managing the entrepreneurial identity and the non-work identity, either through compartmentalization or integration (two strategies suggested by the authors), entrepreneurs can optimally satisfy both needs and enhance their psychological well-being. The study provides additional insights with a conceptual model on the effectiveness of one strategy over the other (cf. p 327). Another preliminary work on individual level entrepreneurial identity (Murneiks, 2007) makes the case that entrepreneurial identity is a unique identity of entrepreneurs, which is the precursor of entrepreneurial motives and entrepreneurial behaviors. This work hypothesizes entrepreneurial passion and goal setting as important links in this connection. The study theoretically distinguishes, and empirically corroborates, between "actual entrepreneurial identity prominence" and "ideal entrepreneurial identity prominence." Interestingly, however, unlike its prediction, ideal entrepreneurial identity did not correlate with entrepreneurial passion, nor did it find passion enhancing entrepreneurial behavior.

Farmer et al. (2011), based on the concept of possible selves (Markus \& Nurius, 1986), introduced a construct called "entrepreneur identity aspiration" (it refers to a possible but not yet realized future entrepreneur self). This is a seminal work, in that it identifies an antecedent of entrepreneurial identity. These authors theorize and show 
evidence that the congruence between one's self-definition and perceived entrepreneurial role-definition enhances entrepreneurial identity aspiration. Entrepreneurial identity aspiration, in turn, motivates individuals to engage in entrepreneurial discovery and exploitation. Their findings also suggest that having a prior start-up experience augments (moderates) entrepreneurial discovery and exploitation as a function of entrepreneurial identity aspiration.

Entrepreneurial identity conceptualized as a role identity. The Cardon et al. (2009) paper on entrepreneurial passion theorizes three specific role identities associated with entrepreneurs - an innovator role identity, a founder role identity, and a developer role identity. They conceptualize entrepreneurial passion in terms of identity as "consciously accessible, intense positive feelings experienced by engagement in entrepreneurial activities associated with roles that are meaningful and salient to the identity of the entrepreneur" ( $p$ 517). They define the three role identities of entrepreneurs as:

(1) an inventor identity, where the entrepreneur's passion is for activities involved in identifying, inventing, and exploring new opportunities; (2) a founder identity, where the entrepreneur's passion is for activities involved in establishing a venture for commercializing and exploiting opportunities; and (3) a developer identity, where the entrepreneur's passion is for activities related to nurturing, growing, and expanding the venture once it has been created (p 516).

The major thrust of this conceptual work is that they theorize how entrepreneurial passion is predicated on the salience of various entrepreneurial role identities and translates into three important markers of entrepreneurial effectiveness: opportunity recognition, venture creation, and venture growth. For example, they argue that the effectiveness in entrepreneurial opportunity recognition will be higher when an entrepreneur's inventor 
identity is salient because it enhances creative problem solving. Similarly, they proposed that the effectiveness of venture creation is influenced by entrepreneurial passion that is predicated on founder identity.

Hoang \& Gimeno (2010) develop a theory of organizational founding based on the founder's identity, depicting organization founding as a founder's role transition phenomenon. The chief insight developed in this work is that an individual's ability to transition from some other work role to a founding role is influenced by identity centrality (referred to as the subjective significance of the founding role in the individual's overall self-concept) and identity complexity (referred to as the diversity and richness of the perception of the founder role). These authors argue that two major challenges associated with the transition from some other work role to a founder role identity are "role novelty" (how objectively different the new role is compared to the old role in terms of knowledge, skills, and abilities) and "role conflict" (to what extent the new role is incongruent with existing role identities). They propose: founder identity centrality and founder identity complexity will reduce the negative influence of role novelty and role conflict, and therefore, will increase the probability of successful transition from other work roles to founding roles (to pursue founding activities).

Entrepreneurial identity conceptualized as a social identity. Contending with Cardon et al. (2009) and other similar studies, Fauchart \& Gruber (2011) assert that conceptualizing an entrepreneurial identity in terms of role identity does not fully capture the self-definitions/concepts of entrepreneurs. They argue that such a conceptualization discounts the social aspect of the self-concept that is, arguably, even more central in explaining entrepreneurial behaviors because entrepreneurship is inherently a social 
activity and is a function of social construction. Drawing on social identity theory and based on a qualitative study of 49 firm founders, they expound a typology of social identities of founders. The three pure types of social identity of entrepreneurs advocated by the researchers are Darwinian identity, Communitarian identity, and Missionary identity. The Darwinian identity is referred to as the identity that focuses on competition and in which identity economic self-interest is central. The Communitarian identity is referred to as the identity where the firm an entrepreneur creates is regarded as a social object which has an interdependent relationship with the community at large. Finally, the social identity of founders, where firms are regarded as the political objects designed to advance a particular cause in society, is referred to as the Missionary identity. Thus, the distinguishing characteristics of the social identity of founders, in their scheme, are based on two criteria. The criteria are: the differences in the meanings associated with being a founder and the variations in the interpretation of the nature of the social unit they identify with - that is, the nature of the firm/organization. Fauchart \& Gruber conclude that, based on these different types of identities, entrepreneurs will engage in different entrepreneurial activities and address decision making differently. More particularly, they will differ in terms of core strategic decisions, customer needs, and capabilities and resource deployment.

Entrepreneurial identity conceptualized as a career identity. Some researchers (cf. Dobrev \& Barnett, 2005) have alluded to individual identity in an entrepreneurship context, implicitly, as a career identity. O’Neil \& Ucbasaran (2010), however, examined the identity among a sample of sustainability-driven enterprise founders more directly as a career identity. They also contend that conceptualizing identity in entrepreneurship in 
terms of the salient roles alone (as done by Cardon et al., 2009) overlooks the importance of alternative identity phenomena - a view consistent with the arguments/theory developed throughout this dissertation. Their findings suggested that, among other factors, the founders' transition to entrepreneurship was triggered by authenticity-related identity deficits in their prior careers. The authenticity in this context is referred to as constraints that relate to the expression of personal values, and the identity deficit is referred to as an inadequately defined self. The transition emanated from the belief that in entrepreneurship they could authentically integrate their values into careers.

Entrepreneurial identity conceptualized as a personal identity. Although not touted as an entrepreneurial identity, the personal identity (used for its emphasis on distinctiveness) of an aspiring (or active) entrepreneur is one of the preconditions of the effectuation theory that originated in the entrepreneurship field (cf. Nielsen \& Lassen, 2012; Sarasvathy, 2001). In brief, the effectuation theory developed by Sarasvathy counters the traditional "ends-means" understanding in that it argues that many entrepreneurs begin with what they have and who they are (their identity) and figure the appropriate end among a host of possible ends. Thus, the personal identity of an entrepreneur is assumed ex ante present in the effectuation theory of entrepreneurship. Also, this notion of personal identity is assumed to be relatively stable. Nielsen \& Lassen (2012) contend and complement this notion of a stable, existing personal identity in a qualitative study of student entrepreneurs. They assert that the personal identity of entrepreneurs, or potential entrepreneurs, is a continuous construction process that occurs simultaneously during the effectual processes of entrepreneurial actions. Note that this understanding also perfectly aligns with the position of this dissertation research. 


\section{Other individual level identities (and self-images) of entrepreneurs (broadly}

defined). A quantitative study (Obschonka et al., 2012) looked at the role of social identity in the transition to entrepreneurship from paid-employment. Observing a sample of German scientists, they argue that the identification of the scientists with their academic peers (that is, the group identification/social identification) will have a bearing on their entrepreneurial intentions indirectly through its moderating impact on the cognitive processes. Their results suggest that when the group/social identification was low, the perceived behavioral control (fairly synonymous with self-efficacy as per their operationalization) influenced entrepreneurial intentions. On the other hand, when the identification with the group was high, attitude towards academic entrepreneurship (another variable) influenced entrepreneurial intentions. Social norms influenced entrepreneurial intentions in both conditions (high and low social identification).

Eddleston \& Powell (2008) looked at the issue of why female entrepreneurs are more satisfied with their entrepreneurial careers than their male counterparts, though they are less successful in terms of the routine/regular measures of business successes. The authors argue that it is because of the gender identity of entrepreneurs and the differential value attached to different sources of satisfiers of an entrepreneurship career. Particularly, they find that the impact of the entrepreneur's sex on the preference for status-based career satisfiers (such as money, business growth) is mediated by masculine gender identity. On the other hand, the impact of sex on the preference for socio-emotional career satisfiers (such as the contribution to society) is mediated by feminine gender identity. 
Entrepreneurship researchers more or less converge on the idea that the opportunity-individual nexus is at the foundation of entrepreneurship (Shane \& Venkataraman, 2000; McMullen \& Shepherd, 2006). Mitchell \& Shepherd (2010) maintain that it is important to examine not only the different images of opportunity perceived by individuals but also to investigate the differences within their self-image. Specifically, they introduce two self-images, the self-image of vulnerability (measured as a fear of failure) and the self-image of capability (measured as human capital and entrepreneurial self-efficacy). They found that both types of self-images affected entrepreneurs' opportunity images.

Thus, for the purposes of this dissertation, the literature on individual level entrepreneurial identity, despite being at a very early phase of development, provides in part the critical foundation necessary to advance the theory that I articulate in the following theory development section. To that end, the study by Murnieks \& Mosakowski (2007) is the most critical because their study is the first study that articulates and tests the existence of entrepreneurial identity. While their study lacks a precise and comprehensive definition of entrepreneurial identity, it convincingly argues that as long as the entity called the "entrepreneur" exists, so does the accompanying entrepreneurial identity (p 4). Another study, Shepherd \& Haynie (2009b), conceptualizes entrepreneurial identity as part of a superordinate identity. This provides the logical framework for a thorough conceptualization of entrepreneurial identity in the present dissertation. Note that these authors explicitly refrain from offering a definition because they believe a commonality and a distinction might be simultaneously present among individuals regarding their perceptions of entrepreneurial identity ( $\mathrm{p} 323)$. That is 
precisely one of the theoretical undertakings of the present research-to explain why an entrepreneurial identity might have commonalities and distinctions across individuals, in general, and across entrepreneur types, in particular. Similarly, Farmer's et al. (2011) concept of "entrepreneurial identity aspiration" is consistent with the intrinsically prospected entrepreneurial identity that I introduce in this dissertation.

The review of this literature reveals that scholars have conceptualized entrepreneurial identity in terms of various roles (e.g., Cardon et al., 2009), as a social identity (e.g., Fauchart \& Gruber, 2011), as a career identity (O’Neil \& Ucbasaran, 2010), and even implied as a personal identity (e.g., Sarasvathy, 2001). However, it is evident that we lack an understanding of how these various interpretations and proxies of entrepreneurial identity make sense together. We do not yet have a good big picture/gestalt of the entrepreneurial identity construct. That being said, these studies do provide some important directions for my theory. They unequivocally acknowledge that entrepreneurial identity is a superordinate identity which might be comprised of multiple micro/subordinate identities in a hierarchy (cf. Cardon et al., 2009; Shepherd \& Haynie's 2009b). The identities reviewed above form the building blocks of the entrepreneurial identity conceptualization that ensues in the next section. 
THEORY DEVELOPMENT AND TESTING

\section{Understanding Individual Level Entrepreneurial Identity: Identity Development, Complexity, and Variations across Entrepreneur Types (Essay 1)}

\section{Identity development: The case for a dual-process}

The focus of the theory development in this essay, and the rest of the two essays in this dissertation, is on entrepreneurial identity. Nevertheless, this subsection and the next are devoted to the advancement of a dual-process identity development concept, central to my theory development on entrepreneurial identity. My position is that the dual-process of identity development, articulated in the present research eliciting on existing theory and empirical research, forms the foundational building block of any individual level identity-including entrepreneurial identity. To provide a context, note that the conceptualization of identity has been divergent in the literature in that selfconceptions are referred to as what individuals think of themselves, to what they think

others think of them, and to what others merely ascribe them to be (cf., Beyer \& Hannah, 2002). The literature implies two fundamental, and juxtaposed, identity formation processes which have not been adequately distinguished, articulated and reconciled. I explain this further below.

One approach, the predominant one in identity research, generally suggests that an identity, irrespective of the types or varying conceptualizations, is forged through a 
process of social construction. Researchers either explicitly argue that identity is a socially constructed entity or they implicitly assume it in their theorizing (Alvesson, 2010; Ashforth et al., 2008; Brown, 2001; Chreim, 2005; Creed et al., 2002; Day et al., 1999; Downing, 2005; Fearon, \& Laitin, 2000; Gioia et al., 2010; Gouldner, 1957; Richardson et al., 2009; Savickas et al., 2009; Zimmermann \& Ravishankar, 2011). This notion of identity formation rests on the concept of social constructionism. Social constructionism professes that realities and truths are constructed through various discourses that are created as a function of social relations, structures, and socially negotiated understandings (Dick \& Nadin, 2006; Ibarra, 1999). This notion of identity formation implies that social structures and discursive contexts alone would shape an individual's identity with little or no room for human agency. But there is another approach to identity which emphasizes the role of agency or the agentic power of individuals who are actively seeking certain identities (cf. Alvesson \& Willmott, 2002; Down \& Reveley, 2009; Sveningsson \& Alvesson, 2003). In what follows, I reconcile these approaches to argue that an identity (entrepreneurial identity included) is forged by both social construction and by virtue of the agentic power of individuals - regarding human beings as real actors. My position is that it is only an issue of which type of identity formation is stronger for the focal identity being examined.

The rest of the Essay \#1 is organized in the following way. In this subsection, I first outline the knowledge gap/theory dilemma in the identity formation processes. Then I discuss the premises and the detailed conceptualization of an intrinsically prospected identity (IPI) and a socially constructed identity (SCI). Next, I discuss the additional validation and reasoning behind my theory in light of the existing literature in sociology, 
psychology, and organizational sciences and explain similar concepts in the literature. In the second subsection, I discuss some differences between IPI and SCI in relation to some of the key concepts in the individual level identity domain. In the third subsection, I provide a nuanced and comprehensive conceptual structure for entrepreneurial identity. In the fourth section, drawing on the insights of the earlier subsections, I explain the commonalities and differences of entrepreneurial identity among three distinct types of entrepreneurs. I develop propositions to that end. The final subsection provides the summary conclusion of Essay \# 1.

The knowledge gap/theory dilemma in identity formation processes. Although identity literature is mostly convergent on the idea that the identity formation of an individual is a dynamic and developmental process (see the review in the earlier section), there is much debate and contention around the nature of identity formation (cf. Alvesson, 2010; Down \& Reveley, 2009). In their editorial call for papers on identity construction in an organizational context, the guest editors of the journal Human Relations (Keenoy et al., 2007) identified, among others, two particular areas where a conceptual development was needed to advance the identity literature: “(a) self-narration and imposed identity construction and (b) accounts of the contested, competing and contradictory nature of identity formation(s) (p 396)."

The conceptual dilemma in the identity research emanates from two distinct approaches to subjectivity and reality. The first approach is the humanist approach in which human agency plays a crucial role, and which emphasizes individuals as meaningmakers and reality-creators (cf. Alvesson, 2010; Giddens, 1991; Ibarra, 1999). The other approach is the non-humanist approach (represented by Marxists, structuralists, 
behaviourists, and the discursivists academic traditions) which locates the creation of subjectivity and reality in structures, situations, social relationships, and discourses (cf. Alvesson, 2010; Dick \& Nadin, 2006). The latter approach is the philosophical ground for the concept of the social construction of identity. Consistent with other authors (Alvesson, 2010), I argue that individuals develop two basic types of identity. One is predominantly the function of social construction and the other a function of the agentic powers of individuals (i.e., human agency). I refer to this identity formed by virtue of human agency as intrinsically prospected identity (IPI).The humanist approach to subjectivity and reality is the philosophical ground for the intrinsic prospection of identity.

Despite the fact that there exist two juxtaposed approaches to subjectivity and reality and despite the majority of identity research considering identity formation as a social construction, there is not much focused theorizing (except for passing references) on the identity formation processes (cf. Ibarra, 1999; Pratt et al., 2006). There are, however, some exceptions which deal with some aspects of the issue (see also the upcoming sections). One particular research paper (Alvesson, 2010) directly addresses the issue, and as such, is central to our discussion.

Alvesson (2010) reconciled the humanist and non-humanist approaches (discussed earlier) to develop seven identity image types: strategists, storytellers, strugglers, self-doubters, soldiers, surfers, and stencils. I present two of his seven images (storytellers and stencils) to highlight the intrinsic prospection and social construction distinctions I make. Eliciting Gidden's work (1991), on the storytellers' image, Alvesson states: 
Self-identity (of storytellers) is then conceptualized as a reflexively organized narrative, derived from participation in competing discourses and various experiences, which is productive of a degree of existential continuity and security (p 203).

This image of identity is based on the premise that individuals are capable of creating and maintaining a credible self-narrative. It could be argued that a reflexively organized narrative meant to be instrumental for the sense of continuity and security, in essence, must be a purposeful, intrinsic process directed at achieving identity goals. Alvesson further asserts that the storyteller's identity image "goes beyond role presentations and discourse-driven subjectivity and points to a more integrated and meaningfully created identity (p 203)." Therefore, I argue, this identity image cannot be the function of socially constructed realities, or a socially constructed identity for that matter. Nonetheless, note that neither goals and purposes, nor the longing for the sense of security, nor the sense of uniqueness, nor the need for continuity exist in the absence of social contexts and environments. On the other hand, some other images in Alvesson's framework are fundamentally socially constructed identities. Drawing on Foucault's post-structural narrative, Alvesson writes:

This image (of stencils) views the subject as mainly an effect of the discourse (Alvesson and Kärreman, 2000) operating on it. It is not so much the individual being actively involved in the construction of him- or herself as it is external powers doing this work...the key idea is that external powers are given priority in identity-defining projects. There is no individual before discourse works upon him or her... (p 206, 207).

This image in Alvesson's framework is construed as a result of social construction because human agency and willpower are assumed to be non-functional. The stencil identity image is the virtual imposition of an image on an individual by social systems and discourses. Investigating the intensity of social construction-or intrinsic prospection, 
for that matter-of all the seven types of Alvesson's identities is not within the scope of the current discussion. That being said, the contrast of the stencil's identity image and the storyteller's identity image perhaps suffices to make the case that some identities are predominantly socially constructed and others are predominantly intrinsically prospected. Therefore, in a sense, in this dissertation, I pick up the thread of Alvesson's effort on the reconciliation of two perspectives of how "realities and identities" are created. However, my focus is to argue that every individual level identity has both of these basic components-intrinsically prospected and socially constructed. One component of identity is the result of externally-initiated narratives working on the individual. The other component of identity results from the conception and promotion of narratives about the self by an individual with a relatively robust control of individual agency. I term the willdriven, self-reflective, purposeful, identity construction as the 'intrinsic prospection' of identity to draw a contrast with the social construction of identity.

\section{The premises and the conceptualization of intrinsically prospected identity (IPI)}

and socially constructed identity (SCI). The first fundamental premise upon which I make the distinction of intrinsically prospected and socially constructed identity is: the role of human agency and the role of structural influence both contribute to the development of an identity. The corollary is that human agency is capable of instituting certain realities or truths intrinsically and that these truths and realities can be relatively enduring characteristics of people. The two major theories of identity, social identity theory (Tajfel and Turner 1979; Turner 1982, 1985) and identity theory (Burke 1980; Stryker 1968) do not consider "the self" as "independent of and prior to" society (cf. Hogg, Terry \& White, 1995). Note that the idea of intrinsically prospected identity 
essentially refers to the possibility of a self-concept independent of, and prior to, society. However, this does not necessarily mean that the pursuit or achievement of an intrinsically prospected identity occurs in a social vacuum. Nor does this conceptualization exclude the likelihood of the simultaneous development and interdependence of these two distinct identities. Rather, the distinction lies in that the social construction of identity means that social contexts, social systems, and social discourses are the primary factors responsible for identity formation, rendering individual free will and human agency into peripheral factors. From this point of view, affirming the social construction of identity does not necessarily imply/is not equivalent to denoting complete passivity on the actor's part. This view recognizes that individuals $d o$ respond to external influences and discourses. The emphasis is that the development of a socially constructed identity is a reactive negotiation process with the social units, referents, and other secondary actors related to the identity construction process. On the other hand, the development of an intrinsically prospected identity is a proactive negotiation of one's identity, invariably involves a self-reflection process, a constant dialogue with the self, and a continuous attempt to promote the narratives about the self to the outer world, irrespective of the level of conformity from external audiences/actors.

The second premise is that "who am I" is not the only basic anchoring question of individual identity development, as assumed or asserted in many identity articles/theory developments (see the discussion earlier). I reason that the social construction of an identity occurs largely in the pursuit of understanding "who am I". However, "who do I want to be" is an equally important, if not more important, anchor question in identity formation. The agent-initiated development of identity occurs largely in one's pursuit of 
understanding "who do I want to be." To paraphrase, the identity developed in the pursuit of answering "who do I want to be" is essentially an intrinsically prospected identity. This component of identity is inherently inward centered, agent-constituted, and formed more or less exclusively through a self-reflective process. The actor consciously and subconsciously initiates and nurtures self-narratives to achieve his or her identity, and the corresponding aspired goals. Similar to the classical concept of "intrinsic motivation", the term "intrinsic" in this identity conceptualization refers to the "internal locus of causality" (cf. Leonard, Beauvais, \& Scholl, 1999: p 970). The term "prospection" corresponds to the meaning found in the Merriam Webster dictionary, which defines it as "the act of exploring." Therefore, intrinsically prospected identity means the identity which contains an internal locus of causality, and for which to develop, self-exploration is a necessary condition. In the intrinsic prospection of identity, individual free will and human agency take center stage. I reason that this is in unambiguous contrast with the generally understood meaning of the social construction of identity in the current literature. The social construction of identity implies an external locus of causality and a structurally/externally-defined self-concept (Alvesson, 2010; Creed et al., 2002; Dick \& Nadin, 2006; Downing, 2005; Richardson et al., 2009). Throughout this dissertation, I explicate this distinction in the context of entrepreneurial identity, and other identities, when appropriate.

Let's take an example of an adolescent whose parents are entrepreneurs. Arguably, in most societies, she will have an entrepreneurial identity conferred upon her. This conferred identity will be the function of social construction attributed to the family's discussions of entrepreneurship and corresponding expectations, others' 
perception of the adolescent as a potential entrepreneur, her interactions in the social circles of parent entrepreneurs, the family as a unit of entrepreneurs' social networks, and other similar social factors. These factors will constantly associate and ascribe her with an entrepreneurial identity. Recall the identity in family business context reviewed earlier. We know that identity confirmation works as an inimitable resource for family businesses (Milton, 2008). It means that, even for strategic reasons, such a conferral of entrepreneurial identity is likely. If the adolescent is actually interested in entrepreneurship and has constituted an entrepreneurial identity for herself, the conferred/socially constructed entrepreneurial identity will conceivably foster the intrinsically prospected entrepreneurial identity. On the other hand, for instance, this individual might be interested in athletics and might proactively craft and nurture an "athletic identity," that is, an intrinsically prospected athletic identity. This intrinsically prospected athletic identity, however, might not be in harmony with her socially constructed entrepreneurial identity. In this scenario, in more family-oriented and collectivist cultures like that of Japan (Abramus et al., 1998), this individual might even face a conflict of the socially constructed part of her identity [who she is/entrepreneurs' offspring] and the intrinsically prospected part of her identity [who she wants to be/an athlete].

\section{Conversations, theories, and evidence in the literature consistent with the IPI}

and SCI distinction. One socio-anthropological conception of identity is: a selfconstituting narrative that provides enduring characteristics to individuals (cf. Brown, 2001; Josselson \& Lieblich, 1997). On the one hand, it is logical to conclude that the origin of these narratives within the individual means that the intrinsic prospection of 
identity has taken place. On the other hand, if one develops enduring characters through the narratives which originate outside the individual, which is also a possibility, arguably, it is the social construction of identity that has occurred. Note that individuals "work on" these self-narratives through internal soliloquies as well as external interactions (Beech, 2008; Clarke et al., 2009; p 324) to develop or solidify the identity in question. For intrinsically prospected identity, internal monologues and soliloquies will be the more dominant form of self-narrative creation. Nevertheless, an individual will be involved in various communications and interactions with the external world for 'a reality check and to seek support for' the internally prospected identity. Because prospected identity is a story about "the image of self" presented to the outer world by an individual, she/he needs to periodically assess to what extent that self-narrative is being accepted or thwarted.

When the externally initiated narratives are in harmony with the internally initiated narratives, both of these identities will substantiate each other. On the other hand, when the externally originated narratives (those that label an individual) are in disharmony with the internal narratives, the actor is likely to consciously downplay the external narratives and attempt to make internal narratives more prominent.

The major idea theorized and empirically tested in this dissertation, that individuals can intrinsically prospect identities, is also consistent with the theory insights and empirical findings in the social psychology literature. Burke \& Reitzes (1991) argue that individuals are actually agents who control and maintain their own identity processes; that the commitment to certain identities enhances identity control and maintenance processes ( $\mathrm{p} 250$ ). The notion of intrinsic prospection is also congruent with 
social cognitive theory (cf. Bandura, 1989) which advocates an agentic approach to explain human behaviors, particularly the ability of individuals to control their own thoughts and behaviors through self-regulatory processes (Bandura, 1989). Agents not only conceive and nurture identities to orient themselves towards the "future" which is an essential part of their present self-image, but they may also require it. In other words, they may need to intrinsically prospect those identities.

The findings of Gioia \& Thomas's study (1996), which was conducted to examine the role of identity and organizational image (in the sense of prestige/reputation) on 'sensemaking by top management teams during strategic change,' lend empirical credence to these concepts. One of the findings of their qualitative study is that institutional identity emerged as a function not only of answering "who we are" but also, equally, of answering "who we want to be." Arguably, there must be an individual level identity parallel to this finding. Given the role of agency, will power, and intentionality, individual level identities are much more likely to be the function of both "who I am" and "who I want to be" compared to the collective identity of social units.

The two fundamental identity development processes of social construction and intrinsic prospection advanced in this dissertation are consistent with some well-received theories of career choice as well. For instance, homeostasis theory views human individuals as organisms that self-regulate in order to satisfy their needs. That is, they do not merely respond to the environmental and social conditions, external processes, and systems (Marco, Hartung, Newman, \& Parr, 2003). The following excerpt sheds light on the notion that career choices, and career identities, for that matter, are not merely the function of external factors: 
Personal homeostasis, or organismic self-regulation, refers to the processes whereby the human organism maintains a sense of balance between personal needs and environmental demands and circumstances. From this perspective, career decision making can be conceptualized as a process of satisfying internal needs and coping with external demands to make effective educational or vocational choices (Marco et al., 2003: p 2).

Relatedly, the emphasis of image theory on the present and future self-image as significant determinants of decision making (Thompson \& Dahling, 2010) supports my argument. It supports the idea that individuals not only have a multitude of identities, but they also hold current and future identities; and future identities are methodically prospected by an actor, as opposed to simply reacting and adjusting to the dictates of the social system. Similarly, Gidden's (1991) structuration theory suggests that it is not only the environment that shapes an individual actor's perception of reality, but it is also the reality of the actor that shapes the reality of the environment. It implies that, while an individual's identity might be the reality as constructed by the environment (society), the individual's self-initiated identity might also be pushed into the environment to be accepted as a distinct reality.

Finally, the additional credence of intrinsic prospection of identity comes from Foucault's (1988) concept of 'technologies of the self' that require "the truths of the self" to be discovered through self-examination and expressed through language in order to affirm and transform oneself. In these processes, "the individual becomes both the object of improvement and the subject that does the improving" (Kosmala \& Herrbach, 2006: p 1397). This is precisely what an individual does when she/he is prospecting an identity: one initiates an identity as a truth to be realized and tells the narratives of that truth, which are explored through the self-examination processes. 
Overlapping concepts. Although this dissertation conceptualizes and articulates the "non-social-construction" process of identity formation, the concept of intrinsically prospected identity is not entirely novel.

The concept of intrinsically prospected identity has some parallel with the concept of "possible self" advocated by Markus and colleagues (Markus \& Nurius, 1986; Markus \& Nurius, 1987) because both constructs have the same anchoring question of "who do I want to be." Drawing on these pioneering works by Markus and colleagues (Markus \& Nurius, 1986), some studies have looked at the aspirational identity of individuals (e.g., Thornborrow \& Brown, 2009; Farmer et al., 2011). However, despite their conceptual similarity in terms of the self-image of the future, intrinsically prospected identity in this dissertation is conceptualized by highlighting human agency and in contrast with socially constructed and externally conferred identity. In addition, as Ibarra (1999) argued, there is limited development of this concept of "possible self", particularly in terms of the processes of how these possible selves are formed, threatened, and claimed. Ibarra adds to this concept of possible self by advancing the concept of provisional identity when people are in the role transition (e.g., from a manager to consultant role) in their careers. The intrinsic prospection of identity concept advanced here also contributes to this conversation of "possible self."

The SCI and IPI concepts also have a parallel in "conferred identity and selfconstructed identity"--constructs that have been conceptualized but not developed well in career literature (cf. Flum \& Blustein, 2000; Marcia, 1993):

When one becomes progressively aware of one's basic features, the roles one plays, one's affiliations, and, in general, one's niche in the world, identity is conferred. When a person takes an active role in the process of 
self-definition and explores the different identity elements in order to author one's becoming, identity is self- constructed. (Flum \& Blustein, 2000: p $386,387)$.

"Conferred identity" has conceptual similarity with socially constructed identity and "self-constructed identity" has conceptual similarity with intrinsically prospected identity. However, as I articulate throughout this dissertation (refer to the conceptualization earlier and the extensive distinctions of IPI and SCI in the immediately following section), the concepts of intrinsic prospection and social construction of identity are much broader. "Conferral of identity vis-à-vis self-construction of identity" is only one such distinction in the theory development of this dissertation.

The final conceptual overlap of intrinsically prospected and socially constructed identity is with the "actual identity" and "ideal identity" distinction made in an unpublished dissertation work (Murnieks, 2007). It concerns what the author terms "actual identity prominence and ideal identity prominence" to accentuate the "prominence" of identity. There is some similarity in that the operationalization of the constructs captures similar temporal distinctions as well as the fact that intrinsically prospected identity and ideal identity are both aspirational in nature. However, there are two important differences. One difference is in the essence of the conceptualization and the operationalization of the constructs. Murnieks' research is focused on the separation of the self-image, or on "the actuality and the ideal version of that actuality." Therefore, to capture the distinction, the author explicitly uses the word "ideal entrepreneur" in all items of his measurement scale. As shown in the upcoming section, the conceptualization and operationalization of "intrinsically prospected identity" in this dissertation, however, captures a more general, prospective "entrepreneurial self" which may or may not be 
ideal. Second, 'the role of human agency and whether the realities are socially constructed or intrinsically prospected' form the core of the theory I am building and testing, which is not alluded to in Murnieks' work. In other words, the theoretical foci and empirical explorations are entirely different. That being said, the current dissertation research, in many aspects, will be complementary to Murnieks' work-as well as to the other preliminary works on entrepreneurial identity discussed earlier.

\section{The differences and similarities between intrinsically prospected identity and socially constructed identity}

I distinguish IPI and SCI invoking several concepts and dialogues in the identity literature, note however, that some of these constructs are interdependent and essentially substantiate each other. The summary of the distinctions is presented in Table $\mathbf{1}$.

Table 1

The Distinctions between IPI and SCI

\begin{tabular}{|l|l|l|}
\hline Fundamental & Intrinsically Prospected Identity & \multicolumn{1}{|c|}{ Socially Constructed Identity } \\
anchor question \& & Fho do I want to be? & Who am I? \\
orientation & Past \& present orientation \\
\hline $\begin{array}{l}\text { Role of human } \\
\text { agency in identity } \\
\text { development }\end{array}$ & Exclusively human agency driven, & Limited role of agency, largely \\
& proactively and passionately & conferred identity, and conferred \\
negotiated with the external world. & identified. \\
\hline construal & Independent self-construal & Interdependent self-construal \\
\hline
\end{tabular}




\begin{tabular}{|c|c|c|}
\hline $\begin{array}{l}\text { State of identity } \\
\text { (fluid vs. fixed) }\end{array}$ & $\begin{array}{l}\text { Relatively fluid, mostly an identity } \\
\text { project in progress }\end{array}$ & $\begin{array}{l}\text { Relatively fixed, either identity } \\
\text { confirmation or disidentification is } \\
\text { likely }\end{array}$ \\
\hline $\begin{array}{l}\text { Identity intensity } \\
\text { (cognitive and } \\
\text { affective) }\end{array}$ & $\begin{array}{l}\text { Relatively more intense in both } \\
\text { cognitive and affective dimensions }\end{array}$ & $\begin{array}{l}\text { Relatively less intense in both } \\
\text { cognitive and affective dimensions }\end{array}$ \\
\hline Identity regulation & $\begin{array}{l}\text { Internal regulators (personality, } \\
\text { values, abilities, needs, etc.) are } \\
\text { dominant. }\end{array}$ & $\begin{array}{l}\text { External regulators (e.g., contexts, } \\
\text { work roles, relationships, etc.) are } \\
\text { dominant. }\end{array}$ \\
\hline $\begin{array}{l}\text { Regulatory focus of } \\
\text { identity }\end{array}$ & $\begin{array}{l}\text { Promotion focus } \\
\text { (focused to maximize gains) }\end{array}$ & $\begin{array}{l}\text { Prevention focus } \\
\text { (focused to minimize loss) }\end{array}$ \\
\hline Identity motives & $\begin{array}{l}\text { Self-enhancement } \\
\text { Self-exploration } \\
\text { Self-verification } \\
\text { Self-expansion } \\
\text { Distinction }\end{array}$ & $\begin{array}{l}\text { Self-enhancement } \\
\text { Self-consistency } \\
\text { Uncertainty reduction } \\
\text { Belongingness }\end{array}$ \\
\hline $\begin{array}{l}\text { Realization of } \\
\text { identity motives }\end{array}$ & $\begin{array}{l}\text { Identity motive realization occurs } \\
\text { predominantly through facilitation } \\
\text { and legitimation. }\end{array}$ & $\begin{array}{l}\text { Identity motive realization occurs } \\
\text { predominantly through confirmation } \\
\text { and corroboration. }\end{array}$ \\
\hline Identity rewards & $\begin{array}{l}\text { Rewards are enthusiastically } \\
\text { appreciated, more affect-laden, and } \\
\text { will generate greater number of } \\
\text { activities for further development of } \\
\text { the prospected identity. }\end{array}$ & $\begin{array}{l}\text { Identity rewards are relatively less } \\
\text { appreciated, less affect-laden, and } \\
\text { will generate fewer activities for the } \\
\text { further development of the socially } \\
\text { constructed identity. }\end{array}$ \\
\hline
\end{tabular}


The fundamental anchor question and temporal orientation. In the preceding section, I claimed that "who I am" is the fundamental anchor of socially constructed identity and "who I want to be" is the fundamental anchor of intrinsically prospected identity. Note that the conceptualization of prospected identity is not merely an aspirational self-image of the future. It is essentially a process where an actor proactively initiates, nurturers, and promotes narratives about the self which she/he wants to be "perceived as" by the society in question. The individual who initiates and presents such self-narratives may be quite near to being who she/he wants to be, or alternatively may have a long way to go to become what she/he wants to be. Identity prospection is the process of conceiving and developing a certain identity to present it to the outside world and to guide one's actions and behaviors-irrespective of the chances of that identity becoming the future reality of that individual. For instance, someone who lands occasional non-paid gigs at local bars and who is not actually gifted enough to be a real musician in the future, might possess a "musician identity" as strong as or stronger than the "musician identity" of a talented and recognized musician. When somebody asks the question, "who am I", especially in the early years of identity development, the likely answer is: "I am X because other people think or tell me I am X." After becoming aware of the fact that "I am what other people think or tell me I am", the individual is likely to find some comfort in that it will immediately situate her/his existence in some sociopsycho-cultural map of society.

Identity that develops as a socially constructed reality can have a high impact on what the agents think of where they stand relative to that society. Very likely, this situating of socially constructed identity does not involve much evaluation and reflection. 
If this conferred identity is congruent with their desires, personality, and the value systems they have developed up to that point, they will further nurture that conferred identity. Thus, socially constructed identity is largely stamped in the past and present. On the other hand, if the conferred identity does not support or is incompatible with those internal factors, they will immediately ask, "who I want to be/to be seen as." Finding the answer to this question requires a more serious reflection on the internal factors discussed above, as well deeper evaluations of the individual's social, psychological and cultural contexts. An individual, then, creates a narrative about herself/himself based on those internal factors and contexts. He or she not only attempts to get the external world to recognize these self-narratives, but also tries to refine and internalize those narratives over the course of time. The aim is to be defined in the way they want rather than to be defined externally. Therefore, it essentially will be a future-oriented endeavor on the agent's part.

The role of human agency in identity development. As I already articulated in detail, human agency is the single most important, necessary condition in the intrinsic prospection of an identity. Structural and social factors either "facilitate" or "impede against" the identity prospection process. When social and structural factors facilitate agent-initiated self-narratives, the "prospected identity" is likely to strengthen. On the other hand, if social and structural factors challenge or thwart these self-narratives and the prospected identity, the agent will feel what researchers call "an identity threat" (Aquino, \& Douglas, 2003; Elsbach, 2003). The actor, then, is likely to engage in an active identity negotiation process (Kreiner, Hollensbe \& Sheep, 2006). Similarly, when a conferred identity and a prospected identity are "in conflict" (cf. Ashforth \& Mael, 
1989; Shepherd \& Haynie, 2009), the actor is likely to protect the prospected identity. In either situation (the facilitation or the thwarting of the prospected identity by the external factors), the agent is likely to proactively and passionately engage in defining the self. In clear contrast, in the case of a socially constructed identity, the role of human agency is not central. Either the actor "confirms" the conferred identity (cf. Milton, 2008) or she/he simply tries to "disidentify" with it (referred to as the act of distancing oneself from some identity) (cf. Kreiner \& Ashforth, 2004).

The nature of self-construal. One of the fundamental questions facing identity researchers relates to how an individual construes the "self." One approach to answering this question is what scholars call "interdependent vs independent" self-construal. The distinction refers to whether an individual defines/conceptualizes his- or her "self" in relation to, and intertwined with, other people or does so in isolation and unique separation from others (Holmvall \& Bobocel, 2008). When individuals intrinsically prospect an identity, they define themselves based on their own assessment of their attributes, values, skills, abilities, and belief systems. Therefore, IPI is basically a function of independent self-construal (Holmvall \& Bobocel, 2008; Singelis, 1994). On the other hand, in the case of SCI, the definition of self is the function of roles, relationships, and affinities with others (individuals or social units) - i.e., interdependent self-construal. Note that researchers (e.g., Cooper \& Thatcher, 2010) have also separated the interdependent self-construal in two parts-as relation-based and social unit-based ( $\mathrm{p}$ 522). For the purposes of the present discussion, that distinction is not warranted. 
The state of identity (fluid vs. fixed). Although I articulate and advocate dynamism in identity throughout the dissertation, the IPI and SCI distinctions beg some further clarification based on the state of identity. Among identity theorists, there is some divergence in opinions regarding the state of an identity. At the extremes, the issue is whether an identity is stable and fixed or if it is fluid and malleable (Kreiner et al., 2006). Consistent with many other researchers, I avoid the extreme positions. In fact, I believe that the state of an identity is best interpreted in relational terms rather than in absolute terms: certain identities might be relatively more stable than other identities. In this regard, a socially constructed identity is likely to be fixed relative to an intrinsically prospected identity. Researchers have already well-argued that just like identification, individuals engage in disidentification (cf. Kreiner \& Ashforth, 2004). When a conferred, socially constructed identity is incongruent with the values, beliefs, and intrinsic motivations of an individual, the actor is more like to disidentify him/herself from that constructed identity rather than trying to confront it. On the other hand, intrinsically prospected identity is, by definition, "an identity work" ${ }^{\circ}$ in progress geared towards a desired self, and therefore, is likely to be more fluid and malleable.

Identity intensity (cognitive and affective intensity). The cognitive intensity visà-vis affective intensity of identity (Ashforth et al., 2008; Bergami \& Bagozzi, 2000; Harquail, 1998; Tajfel, 1978) conversation can also be enriched with the IPI and SCI distinction. Cognition is generally associated with mental schema, information perception

\footnotetext{
${ }^{6}$ The concept of "identity work" in identity literature explicitly regards the agentic role of the social actor rather than just being the subject the structural factors act upon.
} 
and processing, and creating and enacting meanings while affection is considered as the state of feeling. Because IPI involves self-reflection, creating narratives based on the individual's motivations and values, and the continuous exploration of oneself and one's environments, it involves high cognitive intensity relative to SCI. Similarly, because the "who do I want be" component of an identity is gradually and deliberately nurtured, it arouses more intense and positive feelings compared to the "who am I" component of identity in the identity development process. In the event of a threat to the identity, the affective intensity might be even more intense in the prospected identity. Therefore, both affective and cognitive components will be more intense in IPI relative to SCI.

Identity regulation. Organizational scholars claim that the function of management, in part, is to regulate the identities of employees (cf. Alvesson, 2001; Alvesson \& Willmott, 2002). The external regulation of an individual's identity is more or less a deliberate design of the social system, such as an organization, governing how the individuals should view themselves and accordingly, how they should behave (Alvesson, 2001; Alvesson \& Willmott, 2002). It is conceivable that these deliberate designs to regulate the employee's identity in order to regulate the behaviors of the individual are likely to be more effective or applicable to a conferred and socially constructed identity relative to an intrinsically prospected identity. That is the case because when the individual agency is central to the identity development and when the agent defines the self largely independently of the external roles, contexts, and relations (the intrinsic prospection), it essentially suggests an internal regulation. In fact, the concept of self-regulation per se, in addition to a huge body of research in the psychology domain on self-regulation, signifies internal regulation (cf. Flum \& Kaplan, 2006). For 
example, role identity researchers stress that when a certain role identity becomes highly central in an individual's sense of self-often referred to as identity centrality, it could literally be a merger of "the role and the person" (Farmer \& Van Dyne, 2010: p 504), accordingly guiding her/his behaviors to suit that particular role identity. It is logical to contend that such a merger of the role and the person is more likely when the role identity in question is self-constituted and regulated through internal factors. The internal regulators include, but are not limited to, deeply held values, the abilities the agent is conscious of or believes in (e.g., knowing that you have the abilities to be an entrepreneur even if the external world is not aware of it), and the composition of their needs. Arguably, the forces that internally regulate an identity for a desirable behavior (or selfmanagement), such as the ones stated above, might be even more potent, enduring, and long-lasting. In summary, intrinsic prospection of an identity can be characterized as the identity worked on and worked through internal regulators.

The regulatory focus of identity. Since "identity" is an instrument to achieve goals, the IPI and SCI comparison in this regard is important. Classic regulatory focus theory (cf. Higgins, 1998; Johnson, Chang \& Yang, 2010) states that individuals have two basic foci on how they pursue their goals. The promotion focus is oriented to maximize gains and achievements, is driven by developmental needs, and reflected in ideal, aspirational goals (Carver \& Scheier, 1998; Johnson et al., 2010). On the other hand, the prevention focus is oriented to minimize losses and failures, is driven by security needs (e.g., protecting oneself from psychological harms), and is characterized by setting goals to avoid adverse situations/consequences (e.g., an entrepreneur aiming at a small niche market to avoid competition from the main-stream competitors). Given the 
above distinction, when an individual consciously works on an identity to orient her/himself towards an aspired self (i.e., IPI), it is logical to think that s/he is becoming more promotion focused. Conversely, an individual is likely to be more prevention focused when an identity is an externally forged reality and conferred on the individual. The individual may accept the conferral of an identity just to avoid adverse situations. Recall the earlier example of an individual with entrepreneur parents who might be intrinsically prospecting an "athletic identity." She might just be confirming the "entrepreneurial identity" conferred on her to avoid any conflict with the parents and other family members- unless her entrepreneurial identity is in direct conflict with her athletic identity.

Identity motives. Why do individuals seek, develop, and enact various personal, social, role identities? Many motives for identification have been identified in the literature: that of fulfilling "distinctiveness and belonging” needs, enhancing status, reducing uncertainty, as well as for self-verification, self-enhancement, self-exploration, and self-expansion-among others (Cooper \& Thatcher , 2010; Goldberg et al., 2010; Hogg \& Terry, 2000; Milton, 2008; Shepherd \& Haynie, 2009b). While some of these motives could apply to both IPI and SCI, others are more likely to be accentuated in one or the other type of identity. For example, the self-enhancement motive (to boost one's self-esteem) might underlie both IPI and SCI. When a technology-savvy consumer prospectively identifies with Apple Inc. (IPI) and when an Apple Inc. employee is confirming a constructed identity because of the employment with Apple Inc. (SCI), selfenhancement might be the underlying motive for both of these actors. On the other hand, individuals who prospect some identity (say an entrepreneurial identity) because of their 
abilities, values, and the perceptions of their own skills, it is likely to serve the distinctiveness need. In contrast, if somebody (say, the offspring of entrepreneur parents) is conferred with "an entrepreneurial identity", it likely serves the belongingness need more than the distinctiveness need. The identity motives discussed above are only a few examples. Discussing all the identity motives studied in the literature is not in the scope of this dissertation. The distinctions made above should suffice to conclude that IPI and SCI may differ in the underlying motives of identification.

The realization of identity motives. From the immediate paragraph above and from the review also, it is clear that when individuals develop some identity or when an individuals' identification occurs with some social/collective unit or role, certain motives are associated with that identity. I reason that there might be fundamentally different processes which assist in the realization of these motives of identity. Using intrinsically prospected entrepreneurial identity and socially constructed entrepreneurial identity as examples, I introduce and briefly distinguish these identity motive realization processes. The first process I term as the "facilitation and legitimation process." This process refers to the activities that facilitate the perception of an external audience in accepting the desired self-image of the agent. Take the example of someone who is nurturing an entrepreneurial identity internally (IPI) but does not have the family business connections or any prior experience of entrepreneurial activities to claim an entrepreneurial identity. Very likely, such a person will not be viewed as holding an entrepreneurial identity from the perspectives of the related external audiences. He may not be conferred any entrepreneurial identity by these audiences. In this scenario, some relevant activities, say visiting an entrepreneurship conference and pitching a business idea, might facilitate the 
individual's internally prospected entrepreneurial identity, allowing it to be positively viewed by the external audiences. The external audience is providing some preliminary form of legitimacy to his identity claims despite the absence of a history of activities or the connections typical of such identity claims. Taken together, I refer to this as a process of facilitation and legitimation.

On the other hand, imagine the daughter of a business tycoon who goes to the same entrepreneurship conference to pitch a business for collaboration with other entrepreneurs. Say, she is an architect and for her the "architect" identity is more central than the "entrepreneurial identity" in her overall self-concept. The external audience in this scenario can fulfill her motive of belongingness by conferring an entrepreneurial identity by default. The act of pitching a business for collaboration will confirm and corroborate the identity which was constructed and conferred to her even before she came to that platform. I refer to this process of identity motive realization as the confirmation and corroboration process. Therefore, I argue that in the case of IPI, the realization of identity motives will occur predominantly through facilitation and legitimation processes and, in the case of SCI, the realization of identity motives will occur predominantly through corroboration and confirmation. Note that I am referring to the distinction in terms of the predominance of one process over the other (and not exclusively of one process or the other) because these processes exist in both IPI and SCI.

Identity rewards. While identity may not be "the exclusive source" of intentional efforts as asserted by White (1992), we now have a consistent theory and empirical research to suggest that identity is one of the reasons for intentional behaviors that has an associated motive (Cooper \& Thatcher, 2010; Goldberg et al., 2010; Hogg \& Terry, 
2000). Researchers argue that when individuals are performing certain tasks they might be primarily for achieving a certain identity (Anteby, 2008; Brower \& Abolafia, 1997), rather than for specific outcomes related to the roles, relationships, or collective units. Brower \& Abolafia (1997) introduce the term "identity rewards" to refer to such end results of pursuing and achieving an identity. However, not much literature exists about the nature of such identity rewards. It is logical to think that the rewards associated with IPI and SCI might be different, either because they are formed differently, or they underlie different motives, or they have different processes for the realization of those motives, as I articulated earlier. I argue that "identity rewards" for IPI are more affectladen (that is, full of intense feelings), are likely to be more enthusiastically appreciated by the individual, and may generate greater number of activities which further develop the identity relative to the "identity rewards" associated with SCI. I allude to the earlier example of the aspiring entrepreneur in support of this argument. Recall that he does not have any obvious entrepreneurship networks; nor does he have a record of involvement in hands-on entrepreneurial activities. However, he holds a strong prospected entrepreneurial identity. When this aspiring entrepreneur receives recognition and admiration from some of the entrepreneurs at the conference, it constitutes an identity reward for him. In all likelihood, he will feel emotional about the identity rewards and obtain the encouragement to further engage in entrepreneurial activities. Now recall the architect daughter of a business tycoon discussed earlier who is conferred an entrepreneurial identity, i.e., who holds a socially constructed entrepreneurial identity. In contrast, for her the same admiration for her business idea for collaboration might be 
affectively less intense and may not generate as many additional entrepreneurial behaviors (relative to the aspiring entrepreneur).

\section{The conceptualization of entrepreneurial identity and its potential advantages}

\section{The definition, hierarchy, and complexity of entrepreneurial identity. To}

reiterate, the identity literatures across sociology, management, psychology, organization studies and other disciplines have almost unanimously posited that individuals identify themselves with a bundle of multiple identities. More particularly, individuals have multiple social identities (cf. Ashforth and Mael, 1989; Brewer \& Pierce, 2005) and multiple role identities (cf. Cardon et al., 2009; Callero, 1985). On the other hand, a personal identity by its very definition is heterogeneous across individuals and is shaped by their varied experiences (Bagozzi et al., 2012; Beyer \& Hannah, 2002). Therefore, all individuals hold a unique combination of a multitude of identities in order to make sense of a complex social order, and guide their actions accordingly. For example, an entrepreneur who is also a mother and serves on the governing board of a local church might have a social identity affiliated with the organization she founded as well as with the church. On the other hand, every entrepreneur has a unique, idiosyncratic component of her self-concept, that is, a personal identity (Ashforth \& Mael, 1989; Brickson, 2000; Brewer and Gardner, 1996). As the identity literature suggests, the purpose of an identity is to position an individual in certain contexts that guides the individual's thinking, actions, and feelings (Ashforth and Kreiner, 1999; Ashforth \& Mael, 1996). Identity research tells us that managing multiple identities to guide one's behavior and to achieve various personal, career, and organizational goals is challenging. Social psychologists 
have even introduced a term called "social identity complexity" for the management of multitudes of social identities (Brewer \& Pierce, 2005; Roccas \& Brewer, 2002). Similarly, role identity scholars consider "the self" to be a structure of "roles and role identities" (Callero, 1985). From the extensive literature review earlier, it is also evident that entrepreneurial identity has been conceived in various different ways; entrepreneurial identity is, without a doubt, a complex identity. All this preceding discussion leads to an important question: how do we make sense of an identity, the entrepreneurial identity, which in itself appears to manifest as a collage of personal identity, social identity, career identity, and role identity simultaneously?

The early conceptual studies on entrepreneurial identity offer some insight that helps us to comprehend the complexity of entrepreneurial identity and to provide it with a meaningful structure. Entrepreneurship theorists have unequivocally acknowledged that entrepreneurial identity is likely a culmination of a number of micro-identities (Shepherd \& Haynie, 2009b: p 323) that can be organized in a hierarchy of importance (Cardon et al., 2009: p 517). In this light, I conceptualize entrepreneurial identity as a composite, superordinate identity generally manifested through its subordinate identity components (or interchangeably, 'micro identities,' as Shepherd \& Haynie, 2009b refer to them) in different occasions/contexts. I define entrepreneurial identity as a composite of multiple identities in a hierarchy that become differentially salient in different conditions or circumstances that bestow active and potential entrepreneurs with a coherent sense of self across contexts as well as in different stages of their career. This conceptualization of entrepreneurial identity as a composite of micro-identities (personal identity, career 
identity, organizational identity, and five particular work role identities) at different levels of identity hierarchy is presented in Figure 1 below.

Having conceptualized and defined entrepreneurial identity as a superordinate identity, I now explain the logical foundation of this conceptualization and definition. To arrive at this conceptualization, I used a two-prong approach. First, I identified the identities that are typically considered to be entrepreneurial identities, or the microidentities associated with entrepreneurial identity, or, at minimum, the conceptual proxies of entrepreneurial identities. Second, I organized these different identities which, it could be argued, are either different manifestations of entrepreneurial identity or the subsumed components of entrepreneurial identity based on two rational criteria-identity centrality and identity salience across contexts (which I explain in the following paragraphs).

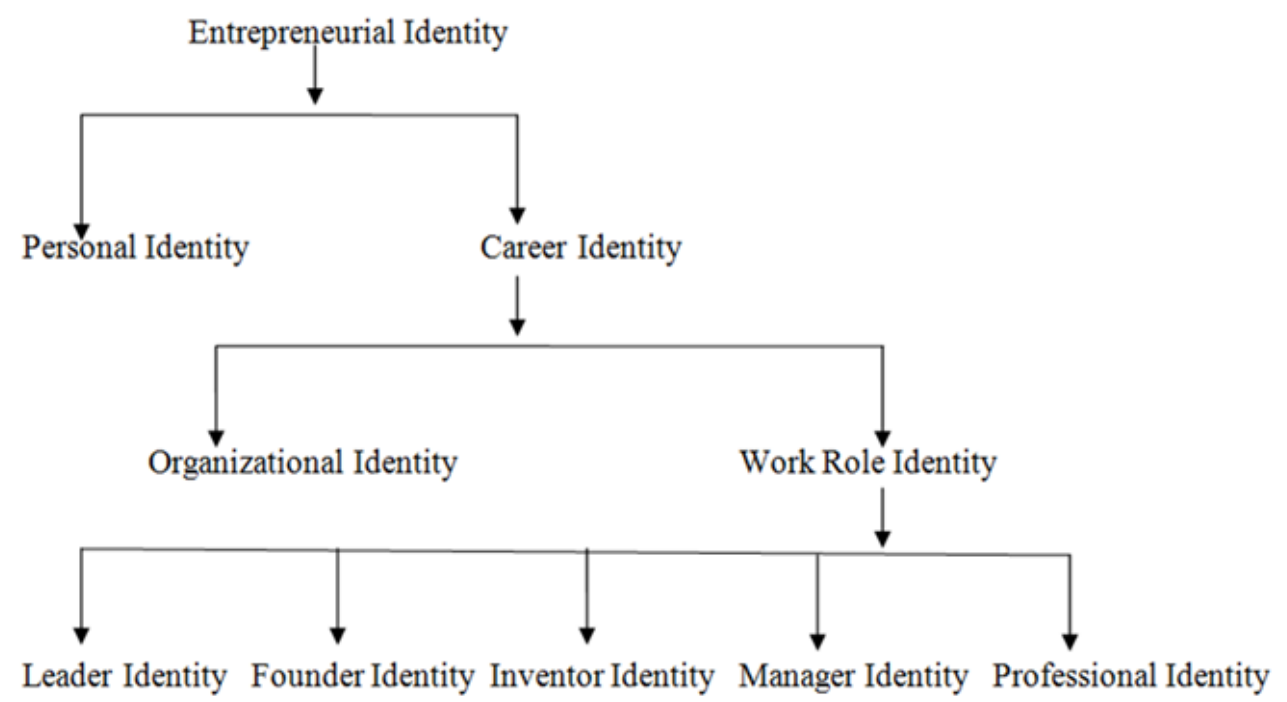

Figure 1. Conceptualization of Entrepreneurial Identity as a Superordinate Identity 
From the discussion throughout this dissertation, it is evident that "individual uniqueness or idiosyncrasy" is an essential hallmark of an entrepreneur's sense of selfimage and self-definition. Research in entrepreneurship suggests that entrepreneurs have a heightened motivation for self-esteem and self-actualization (Murnieks \&Mosakowski, 2007; Shepherd \& Haynie, 2009b). Since being an entrepreneur provides that sense of distinctiveness (Shepherd \& Haynie, 2009b) and fulfills the need for self-esteem and selfactualization, in part, it is essentially a personal identity, and a critical component of his/her self-definition. To borrow Brewer's words, personal identity is "the individuated self - those characteristics that differentiate one individual from others" (Brewer, 1991; Kreiner et al., 2006). Personal identity is signified when an individual perceives the identity as uniquely her/his only: neither an identity shared with others, nor an identity attributable to any particular role context. There are probably few other careers where an individual can assert this personal aspect as much as in an entrepreneurship career. An entrepreneur is disposed to have that sense of uniqueness, even relative to other entrepreneurs. Personal identity is therefore arguably the most central part of an entrepreneur's self-definition.

Similarly, like any other career or occupation, becoming an entrepreneur is a profession which is aimed at fulfilling basic needs (such as financial security) as well as higher order needs (such as status). Therefore, irrespective of where they are in the entrepreneurial processes, potential and active entrepreneurs are likely to deem entrepreneurial identity as their career identity--with some possible exceptions, for instance, where some other identity is already established as a career identity. For example, an accomplished singer who starts and operates a clothing empire might still 
consider "singer identity" as her career identity rather than "entrepreneurial identity" as her career identity. For entrepreneurs in general, however, we can expect, with some caveats, "entrepreneurial identity" to be their career identity. In fact, as I discussed in the review section, entrepreneurship researchers have already started to conceptualize entrepreneurial identity as a career identity (O’Neil \& Ucbasaran (2010). Nevertheless, some entrepreneurs might identify with an entrepreneurial career identity quite strongly, while others might do so only modestly.

Although entrepreneurs are likely to have multiple social identities, one particular type of social identity is likely to be the most prominent, and pertinent, to them. They are likely to identify with the organizations that they found, own, and operate--that is, hold an organizational identity. Similar to other types of stakeholders, entrepreneurs will also consider themselves as the member of an "in-group" prototype, feel a sense of belongingness, and be proud of the organization they found, own and operate (Blader \& Tyler, 2009; Stets \& Burke, 2000). They may strongly hold all three dimensions (belongingness, pride, and respect) of a social identity (Tyler \& Blader, 2001) wherein the organization is the identity target. Cardon et al. (2005) rightfully argue that the entrepreneurs who found or start an organization will show more intense organizational identity relative to all other stakeholders. Even more so, I reason, they will be the ones who forge these organizational identity narratives and standards that the other stakeholders subscribe to and contribute to. This is consistent with the empirical research which suggests that an entrepreneur's identity imprints the organizational identity (cf. Dobrev \& Barnett, 2005). Also, recall the typology of the founder identity that Fauchart \& Gruber (2011) advocate. Those identities, in part, are based on the interpretation of the 
nature of the organization, and the organization is the target object of identification. In summary, an organizational identity is a strongly manifest component of, or a proxy for, an entrepreneurial identity.

As discussed in the literature, entrepreneurs interact with others and make sense of the world through various work roles in their entrepreneurial career. More relevant in the present context are the three role identities of entrepreneurs that Cardon et al. (2009) have identified- the inventor identity, the founder identity, and the developer identity. To sum up, the literature tells us that an entrepreneurial identity represents a personal identity, a career identity, organizational identities (to include the option of a portfolio entrepreneur who might have multiple organizational identities) and multiple role identities.

From the preceding literature review section and theory section, it is clear that an identity serves multiple purposes. "Self-regulation" is conceivably one of the most critical reasons individuals develop an identity. Put differently, an identity is the tool which allows an individual to navigate through the complexities of the society around him/her while enhancing or keeping intact the self-esteem of the individual. However, different identities contribute to the regulation of an individual in different contexts. Some identities become salient (manifest) and other identities become latent, contingent on the contexts and conditions (Gouldner, 1957). Arguably, some identities might be more central in an individual's self-concept (identity centrality) than others. An identity will have the strongest influence in guiding the individual's behaviors when the identity is central and when it is likely to be salient across multiple contexts. 
For an active entrepreneur or a potential entrepreneur, consistent with the premise of the effectuation theory of entrepreneurship (Sarasvathy, 2001), I reason that personal identity is both more central and salient across contexts than other forms of identity because it provides entrepreneurs with the satisfaction of the "distinctiveness" need (Shepherd \& Haynie, 2009b). In addition, a personal identity can be simultaneously salient (enacted) along with other identities of the entrepreneur. Say, for example, an entrepreneur is pursuing some government policy makers on certain aspects of his/her industry on behalf of his/her peer organizations in the industry. In this context, expectedly, the entrepreneur's founder identity will be more salient than her/his manager identity. Even in this scenario, in his/her consciousness, she/he likely will be aware of the uniqueness which allows him/her to navigate through those complex interactions successfully.

Consistent with career identity researchers, I argue that a career identity is one of the most central elements of an individual's self-concept (Ashforth \& Kreiner, 1999). That people switch to an entrepreneurial career for authenticity in their identity ( $\mathrm{O}^{\prime} \mathrm{Neil}$ \& Ucbasaran 2010) also vindicates the notion that career identity (viewing entrepreneurship as a career) is also central to potential and active entrepreneurs. Since a career identity is likely to serve many needs of an active or potential entrepreneur (security needs to achievement needs), it is also likely to be salient across multiple contexts. Therefore, based on the criteria of identity centrality and identity salience across contexts, personal identity and career identity constitute the highest order constituent identities in the entrepreneurial identity structure presented in Figure $\mathbf{1}$ above. 
As reviewed in the preceding sections, entrepreneurial identity also has been conceptualized in various role identities and social identities. How does that fit in a general conceptualization of entrepreneurial identity, of which career identity is an integral part? Scholars have already made the point that a career identity is a combination of organizational identity and work role identity (cf. London, 1993). London states:

Career identity is the degree to which people define themselves by their work and by the organization for which they work. It involves the degree to which they immerse themselves in activities related to their job and the organization, work hard, view themselves as a professional or technical expert and express pride in their employer (p 56).

Therefore, reasonably, the self-concept which an individual perceives regarding entrepreneurship as a career choice is likely to be in itself a meta-identity that contains various work role identities and an organizational identity. In line with other identity researchers, I propose that, for entrepreneurs, a career identity controls and harmonizes the meanings of these various role identities and the organizational identity (Burke, 2003; Shepherd \& Haynie, 2009). Even though the targets of social identity of entrepreneurs could be many (a church, a golf club and the like), the organization they create and operate is often their most prominent social identity target. Thus, they are also likely to hold an organizational identity more strongly relative to all other stakeholders of the organization, as rightfully argued by Cardon et al. (2005).

Concerning role identity, as discussed in the literature, entrepreneurs interact with others and make sense of the world through various work roles in their entrepreneurial career. Obviously, an entrepreneurial career can contain many job roles. The three role 
identities (the inventor identity, the founder identity, and the manager $/{ }^{7}$ developer identity) advanced by Cardon et al. (2009) best serves the purpose as the foundational role identities of an entrepreneurial career (for achieving the balance of parsimony and complexity in theory building). That being said, their scheme misses two particular role identities of entrepreneurs that, I argue, are as important as the other role identities: professional role identity and leader role identity.

Imagine an entrepreneur of a robotic design firm who is also a robotic engineer (he has worked in such a capacity in paid-employment) and the chief technology officer of the company he founded. In all likelihood, this entrepreneur will retain his professional role identity as a work role identity as strongly, if not more so, than his founder role identity. Similarly, entrepreneurship researchers have argued that individuals who spearhead the development of ideas and resources that result in functional organizational forms are the "authentic leaders" (cf. Jensen \& Luthans, 2006). Relatedly, the researchers in the organizational and applied psychology domain have already documented that "leader identity" is a credible role identity which influences the behaviors of both leaders and followers (cf. Johnson, Venus, Lanaj, Mao, \& Chang, 2012). In addition, if we ask entrepreneurs "who they are", it is likely that many of them will refer to themselves as "leaders" of the society. Therefore, we can conclude that a leader role identity is a sine

\footnotetext{
${ }^{7}$ I use the term "manager identity" hereafter because the conceptualization of an entrepreneur in this dissertation is broader than the Cardon's et al. interpretation and also because the concept of "the developer" in their study is fairly synonymous with the concept of a manager. I believe the term "manager identity" would bring more clarity to the role of nurturing and growing a venture- the role of any top management, new ventures or otherwise. Every entrepreneur, arguably, must perform a manager's role.
} 
qua non constituent identity of the entrepreneurial identity composite. Taking all these pieces together, consistent with the existing literature, I propose that entrepreneurial identity is a superordinate identity generally manifested in its subordinate identity components, in a hierarchy, as presented in Figure 1.

The potential advantages of entrepreneurial identity. A genuine next question in this scheme of the hierarchical, complex nature of entrepreneurial identity is the following: Would conceiving entrepreneurial identity as a hierarchical assortment of multiple identities create identity conflicts and problems for the coherent/stable selfconcept? This question becomes even more relevant in the context of another question researchers have been grappling with, namely, the tensions between personal identity and social identity that exist within an individual (cf. Hitlin, 2003; Mullen, Migdal, \& Rozell, 2003). Furthermore, these identity conflicts may come with potential costs (Prat \& Foreman, 2000; Shephered \& Haynie, 2009). In the following paragraphs, I make the case that the complex and superordinate nature of entrepreneurial identity, with multiple micro identities, actually works to the advantage of active and potential entrepreneurs. I extend multiple arguments to that effect, drawing on insights from various literatures.

To begin with, scholars have asserted that "in cases where identities have shared meanings, intersect, and are activated together, those identities likely exist in a hierarchy of meaning where identities at the top of the hierarchy control the meanings of identities lower in the hierarchy" (Burke, 2003; Shepherd \& Haynie, 2009: p 1253). This is indeed the nature of entrepreneurial identity, which consists of identities that have shared meaning and, generally, are likely to be activated together. Also, in all likelihood, individuals with multiple identities are expected to have the capability to meet a wide 
range of expectations, respond better to a variety of situations, and can draw from broader referential frames while navigating through complex social systems (Pratt \& Forman, 2000). All these advantages may get better when the different identities are part of a composite/meta-identity where different identities are aligned and they place complementary demands on the individual rather than conflicting demands (cf. Pratt \& Foreman, 2000). Entrepreneurial identity is viewed as such a composite identity; and it therefore enables a larger behavioral repertoire which allows entrepreneurs to cope with emerging challenges such as the skills, knowledge, and abilities associated with new and varied roles (cf. Hoang \& Gimeno, 2010). Thus, it is likely to assist entrepreneurs in navigating through socio-economic as well as psychological complexities during the startup and growth phase.

Second, "the dramaturgical perspective" in sociology holds that "the self" is the combination of various parts individuals play. Each part caters to different audiences in different social interactions, and together those interactions contribute to the construction and development of an identity (Down and Reveley, 2009). In a similar vein, if we regard entrepreneurial identity as the assorted whole, an entrepreneur will be displaying a certain identity (ies) of that identity assortment contingent upon the setting of the social interactions. For example, say an entrepreneur is passing through a financially difficult phase in sustaining her organization. To persuade her family members to invest their personal wealth in the business, her personal identity might work to her advantage. On the other hand, if she is pitching to a group of business angels for further investment in the business, her founder identity might be salient and it might help her acquire those resources. Recall that an identity has been linked to better resource acquisitions 
(Lounsbury \& Glynn, 2001; Martens et al., 2007). Yet, if the same entrepreneur is talking to her employees to request a salary deferral as a means to pass through current hard times, her manager role identity might become more salient than other micro identities.

Third, entrepreneurial identity also provides an individual a personalization and depersonalization balance. The perception of personal uniqueness and personalization make up the core of a personal identity. On the other hand, depersonalization (considering the self as an embodiment of a certain social group or a particular role) of an individual's self-concept is central to social identities and role identities (Alvesson, 2010; Stets \& Burke, 2000). This depersonalization, owing to social identities or role identities, allows individuals to leave the "isolated plane of self-concept" for the "shared plane of self-concept." Researchers have already made the case that striking an optimal balance of personal and social identity is the key to managing the multitudes of identities and the conflicting demands placed by those identities (Kreiner et al., 2006). Entrepreneurial identity serves this dual purpose of personalization and depersonalization of the selfconcept, providing the entrepreneur with the needed optimal balance. This deduction is consistent with the theoretical insights of 'identity management' advanced by Shepherd \& Haynie (2009b) in the context of entrepreneurial identity (cf. the literature review).

Finally, scholars assert that multiple identities are beneficial because they help people meet different needs based on competing priorities and contexts, provide psychological well-being, and an existential security (Briscoe et al., 2012; Farmer \& Aguinis, 2005; Lang \& Lee, 2005)--particularly when these various identities are likely to be in harmony (Brook et al., 2008). Lang \& Lee (2005) sum up the advantages well: 
Multiple identity involvements translate into greater 'existential security' or a sense of meaningful existence and purposeful, ordered behavior that is important to one's psychological health that results in reduced feelings of anxiety and despair (p 295).

\section{Entrepreneurial identity across entrepreneur types}

Imagine an engineer who invented and commercially introduced a new driving safety device that created a new market in the auto industry; a restaurateur who opened an Italian restaurant in a town full of other Italian restaurants; and a lawyer who established a law firm hiring other lawyers, paralegals, and general administrative employees. Who is an entrepreneur among them? As I alluded to in earlier sections, "who an entrepreneur is" can be defined from different perspectives depending upon one's understandings of entrepreneurship. In this dissertation, anyone who founds and/or owns

and operates a business is referred to as an entrepreneur. Are they likely to have the same identity or different identities as an entrepreneur? I argue that their entrepreneurial identities have both commonalities and distinctions. The three entrepreneurs above represent three distinct types of entrepreneurs-innovators, imitators, and self-employed professionals, respectively. The novelty of products and services entrepreneurs introduce is the "logical and literature-based" criterion that I apply to propound this particular typology of entrepreneurs. The explanation follows.

Novelty of products and services has always been central to entrepreneurship discourse, from Schumpeter (1934) to contemporary entrepreneurship theorizing (Aldrich \& Kenworthy, 1999; Amason, Shrader, \& Tompson, 2006; Shane \& Venkataraman, 2000). On the other hand, researchers often operationalize self-employment as a proxy for entrepreneurship (Parker, 2009). Making the case that most organizational foundings 
are merely simple reproductions of existing organizational forms which fall along an innovation-reproduction continuum, Aldrich \& Kenworthy (1999) use the terms "innovators and reproducers" to accentuate general distinctions among these firms. On similar grounds, I classify entrepreneurs in these three broad types for theoretical simplification as well as for the pragmatic purpose of theory building and testing. In my classification, someone who introduces novel products or services or who creates new markets for existing products or services, or who designs an innovative process of value creation will belong to the 'innovator' category. Someone who introduces the same or similar products and services prevalent in the market, employs the same or similar business processes existing in the industry, and serves an existing market will fall under the general 'imitator' category. A professional, who organizes his /her services by establishing an organization, employing other professional and non-professional staffs, will fall under the 'self-employed professional' category. Since professional services are, by definition, required to reproduce more or less standardized products/services, the variation in organizational forms and the novelty of their products or services will be, on average, essentially lower than the regular imitator type. To further clarify, refer to the imitator entrepreneur mentioned above. His Italian restaurant in the city might be similar to many of the other Italian restaurants in the city in some respects. However, in other respects, it will have a definite distinction from all the remaining restaurants in its products, services, production systems, and organization. Thus, it makes sense to distinguish between the self-employed professionals and other regular imitators. Exploring the dimensions of entrepreneurial identity, based on the processes of identity formation proposed earlier, may illuminate the subtle differences of identity 
across these entrepreneur types. I reason that the overall strength of an entrepreneurial identity and the constitution of IPI and SCI will be different among these three types of entrepreneurs depending on their micro-identities of entrepreneurial identity composite. Note here that the discussion that follows is predicated on the notion of identity as developmental and dynamic that I established and explained earlier. That is, at any point in time, identities are considered as a work in progress (or in detour if the agent is in the process of disidentification). I further explain the commonalities and differences of entrepreneurial identity among these three types of entrepreneurs below, succinctly presented in the conceptual model in Figure 2.

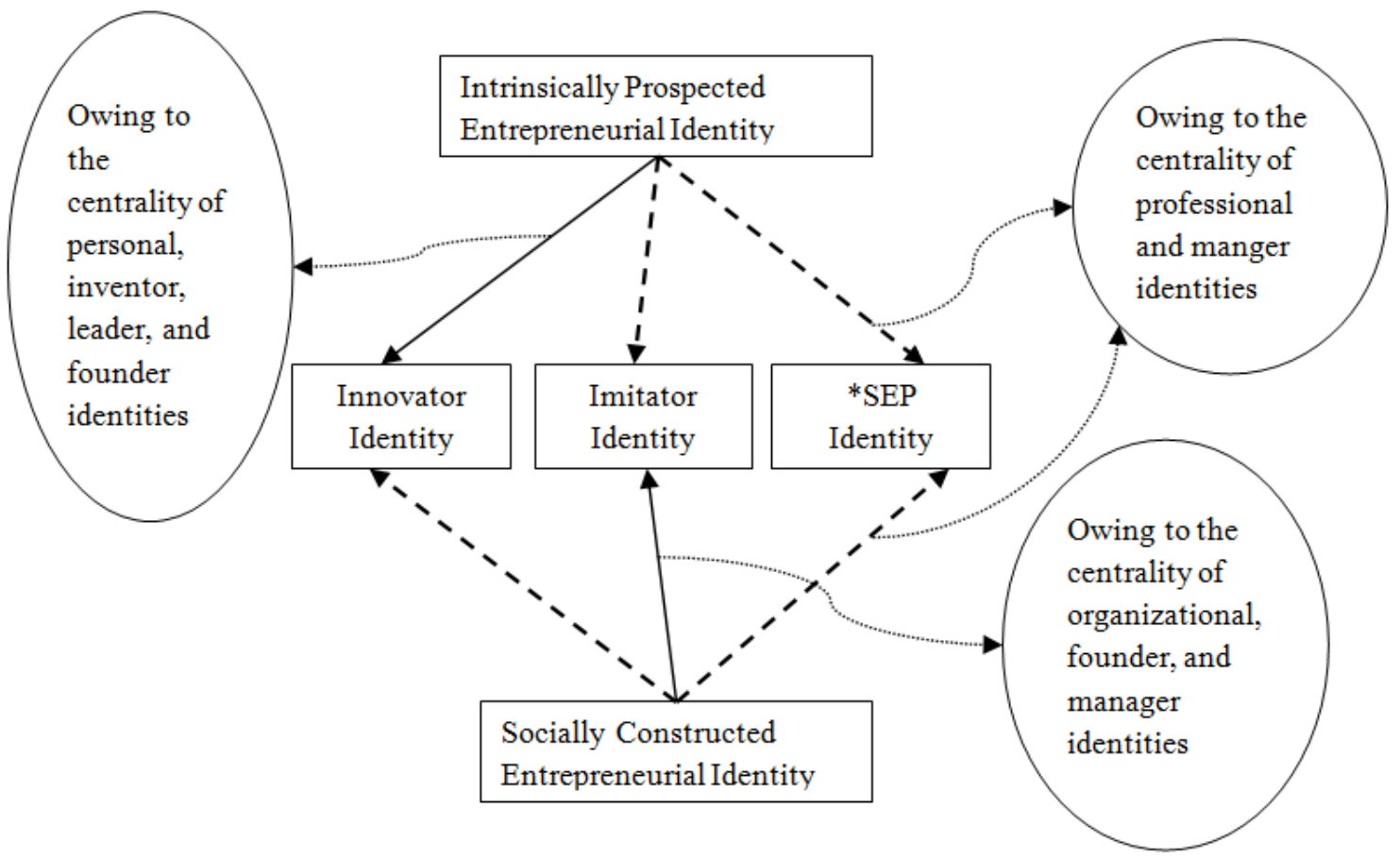

Figure 2. Constituents of Entrepreneurial Identity (EI) across Entrepreneur Types

\footnotetext{
$\longrightarrow$ This arrow represents strong identity component

$\rightarrow \quad$ This arrow represents weak identity component

*SEP: $\quad$ self-employed professionals
} 
Entrepreneurial identity of an innovator type. First, the innovator type entrepreneurs are likely to be motivated by three specific need satisfactions-- the need of "distinctiveness" (Shepherd \& Haynie, 2009b), "independence" and "self-actualization /self-realization" (Carter et al., 2003; Wilson et al., 2007). A personal identity is likely to facilitate those three needs more than any other micro identity. Therefore, it is likely to be a more central identity of innovator type entrepreneurs. Note that entrepreneurs can satisfy these needs by creating narratives with the same or similar meanings with the development of a personal identity. Next, as the Cardon et al. (2009) study suggests, the inventor identity is more associated with creativity and innovation. Therefore, the inventor identity is more likely to be the hallmark of an innovator type entrepreneur.

Finally, the founder identity and the leader identity are also likely to be stronger with the innovator types relative to the other two types of entrepreneurs. The innovative entrepreneurs often found the business as a means to realize their personal vision of changing the world rather than other less idealistic motives, such as financial security. In fact, Dobrev \& Barnett (2005) found that as the organization of the entrepreneur grows in size and years, its founder is more likely to move on to found another organization (pursuing other entrepreneurial opportunities) relative to the possibility of such a transition for other members of the organization. They argue that, as the organizational systems get more routinized, the founders face a threat to their founder identity, at least on two fronts. Their initial independence of decision-making gets diminished (forming a threat to their leadership) and the routinized systems create constraints for the entrepreneur to push through the innovative ideas (a threat to their innovativeness). This indicates the significance of a leader identity and a founder identity in innovator type 
entrepreneurs. Therefore, from this discussion, we can deduce that personal identity, founder identity, leader identity and inventor identity are likely to be more central elements of the innovator type entrepreneurs' self-concept in comparison to the other micro identities of entrepreneurial identity composite.

These four particular micro-identities of the composite are more likely to be the function of the intrinsic prospection process than the social construction process. Personal identity by virtue of its very definition (also refer to earlier discussion on personal identity conceptualization) is less likely to be socially constructed and conferred. In the case of the other three also, they are more likely to be developed through the intrinsic prospection because of their dependence on internal regulators such as values, abilities, beliefs, and the specific needs described above. For instance, what type of a leader of the society an entrepreneur considers him/herself to be, and the accompanying leader identity for that matter, is more likely to be the function of one's own reflective assessment of leadership qualities, values, intrinsic motivation, and belief systems. I acknowledge that the leader identity of an entrepreneur can be influenced by structural factors, and conferral of such a leader identity to an entrepreneur is also possible. However, my point of view, and the emphasis, is that the internal regulatory forces mentioned above play a more vital role in the leader identity development of an entrepreneur.

To summarize, for the innovator type entrepreneurs, personal identity, founder identity, leader identity, and inventor identity will be central to their entrepreneurial identity composite. Since the majority of these micro identities develop through intrinsic prospection, innovators will have a stronger prospected entrepreneurial identity relative to the other types of entrepreneurs. Thus: 


\section{P1: The identity of innovators will constitute a strong intrinsically prospected}

entrepreneurial identity and a weak socially constructed entrepreneurial identity.

Entrepreneurial identity of an imitator type. In contrast to the innovator type entrepreneurs, the imitator type entrepreneurs are more likely to be motivated to satisfy "belongingness needs" (Shepherd \& Haynie, 2009b) and "security needs" (financial success and safety) (Carter et al., 2003). Among the micro identities of the entrepreneurial identity composite, I conjecture that organizational identity and manager identity will facilitate the satisfaction of the above mentioned two needs.

First, organizational identity is a social identity where the organization is the unit of identification. Therefore, it is likely to provide the sense of belongingness to the entrepreneur who has started one or more businesses. Second, we can expect that the imitator type founders are more likely to hold what Fauchart and Gruber (2011) call the Darwinian identity whose focus is on economic self-interest. These imitator type entrepreneurs (refer to the earlier example of a restaurateur) are driven by strong safety needs and they will develop a higher manager role identity as well. Since they are less likely to engage in innovation in products, services, and business processes in the industry (relative to their innovator type counterparts), to meet their safety needs (e.g., healthy business growth and performance), they will likely focus more on managerial roles and managerial identity. However, the founder identity of imitator type entrepreneurs will probably be as strong as that of innovator type entrepreneurs. That is because the imitators will have a similar need for personal development as the innovator type entrepreneurs, which can be fulfilled by founding a firm. 
The Darwinian type social (organizational) identity and manager (role) identity are more likely to be the function of the social construction process. Note that these two identities cannot be conceived of "independent of and before" the founding of the social unit (the organization) and before taking up the role (the manager role). And as soon as it is founded, the conferral of identity is likely. These identities will be substantiated through the process of confirmation and corroboration discussed earlier. It is not difficult to conceive that the centrality of the founder identity, Darwinian social (organizational) identity and manager identity also constitute a consistent narrative for the imitator type entrepreneur. Despite my arguments that founder and manager identities are predominantly the function of social construction, I acknowledge, it is possible that these two identities can also be self-constituted and gradually strengthened, as in the case of inventor identity or leader identity. The point is that they are predominantly socially constructed.

In conclusion, for the imitator type entrepreneurs, organizational identity, manager identity and founder identity will be central to their entrepreneurial identity composite. Since all of these micro identities develop predominantly through social construction and will likely be conferred, the imitators will have a stronger constructed entrepreneurial identity relative to the innovators and the self-employed professionals. Therefore, I propose:

P2: The identity of imitators will constitute a strong socially constructed entrepreneurial identity and a weak intrinsically prospected entrepreneurial identity.

Entrepreneurial identity of a self-employed professional (SEP) type. For the self-employed professional type entrepreneurs, I argue professional identity and manager 93 
identity are likely to be more central to their overall self-concept than the other micro identities of entrepreneurial identity composite. Studies that looked at the identities of professionals, such as accountants and engineers, found that these professionals, when employed in some organizations, pursue a "fostered and desired" occupational identity/professional identity (Anteby, 2008; Kunda, 2009). Even the individuals whose profession/professional identity is generally considered to be of lower status and stigmatized (e.g., so called dirty-work professions) are also equally proud of their professional identities (Ashforth \& Kreiner, 1999; Kreiner, Ashforth \& Sluss, 2006). They see their professional identity as self-esteem enhancing and hold it strongly. Therefore, it is safe to conclude that, on average, the professional identity of selfemployed professional type entrepreneurs will be the central identity of their selfconcept.

However, unlike the other micro identities of the entrepreneurial identity composite, a professional identity has the possibility to be in conflict with other micro identities. For example, refer to the lawyer entrepreneur stated at the beginning of this subsection. Imagine her organization is in need of taking some bold strategic steps by adopting new technology and reducing the number of paralegals and attorneys. In this scenario, the professional identity of the lawyer founder might be in direct conflict with her founder identity. On the one hand, because of her professional identity, she might hold a strong sympathy for the professionals who have to be laid off for the needed strategic change. As such, she might resist the strategic change. On the other hand, her founder identity might prompt her to make those strategic decisions. Founder identity is characterized by the typical behaviors of channeling efforts and resources where the 
needs are, and ensuring the firm's competitive success. Recall the earlier argument that, for an identity to be strong for an individual, it must be both central to one's overall selfconcept (identity centrality) and must be enacted in various contexts (identity salience across contexts). Conceivably, due to the likelihood of conflict with other micro identities of entrepreneurial identity composite, the salience of professional identity will therefore be weaker.

A professional identity is also likely to be forged through both intrinsic prospection and social construction. An individual is likely to self-constitute professional identity (IPI) when they are in professional training (say in a law college) or even before their professional training. Later, after earning a bar license, the prospected professional identity will be complemented with social conferral as well. Overall, while the professional identity of SEP type entrepreneurs is likely to be central to their selfconcept, their professional identity also may be weakly salient due to conflict with other identities, and it will be formed in a mixed fashion-- through intrinsic prospection as well social construction.

Concerning "manager identity" being a central identity to SEPs, I draw on the possible basic motivation of a firm founding. In general, an innovator type entrepreneur founding a firm can be conceived of as someone who wishes to realize a vision to change the world through their creativity and innovation. It could be safely argued that an imitator type entrepreneur founding a firm is primarily meeting financial and other security needs (e.g., income, livelihood). However, for the self-employed professional type entrepreneurs, founding a firm can be, arguably, an institutional extension of the services they were already providing on a personal basis. In other words, the firm 
founding is a collective basis of organizing to enhance the scale and scope of their service to clients. In addition, it is likely that the security needs (e.g., financial security) are also central to the SEPs. Because of their two primary motives (enhancing the scale and scope of the services and meeting their security needs), manager identity is of critical importance to them.

I discussed earlier that the manager role identity will be forged through the social construction process. However, the social construction and conferral of manager identity will be weaker for the SEPs compared to the imitator entrepreneur types. Alluding again to our representative entrepreneurs, think of a scenario where both the restaurant founder and law firm founder successfully placed their organizations in a strategically advantageous position relative to the competition in their industry. In this scenario, the external audiences' conferral, confirmation, and corroboration of the manager identity to the lawyer entrepreneur will be weaker relative to the restaurateur because the professional identity of the lawyer acts as some form of blinder to the audiences.

In summary, for the SEP type entrepreneurs, the professional identity and the manager identity will be central to their entrepreneurial identity composite. Since the professional identity partly develops though both processes (the intrinsic prospection process and the social construction process) and can contradict with other micro identities of entrepreneurial identity, it likely has a weak salience (despite the centrality). Similarly, the manager identity has a weak social conferral for SEPs. For these reasons, SEPs will have a weakly prospected entrepreneurial identity as well as a weakly constructed entrepreneurial identity. As such: 


\section{P3: The identity of self-employed professionals will constitute a weak}

intrinsically prospected entrepreneurial identity and a weak socially constructed entrepreneurial identity.

In addition to the differences in the relative strength of intrinsically prospected and socially constructed entrepreneurial identities theorized above, the overall strength of entrepreneurial identity composite is also likely to be different across these entrepreneur types, at least on two grounds.

First, note that the three types of entrepreneurs have a different number of identities which are central to their overall self-concept. For innovators, four identitiespersonal identity, inventor identity, founder identity, and leader identity-are central, which are likely to be strongly salient as well. For imitators, three identities-founder identity, manager identity, and organizational identity-are central, which are likely to be strongly salient too. For SEPs, two identities-professional identity and manager identityare central, but are likely to be weakly salient. Recall the gist of the arguments I offered in "the potential advantages of entrepreneurial identity" subsection; that is, a higher number of micro-identities are likely to create a higher impact. Also recall the positive effects of "harmonizing identities" on an individual's psychological well-being discussed in the literature review (cf. Brook et al., 2008). Because the four central identities of innovators are more likely to be in harmony and create a strong synergy effect, the entrepreneurial identity composite of innovators will be the strongest among the three types of entrepreneurs. In contrast, because of the only two central identities which may have a weak synergic effect, the entrepreneurial identity composite will be the weakest for SEPs. 
The differential strength of entrepreneurial identity among entrepreneur types can be argued from a career identity prospective as well. These three types of entrepreneurs will differentially consider entrepreneurial identity as their career identity. We can expect innovators to relate to "entrepreneurship" as their career most strongly and SEPs to relate to "entrepreneurship" as their career most weakly. The phenomenon of habitual entrepreneurs (serial and portfolio entrepreneurs) provides insight on to this observation. A career identity generally develops as a series of job related experiences which constitute a career. In the case of entrepreneurship, the series of job related experiences include: identifying and exploiting novel opportunities and organizing those entrepreneurial opportunities by founding a firm or by the unique and novel resource deployment within an existing firm or in a market (Shane \& Venkataraman, 2000; Gregoire \& Shepherd 2012; Wright, Robbie, \& Ennew, 1997). Conceivably, innovators are more likely to have had these related experiences compared to imitators who are likely to stick with their first organization, focusing on its growth. Ceteris paribus, an innovator is more likely to gain the serial entrepreneurship and portfolio entrepreneurship experiences that will bestow her with a strong sense of entrepreneurial identity as a career identity. In sharp contrast to innovators, and compared to imitators as well, SEPs are less likely to deem entrepreneurial identity as their career identity, based on the serial and portfolio entrepreneurship insight. In addition, SEPs may have already developed a strongly held professional identity which they might refer to as their career identity. With this discussion: 


\section{P4: The entrepreneurial identity of innovators will be greater than that of} imitators, and the entrepreneurial identity of imitators will be greater than that of selfemployed professionals.

With the preceding theory, it is reasonable to conclude that different types of entrepreneurs will have significant similarities in their entrepreneurial identity. It is because the socially constructed component of entrepreneurial identity is relatively common across entrepreneurs due to its conferred nature and for the similar settings of social structures, institutions and understandings that govern the identity conferral. ${ }^{8}$ The similarities are attributable to the shared micro identities as well. The centrality of founder identity in both innovator type and imitator type entrepreneurs' self-concept is one such example. On the other hand, the intrinsically prospected component of entrepreneurial identity will result in variations in entrepreneurial identity. Two basic types of variations can be conceived. First, it will create a between-group variation across the entrepreneur types. That is, an innovator's entrepreneurial identity will be distinct from the entrepreneurial identity of an imitator. Second, the prospected component of entrepreneurial identity will create heterogeneity of entrepreneurial identity among individuals of the same category. In other words, it will create a within-group variation as well. The within-group variation occurs because the prospected entrepreneurial identity is largely the function of people's personality, their own understanding of their personality, the values and beliefs they hold dearly, their mental schemata, their sense of what is

\footnotetext{
${ }^{8}$ The larger socio-cultural context is assumed here to be the same. However, when socio-cultural contexts change, say for example, entrepreneurs in the USA vs. entrepreneurs in Nepal, even the socially constructed entrepreneurial identity might vary between the entrepreneurs of these countries.
} 
important to them, their skills and abilities, and their reflective assessments of those skills, among others.

\section{Conclusion}

The beginning sections of this essay aimed to contribute to and initiate debates in the broader identity literature itself. I argued that an identity generally develops through two fundamental processes -intrinsic prospection and social construction. I articulated that the intrinsic prospection of an identity differs from the social construction of the identity in many aspects. Particularly, they differ in the anchor questions related to the identity; the temporal orientations; the fluid versus fixed nature of identity; the identity motives; the processes of realizing the identity motives; the affective and cognitive intensity of the identity; the degree of human agency in the identity development; the nature of self-construal; the identity rewards; the mechanisms of identity regulation; and, the regulatory focus of the identity. I also provided support from the existing literature to argue that this distinction is meaningful. To that effect, I articulated the knowledge gap recognized by identity researchers. Then, I built on the works of other researchers who attempted the reconciliation of the two juxtaposed approaches (the humanist and the nonhumanist) on the nature of identity formation (Alvesson, 2010).

The later sections developed insights on entrepreneurial identity. Eliciting from the entrepreneurship specific literature as well as the broader identity literature, I first articulated entrepreneurial identity as a superordinate identity (or a meta-identity synonymously). The meta-identity comprises a personal identity, a career identity, an 
organizational identity (as a social identity of entrepreneurs) and five role identities (founder, inventor, manager, professional, and leader). I then organized these micro identities, with the insights from the literature, into a hierarchy depending on the identity centrality and the likelihood of identity salience across contexts. One could contend that there might be other role identities (say the symbolic liaison role of an entrepreneur connecting a firm with consumers) or one could challenge why I did not include different forms of social identity of entrepreneurs (say the three types advocated by Fauchart and Gruber, 2010). I acknowledge these possibilities. However, as the very basic rule of theory building requires, I needed to draw "a theory boundary" and I needed to strike a balance of "parsimony and comprehensiveness" (cf. Whetten, 1989).

In the final section of the essay, I explained the nuanced differences as well as the commonalities regarding the entrepreneurial identity of three entrepreneur types. I furnished theoretical insights, arguments and evidence, when available, for that purpose. Largely based on the criteria of the centrality and salience of the constituent identities of the entrepreneurial identity composite as well as their likely development processes, I drew the following logical conclusions. The entrepreneurial identity of innovator type entrepreneurs will be dominantly intrinsically prospected and that of imitators will be dominantly socially constructed. Further, the entrepreneurial identity of SEPs will be weakly prospected and weakly constructed. In addition, the overall entrepreneurial identity will be the strongest for innovators and the weakest for SEPs. 


\section{Exploring the Determinants of Individual Level Entrepreneurial Identity (Essay 2)}

\section{Introduction}

Identity researchers have long argued that the performance of any role without an identity, and the commitment to that identity, results in empty behaviors (Burke \& Reitzes, 1991). In other words, developing and committing to an identity is a necessary condition for meaningful actions and an active self. Relatedly, one of the fundamental purposes of identity development is that identity provides a simultaneous sense of coherence and distinctiveness to individuals (Albert \& Whetten, 1985; Alvesson \& Kärreman, 2007) which assists them in successfully coping with their career and in other social settings (Alvesson \& Kärreman, 2007; Alvesson \&Willmott, 2002). The more dynamic and unstable a career or work context is, the more crucial it becomes for an individual to develop a sense of identity (Alvesson \& Kärreman, 2007; Deetz 1998). Because uncertainty and risk are fundamental attributes of entrepreneurship (Knight, 1957; McMullen \& Shepherd, 2006; Sarasvathy, 2001; Shumpter, 1934), the complexities of the social interactions that need to be successfully navigated are more challenging and dynamic for an entrepreneurial career, relative to other career choices. Therefore, it could be safely deduced that developing an entrepreneurial identity is critically important for active and potential entrepreneurs. Conceivably, it is even more crucial for prospective and nascent entrepreneurs. ${ }^{9}$ With that statement, the next question

\footnotetext{
${ }^{9}$ Note that some micro identities of the entrepreneurial identity composite might be more applicable than others in the case of potential and nascent entrepreneurs relative to active entrepreneurs. For instance, among the micro identities, the organizational identity might be less applicable to potential entrepreneurs as
} 
we need to ask is: What factors contribute to the development of an entrepreneurial identity and how are those factors likely to influence intrinsically prospected entrepreneurial identity (IPEI) and socially constructed entrepreneurial identity (SCEI) theorized in Essay \# 1?

In the literature review section, I provided a comprehensive picture of the antecedents of various identities at the individual level. From the broad literature, it is evident that identities are the functions of various contextual factors (such as the external prestige of organizations or family interactions) (Alvesson \& Kärreman, 2007; Brickson, 2000; Farmer et al., 2003) and various attitudes (Diemer \& Blustein, 2006; Kornberger \& Brown 2007; Mael and Ashforth, 1992). Even other identities and the past behaviors related with a focal identity (the dependent variable) were found to be the antecedents of an identity (Grant et al., 2008).

Unfortunately, however, due to the very early stage of development of the entrepreneurial identity literature, we do not know anything about the possible antecedents of entrepreneurial identity. As discussed in the review section, the only empirical study to directly investigate the antecedents of entrepreneurial identity is Farmer's et al. study (2011). They tested the impact of entrepreneurial role congruence (a match between the perceived entrepreneurial role characteristics and self-perceived characteristics) on entrepreneurial identity. Although this is a very important contribution

they may not yet have formed their organization. However, given the exploratory nature of this study and the manageability issue of already quite comprehensive research, theoretically and empirically distinguishing the entrepreneurial identity of potential vs. active entrepreneurs is not under the scope of the present dissertation. 
to the entrepreneurial identity literature, it examined only one factor out of many potential factors that could influence entrepreneurial identity. Therefore, theorizing the antecedents of entrepreneurial identity is a rational first step for an exploratory examination of entrepreneurial identity. Observe that in the broader identity literature too, knowledge of the antecedents of an identity is limited. Accordingly, researchers have recently made explicit calls for research in that direction (Dutton et al., 2010).

Even though the broader literature provided some insights, the present research faced a challenge in exploring critical antecedents of entrepreneurial identity because of the absence of entrepreneurial identity theory frameworks. I explored the antecedents based on the general insights of identity literature and the existing evidence.

Because the broad identity literature has provided evidence of the impact of contextual factors (e.g., Ethier \& Deaux, 1994; Brockner et al., 1986; Elsbach, 2003), I first looked at the entrepreneurial identity literature to asses relevant contextual factors (cf. entrepreneurial identity specific literature in the preceding section). Regarding entrepreneurship as a career choice for an individual, one such factor that needs investigation is the possible influence of family background (entrepreneurial or nonentrepreneurial family background) on entrepreneurial identity. Second, psychology researchers have found evidence on the connections of personality characteristics and identity as correlates (Ryder, Alden, \& Paulhus, 2000) as well as the associations of personality characteristics and various roles on which role identities are based (Sheldon, Ryan, Rawsthorne, \& Ilardi, 1997). Similarly, career researchers have also looked at the role of personality characteristics on career interests (cf. Hogan \& Blake, 1999). However, there is a gap in the literature in terms of establishing a causal relationship of 
personality characteristics with identities. Accordingly, identity researchers have made explicit calls for the investigations of the effect of individual personality on identities (Brown, 2001). Therefore, I examine the personality trait determinants of entrepreneurial identity. In addition, because of the relatively stable nature of personality traits (Roberts, \& DelVecchio, 2000) and the dynamic and developmental nature of an identity (established adequately earlier), it is logical to expect personality traits to be the antecedents-not the other way around. Given the constant debates in "personalityentrepreneurship" association (cf. Zhao et al., 2010), it is rational and important to theorize and test the impact of personality factors on entrepreneurial identity.

Finally, driven by a diverse set of motivations, individuals may have heterogeneous career attitudes that influence their entrepreneurial identity. I particularly expect individual differences in attitude towards career related rewards to have a bearing on their entrepreneurial identity. Given the emphasis on job meaningfulness by individuals in entrepreneurial firms (cf. Kemelgor \& Poudel, 2009) and given the significance of creativity in entrepreneurship (cf. Fillis, \& Rentschler, 2010), I reason that the attitudes towards job meaningfulness and creativity are likely predictors of entrepreneurial identity. Note that an individual's valence (the value attached) on job meaningfulness and creativity could be important career attitudes in any career context. I theorize and argue in what follows that these career attitudes are critically important in the entrepreneurship context. The conceptual model of the determinants of entrepreneurial identity is presented in Figure 3.

In spite of the preliminary conceptual work (Hoang \& Gimeno, 2010; Mitchell \& Shepherd, 2010) on individual level entrepreneurial identity, the current literature lacks a 
well-developed and established scale that captures the complex nature of entrepreneurial identity and of the two distinctly formed entrepreneurial identities theorized in Essay \# 1 . Researchers in the entrepreneurship domain have dispensed with empirically testing entrepreneurial identity even when they draw primarily on an entrepreneurial identity concept. For example, making the case for the social context of organizational governance, Miller \& Le Breton-Miller (2011) argue that the owner-manager type has a substantial bearing on firm performance mediated by an entrepreneurial identity. However, they do not actually test the theorized mediation. In any event, my development and validation of an entrepreneurial identity scale which separates intrinsically prospected entrepreneurial identity and socially constructed entrepreneurial identity will fill this void in the literature as well.

\section{Attitudinal Determinants}

\section{Entrepreneurial Identity}

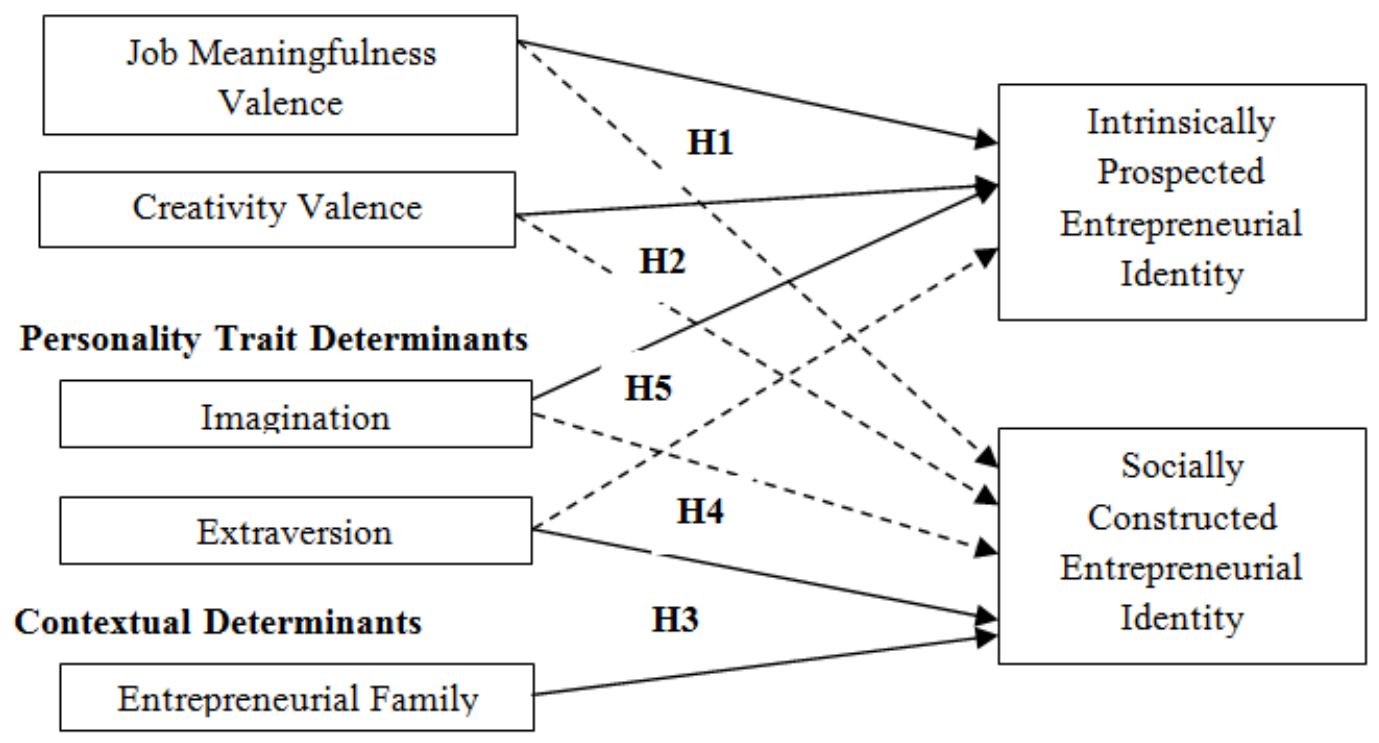

Figure 3. A Theoretical Framework of the Determinants of Entrepreneurial Identity. Note: a solid arrow represents a strong effect and a dashed arrow represents a weak effect. 


\section{Job meaningfulness and entrepreneurial identity}

Given the insights from the literature in preceding sections on the antecedents of identity, in general, I expect career related attitudes of individuals to influence their career identity as well as, in the present context, entrepreneurial identity. To what degree an individual is concerned about and values his or her job being meaningful might be related to his/her career identity. The notion of job meaningfulness, based on job design theory propounded by Hackman and colleagues, refers to an experience attributed to a variety of jobs skills, task identity, and task significance (cf. Kemelgor \& Poudel, 2009; Hackman \& Oldham, 1976). I provide two specific arguments to articulate why someone who attaches a higher value to job meaningfulness might have a better chance of developing entrepreneurial identity relative to those who do not.

Following other studies, in this dissertation I posit that entrepreneurship is a career. With a reasonably logical deduction, it could be argued that entrepreneurship is a series of related jobs certain individuals engage in which facilitate their identity development. Indeed, career researchers assert that job roles are the vehicles of career identity (Hoekstra, 2011). And, it is argued that the option/ability of choosing the “responsibilities, activities, and network contacts within one's job and proactively learning to work in different roles are newer ways to develop a career identity" (Ashforth, 2001; Crant, 2000; Hoekstra, 2011: p161). In essence, various job roles of a career contribute to the development of that career identity. It is logical to expect that if individuals find meaningfulness in various entrepreneurial job roles, they are more likely to identify with the corresponding career identity (i.e., entrepreneurial identity). Further note that entrepreneurship is a career that offers an individual with a multitude of job 
roles, as I argued earlier. Thus, for someone who identifies job meaningfulness with multiple job skills, task identities, and task significance, an entrepreneurial career may be an attractive, sound option. Therefore, taken together, we can gather that value attached to job meaningfulness (job meaningfulness valence) might positively lead to entrepreneurial identity.

For the wide varieties of competencies and skill sets needed, and an optimal balance of them required to be a successful entrepreneur, entrepreneurship researchers in economics have coined a theory called "the jack of all trades" (cf. Lazear, 2005; Parker, 2009; Silva, 2007). This "jack of all trades" notion requires entrepreneurs to balance all these job roles, and the corresponding identities stipulated earlier. To regulate one's attitudes, affects, and behaviors while juggling a multitude of job roles would require that an individual attach a high value on the meaningfulness of such job roles. Second, let's look at the first argument from a slightly different perspective. If a career requires learning and successfully performing a wide range of job roles and skill sets, and additionally, a balancing skill, it could be argued that unless one finds meaningfulness in such roles, the intentionality for such a career is less likely. Note that some identity researchers assert that: 'committing to the corresponding identity is the precondition of a meaningful behavior' (Burke \& Reitzes, 1991; Foote, 1951). When individuals put a high value in the meaningfulness of various entrepreneurial job roles, it will enhance the micro identities associated with those roles. For instance, take the inventor role. If one highly values the various tasks and the skills needed to be an inventor and attaches job meaningfulness to the inventor role, she/he is naturally likely to develop an inventor identity. The enhanced micro identities, in turn, will translate into a stronger 
entrepreneurial identity. To summarize, the individuals who enjoy and derive a sense of meaningfulness in a variety of entrepreneurial job roles and proactively learn to work in different roles are more likely to develop an entrepreneurial identity.

Arguably, such a tendency to seek meaningfulness from various job roles and to proactively engage in those job roles is more likely to be part of a self-constituted identity rather than a conferred identity. To acknowledge, it is possible that individuals will search for meaningfulness even when an identity is socially constructed and externally conferred upon them. However, when individuals self-constitute and nurture a certain identity, they inevitably seek and attach meaningfulness to job roles because the typical role activities associated with that identity are consistent with their own values, characteristics, belief systems, and individual uniqueness. Therefore, they might naturally attach more value in the job roles associated with the identities of which they are the initiators and nurturers. In other words, the influence of the job meaningfulness valence might be stronger in the case of IPEI relative to SCEI. With this discussion:

Hla: The job meaningfulness valence will be positively related with both intrinsically prospected entrepreneurial identity and socially constructed entrepreneurial identity.

HIb: The positive relationship between the job meaningfulness valence and intrinsically prospected entrepreneurial identity will be stronger than the positive relationship between the job meaningfulness valence and socially constructed entrepreneurial identity. 


\section{Creativity and entrepreneurial identity}

The idea that entrepreneurs are the "creative kinds" permeates the consciousness of common people and researchers alike. Entrepreneurship, in its essence, is creative problem solving in order to discover, or create, entrepreneurial opportunities and to exploit them (Cardon et al., 2009; Fillis, \& Rentschler, 2010; Kijkuit \& van den Ende, 2007; Kirzner, 1999; Kirzner 2009; Sarasvathy, 2001; Shane \& Venkataraman, 2000; Schumpeter, 1934). In fact, researchers have even created a construct, “entrepreneurial creativity," to highlight the notion of creativity in entrepreneurship (Amabile, 1996). In sum, creativity is a highly desirable, if not necessary, element in entrepreneurial pursuits and actions. Relatedly, both theory (cf. Cardon et al., 2009) and empirical evidence (Hirst et al., 2009) suggest that the identities of individuals influence creativity and creative problems solving, and thereby induce effective behavioral outcomes. Hirst et al. (2009) found that team identification leads to creative efforts which translate to creative performances by individuals.

Seeing the above insights and evidence in an alternative perspective, we can argue: if an identity leads to creativity and creative behaviors and if such creative behaviors are desirable in a career, the attitude towards creativity should be a contributing factor in the development of that identity. Particularly, to what extent one values the chances of being creative in a career must positively influence one's entrepreneurial identity. The career science literature tells us why. It tells us that career identity development, such as an entrepreneurial identity development, is fundamentally an exploratory process (cf. Jordan, 1963; Brooks, Cornelius, Greenfield, \& Joseph, 1995). Also recall from the literature review section that individuals are likely to engage in an 
intentional and informed assessment of their commitment to a certain identity (cf. Grote \& Raeder, 2009; Whitebourne 1986). Therefore, it is logical to conceive than an individual actor is likely to assess how much value he/she attaches to creativity during the exploratory phase of entrepreneurial identity development. And, the higher value he or she attaches to creativity, the more likely it is that he or she will commit to an entrepreneurial identity. That is because creativity is an important factor, if not a necessary condition, in entrepreneurial actions. Therefore, the value attached to creativity by individuals (creativity valence) will positively influence their entrepreneurial identity.

In the context of this dissertation, the other question is: Does the value attached to creativity by individuals relate to IPEI and SCEI differentially? The answer is affirmative for the following reason. Valuing creativity in one's work or career probably starts when individuals become conscious of their own creative potential and creative interests. The value judgment on creativity is likely to be an intrinsic, self-reflective, self-testing process. This process is not only similar to the intrinsic prospection of identity but it is also likely to directly influence the prospecting of various micro identities of entrepreneurial identity, such as personal identity and inventor identity. Note here that the sense of creativity, the attachment of value to creativity, and the prospecting of personal and inventor identity might form a common narrative for the entrepreneur. Hence, the value attached to creativity by individuals will impact IPEI more than SCEI. In light of this discussion:

H2a: The creativity valence will be positively related with both intrinsically prospected entrepreneurial identity and socially constructed entrepreneurial identity 
H2b: The positive relationship between the creativity valence and intrinsically prospected entrepreneurial identity will be stronger than the positive relationship between the creativity valence and socially constructed entrepreneurial identity.

\section{Family background and entrepreneurial identity}

Researchers have since long studied the impact of family related variables on entrepreneurship. Dyer Jr. and colleagues have argued that an entrepreneur's career path is influenced by various family-related factors at different stages of his/her entrepreneurial career, including the family of origin, the family's level of involvement in start-up activities, the employment of the family, and the ownership and management of the start-ups (Dyer Jr. \& Handler 1994). The take away from their research is that family background impacts an entrepreneur's career. Researchers have also looked at the influence of family background and family interactions on career identity and other workrelated identities (cf. Hargrove et al., 2002). For instance, an achievement orientation in

the family has been found to be an important predictor of vocational identity (Hargrove et al., 2002). Taken together, it is reasonable to speculate that an entrepreneurial family background is likely to play a key role in shaping the entrepreneurial identity of an individual.

That being said, conceivably, it is unlikely that family background will impact the intrinsic prospection of entrepreneurial identity. Family influence (owing to interactions, values, beliefs, cultures, and structures) is evidently an external tool of individual regulation. Business identity (also entrepreneurial identity) developed in the family business context is likely to be a socially constructed identity and conferred with the 
purpose of maintaining and enhancing the values, structures, relation networks, resource management, and the long-term success of the corresponding business, as suggested by the family business research (cf. Klein, 2008; Milton, 2008). This research shows that such an identity is a non-imitable, strategic resource of family businesses that is crucial for their long-term survival interests (Milton, 2008). Klein (2008) argued that in families with businesses, the business itself is a significant contributor for building the identities of the individuals in the family. And the confirmation of identity in a family business context is often sought quite early for the purpose of the business. Therefore, the business identity/entrepreneurial identity that shapes up as a function of the family influence is much more likely to be socially constructed. I illuminate the argument further with the following example. If an adolescent who belongs to a family of musicians is intrinsically prospecting an entrepreneurial identity, it is unlikely that the family would even notice such an identity- unless the adolescent seeks some materialistic verification or support from the family for entrepreneurial activities. On the other hand, an adolescent who belongs to an entrepreneurial family is likely to be conferred a socially constructed entrepreneurial identity, even if that identity is non-central to her/his identity composite. Unless it is in direct conflict with the identity s/he is internally prospecting, s/he is likely to conform to that conferred identity. That happens because the conferred identity serves as a tool of validation (as other family members have it too) for asserting her own existence relative to the external world. Indeed, it is even more so because this conferred identity would not need any verification and would not face any identity threat providing her/him a stable sense of self. With the foregoing discussion: 


\section{H3: Entrepreneurial family background will be positively related with socially}

constructed entrepreneurial identity.

\section{Personality characteristics and entrepreneurial identity}

Ever since the publication of "Enterprising Man" (Collins and Moore, 1964;

Grégoire et al., 2006), one influential stream of research in entrepreneurship has focused on the personality attributes (including traits, preferences, motivations and attitudes) of the entrepreneur including contemporary research (Shane et al., 2003). There is now a general consensus among entrepreneurship researchers that neither the structural, macro factors (also referred to as the environmental factors), nor the attributes of entrepreneurs alone can explain the pursuit of entrepreneurship and entrepreneurial success (Dobrev \& Barnett, 2005; Shane et al., 2003). Even structural, evolutionary theorists have acknowledged the inevitable role of human agency/motivation in entrepreneurial pursuits (Aldrich \& Ruef, 2006; Shane et al., 2003). That being said, the attempts to explain entrepreneurship with personality traits/characteristics have met with limited success and some criticism (cf. Gartner, 1988 for the criticism and a meta-analysis by Zhao \& Seibert, 2006 and Zhao, Seibert, \& Lumpkin, 2010 for the personality traits and entrepreneurship connections). As discussed earlier, there is a likely casual connection between personality characteristics and identities (Brown, 2001; Ryder et al., 2000; Sheldon et al., 1997). Relatedly, a rich body of literature documents the consequences of an identity on behaviors and intentionality (recall the literature review earlier). Therefore, it is reasonable to deduce that "identity" may be the missing link in connecting personality characteristics with entrepreneurial behaviors/activities/pursuits. 
Indeed, the research in psychology, particularly career psychology, points to the possibility of a "personality characteristic $\rightarrow$ identity $\rightarrow$ expected interests/activities/behaviors" linkage. Psychologists have argued that vocational interests are the manifestations/expressions of personality beginning with the seminal work of Holland (1973) (cf. Hogan \& Blake, 1999). There have been decades of empirical investigations trying to link personality characteristics with vocational interests but methodological limitations have been in question (cf. Hogan \& Blake, 1999). In fact, scholars (Brown, 2001) have made explicit calls for the investigation of personality and identity connections:

There is much work to be done examining the conditions under which people are more likely to identify and resist identification with groups and organizations, the role of factors relating to individual personality in determining identification with social categories...(Brown 2001: p 115)

In general, "identity" might be the missing link in connecting personality with career choices and interests. Accordingly, personality characteristics might have a bearing on entrepreneurial pursuits/activities through entrepreneurial identity. I reason that personality characteristics might have influence on career interests/choices through both intrinsic development of career identities and conferral of career identities (that is, through both IPI and SCI). The tandem question in the present research context then becomes: Which personality factors may impact on entrepreneurial identity, and why?

The Big-5 personality characteristics framework (Goldberg, 1990; Goldberg, 1992) which originated in personality psychology is arguably the most-well received and well-researched across disciplines. This personality framework consists of five general personality traits - extraversion, agreeableness, conscientiousness, neuroticism 
(emotional stability), and imagination (openness to experience). Hence, I consider this framework for the present research. I specifically theorize that two personality traits, extraversion and imagination, influence entrepreneurial identity.

Extraversion and entrepreneurial identity. The concept of extraversion generally refers to the enduring characteristics of individuals that are marked by assertiveness, energy, activeness, adventurisms, enthusiasm, gregariousness, friendliness, social skills, and outgoing nature ${ }^{10}$ (Goldberg, 1992; Zhao \& Seibert, 2006). The general argument I make is that extraversion positively influences entrepreneurial identity because these relatively enduring attributes ${ }^{11}$ are vital in performing entrepreneurial roles (such as leader role, inventor role) associated with respective micro identities (such as leader identity, inventor identity) of the entrepreneurial identity composite. Three specific arguments follow.

First, entrepreneurial role performance occurs largely in the context of the limited information available to entrepreneurs (irrespective of active or prospective entrepreneurs) to make rational, informed decisions (Busenitz \& Barney, 1997). Thus, managing uncertainty and risk associated with entrepreneurial opportunities (Knight, 1957; Shane \& Venkataraman, 2000; Schumpeter, 1934) is perhaps one of the most

\footnotetext{
${ }^{10}$ Note that there are differences in the markers of these personality categories across different versions of scales/conceptualizations used. The characteristics referred in the present context best reflect the conceptualization and operationalization done in this dissertation.

${ }^{11}$ The personality research does not anymore consider personality traits as static, however, compared to other constructs that define/describe an individual such as identities, cognitive states, affective states and the like, they can be viewed as enduring attributes.
} 
important factors in an entrepreneurial career. For these reasons, entrepreneurship researchers argue, individuals resort to various non-rational decision making processes and heuristics which likely serve the purpose of identifying and exploiting entrepreneurial opportunities before the window of opportunity slips away (Busenitz \& Barney, 1997). The characteristics that help these individuals to make bold, timely decisions in the face of risk and uncertainty are critical. Plausibly, enthusiasm, energy, optimism, and adventurism-the attributes typically associated with enterprising individuals (Zhao et al., 2010)-all likely prompt them to make those decisions. I articulated in the preceding sections that an identity furnishes individuals with selfesteem as well as provides the meanings for certain intentionality and the resultant behaviors. Hence, for personality characteristics such as enthusiasm, energy, optimism, and adventurism to act upon entrepreneurial intentionality, decision making and actions, the individual first needs to develop that sense of identity-in this case, an entrepreneurial identity. More particularly, performing the roles associated with inventor identity, leader identity, and founder identity would necessitate the presence of enthusiasm, optimism, and energy. Thus, I expect extraversion to positively impact entrepreneurial identity. Second, the pursuit of entrepreneurial activities requires managing a wide and diverse array of internal and external stakeholders such as the employees, investors, strategic partners, business angels, and venture capitalists while performing those various entrepreneurial roles (Zhao \& Seibert, 2006). When we couple the entrepreneurial decision making context of limited information, risk, and uncertainty with the extensive social interactions a prospective or active entrepreneur has to manage, it would be very difficult to do so (if not impossible) without a solid commitment to entrepreneurial 
identity (also refer to the commitment to an identity concept argued for earlier). To recall, an identity is what provides individuals with a sense of coherence and stability while navigating through socio-psychological complexities. The attributes of energy, assertiveness, enthusiasm and optimism are likely to facilitate this coherence and stability, solidifying the commitment to entrepreneurial identity. That, in turn, will assist the entrepreneur in dealing with the extensive networks of stakeholders. Recall the earlier example of an entrepreneur in need of financing her venture, in the preceding essay. Enacting different micro identities of entrepreneurial identity composite allows her to successfully negotiate with different types of social actors from family members to employees. The above stated markers of extraversion are likely to be crucial in shaping these micro identities as well. Therefore, I propose that extraversion contributes to the development of entrepreneurial identity.

In addition to the logical deductions above, a basic insight about the possible influence of extraversion on entrepreneurial identity comes from Holland's classic work (personality types and vocational interest) itself (cf. Holland 1973, p 7; Hogan \& Blake, 1999). Blake and Sackett (1999) analyzed the relationship between the Big-5 personality characteristics and Holland's typology of vocational interest. They found that the trait of extraversion was positively related to "the enterprising type." Thus, it can be safely inferred that extraversion will relate to the identity of individuals who are the enterprising type. In addition, Zhao et al.'s (2010) meta-analysis found evidence that extraversion was related to entrepreneurial intentions and entrepreneurial performance - the likely consequences of entrepreneurial identity (articulated in the next essay). Therefore, extraversion is likely to be positively associated with entrepreneurial identity. 
I expect that the positive influence of extraversion on intrinsically prospected entrepreneurial identity and socially constructed entrepreneurial identity, however, will be different. Discern that the personality attributes/markers of extraversion also include friendliness, gregariousness, and social skills. It is not difficult to reason that these attributes of extraversion are focused on/oriented to social interactions and social affiliations. For that reason, I expect, extraversion will have a stronger influence on socially constructed entrepreneurial identity. All the preceding arguments lead to:

H4a: Extraversion will be positively related with both intrinsically prospected entrepreneurial identity and socially constructed entrepreneurial identity.

H4b: The positive relationship between extraversion and intrinsically prospected entrepreneurial identity will be weaker than the positive relationship between extraversion and socially constructed entrepreneurial identity.

Imagination (openness to experience) and entrepreneurial identity. The notion of imagination/openness to experience generally refers to the relatively enduring characteristics of individuals marked by intellectual curiosity, the search for novelty in experiences, creativity, innovativeness, imagination, and reflection (Goldberg, 1992; Zhao \& Seibert, 2006). Reasonably, this bundle of attributes may have a positive impact on the various entrepreneurial roles and on the development of an identity which underlies and provides a connecting thread of meaning to these roles.

First, the classical theorists of entrepreneurship (Kirzner, 1999; Schumpeter, 1934) and contemporary theorists (Grégoire \& Shepherd, 2012; Sarasvathy, 2001; Shane \& Venkataraman, 2000) all concur on the idea that entrepreneurship is about the innovative and creative ways entrepreneurs combine and recombine resources to create 
value. The exploration of new means of creating value in the form of new products and services, in the business processes, in the strategic sourcing of resources, in exploiting entirely new markets, and the like, form the core of entrepreneurship (Grégoire \& Shepherd, 2012; Shane \& Venkataraman, 2000). The theory of effectuation adds to this understanding which states that entrepreneurs also explore varieties of ends, starting with the limited means they have (cf. Sarasvathy, 2001). Thus, entrepreneurs can either employ novel ways to recombine and utilize their means to exploit an entrepreneurial opportunity (as the causal logic holds). Or, alternatively, they can engage in novel experiments to figure an opportunity from the unknown range of entrepreneurial opportunities (as the effectual logic holds). In either case, the theorists assert that entrepreneurs must be creative and innovative. Even at the collective level/firm level understanding of entrepreneurship, firms ought to be innovative, proactive and risk taking (entrepreneurially-oriented) for better value creation (Poudel et al., 2012; Stam and Elfring, 2008).

From the discussion above, it is reasonable to conclude that the individual attributes associated with imagination and the cognitive and behavioral attributes that are considered to be critically essential for entrepreneurship are almost perfectly aligned. In fact, comparing entrepreneurs relative to managers, the meta-analysis of Zhao \& Seibert (2006) found that "imagination" characterizes entrepreneurs. Another meta-analysis found that imagination was associated with entrepreneurial intentions and entrepreneurial performance (Zhao et al., 2010). Despite the correlations and despite the seemingly perfect overlap between the markers of imagination and the critically important 
entrepreneurial behaviors and competencies, there is, however, a missing link. How do enduring personality attributes translate into intentionality and behaviors?

Entrepreneurial identity, I argue, is the missing link that serves two important functions in the translation process. First, as the identity research claims (cf. earlier discussion on this), entrepreneurial intentionality and behaviors must be infused with meanings and purposes. Second, to manage the attributes of intellectual curiosity, novelty in experiences, creativity, innovativeness, imagination, and reflection in a seamless and synergistic way, the individual needs an entity that provides dynamism (is capable of adaptation and change as needed) as well a sense of coherence. Observe that the generally congruent concept of identity among researchers refers to providing meaning into cognition and behaviors, instilling a sense of coherence and stability in the individual, and enhancing the individual's self-esteem and dignity as the individual tries to make sense of the external world (Alvesson \& Kärreman, 2007; Burke \& Reitzes, 1991; Carter et al., 2003; Kreiner et al., 2006; Wilson et al., 2007). Thus, entrepreneurial identity is that missing link which connects these various individual attributes regarded as markers of "imagination" with typical entrepreneurial behaviors. Therefore, imagination positively contributes to entrepreneurial identity development.

Since imagination is the "individual attribute" which could be largely independent of social influences, and since most of the markers of this personality characteristic imply inward orientation (such as intellectual curiosity and reflection), it is more likely to be associated with IPEI than with SCEI. As I extensively argued in the preceding theory building, IPEI is the function of various internal regulators and processes (not repeated here for brevity reasons). Hence, I derive: 
H5a: Imagination will be positively related with both intrinsically prospected entrepreneurial identity and socially constructed entrepreneurial identity.

H5b: The positive relationship between imagination and intrinsically prospected entrepreneurial identity will be stronger than the positive relationship between imagination and socially constructed entrepreneurial identity.

\section{Method}

Research design, pilot study, and survey instrument development. The population of my study for Essays \# 2 \& 3 comprises currently employed individuals. I employed a purposive sampling method (the rationale is explained below). Since I introduced new constructs in this dissertation, socially constructed entrepreneurial identity and intrinsically prospected entrepreneurial identity, I needed to get a clear idea of whether the operationalization or measures were psychometrically valid and reliable beyond the face validity, and before proceeding to collect the primary, field data. To begin with, I collected a sample of pilot data, surveying current students and alumni at a major research university in the USA for the survey instrument verification as well as for establishing preliminary validation of constructs and their reliabilities. I developed a survey questionnaire (for the independent variables, dependent variables and control variables of Essay \# 2 and 3 of the dissertation) by borrowing established scales from literature, and modifying when desirable. For example, for personality traits, I utilized widely used and validated Big-5 personality traits scales of Goldberg (1992) without any modification. However, I developed an entrepreneurial identity scale taking guidance from an identity expert and drawing on existing scales (details to follow). I applied steps 
suggested by methodologists (e.g., Worthington \& Whittaker, 2006; Hinkin, 1995) for the scale development and validation purpose. For instance, I developed and adopted the scales by thoroughly studying construct definitions and examining the face validity of the constructs. I made appropriate changes in the instrument for the study sample data collection. I also received the University of Louisville's IRB (Institutional Review Board) approval for the survey instrument.

Study sample, sampling rationale and descriptive statistics. Inter-disciplinary literature suggests that existing firms are one of the breeding grounds for entrepreneurs, and thus, naturally, employees make up a very significant source pool of entrepreneurs (cf. Agarwal, Echambadi, Franco, \& Sarkar, 2004; Klepper \& Sleeper, 2005; Hyytinen \& Maliranta, 2008). For example, a study by Hyytinen (2008) examined the organizational factors, among others, that contributed to the switching of individuals from paidemployment to an entrepreneurial career. This study reported that smaller firms generated entrepreneurs more frequently than bigger firms did. I discussed in the theory section the significance of exploring entrepreneurial identity among potential entrepreneurs. Therefore, I employed a purposive sampling method. I determined that employees of a small firm (less than 500 employees) would be an appropriate sample to test the empirical models of the dissertation. Although there are limitations on the generalization of findings (external validity) obtained through the analysis of a non-random sample, nonrandom sampling is widely accepted in social science research (cf. Onwuegbuzie \& Collins, 2007). Some social science researchers even claim that the majority of quantitative research employs non-random sampling (cf. Leech \& Onwuegbuzie, 2002). Additionally, note that the present research is exploratory in nature and the major 
intended contribution is to generate theory insights on entrepreneurial identity grounded in empirical exploration. Therefore, I chose a firm in the service industry, in the mideastern United States, which met the small firm criterion as well as which could provide adequate data points for the empirical tests. A total of 205 employees of the firm at different ranks and tenure were invited to fill out an online survey. I received 143 usable responses with a nearly $70 \%$ response rate. The respondents were $60 \%$ female and $40 \%$ male; the overwhelming majority of the respondents were white; the age of the respondents ranged from 23 years to 65 years (with a mean of 39 years and a standard deviation 10.82 years); and the organizational tenure ranged from 1 year to 39 years (with a mean of 6.8 years and a standard deviation of 6.3 years). Except for race, the basic demographics of the sample are thus heterogeneous. The descriptive statistics which includes the zero-order correlations of the variables in this study is presented in Table 2.

Table 2

Descriptive Statistics. Zero-Order Correlations, AVE, SCR and Cronbach's Alpha ${ }^{\text {a }}$

\begin{tabular}{|c|c|c|c|c|c|c|c|c|c|c|c|c|}
\hline Variables & Mean & S.D. & 1 & 2 & 3 & 4 & 5 & 6 & 7 & 8 & 9 & 10 \\
\hline 1. Sex & & & & -.09 & -.05 & .07 & .00 & .07 & .04 & .13 & .17 & .24 \\
\hline 2. Family background & & & & & .13 & .07 & -.04 & -.06 & -.02 & .14 & .03 & .06 \\
\hline 3. Age & 39.00 & 10.82 & & & & .39 & .09 & .21 & -.09 & -.04 & .16 & .15 \\
\hline 4. Tenure & 6.80 & 6.30 & AVE & SCR & Alpha & & -.02 & .19 & .06 & .08 & .29 & 26 \\
\hline $\begin{array}{l}\text { 5. Job meaningfulness } \\
\text { valence }\end{array}$ & 5.74 & 0.72 & .71 & .88 & .88 & & & .49 & .12 & .05 & .15 & .23 \\
\hline 6. Creativity valence & 5.31 & 0.94 & .81 & .94 & .95 & & & & .20 & .26 & .22 & .17 \\
\hline 7. Extraversion & 3.14 & 0.78 & .75 & .90 & .91 & & & & & .32 & .27 & .24 \\
\hline 8. Imagination & 3.53 & 0.52 & .60 & .81 & .81 & & & & & & .26 & .30 \\
\hline 9. SCEI & 2.43 & 1.31 & .82 & .95 & .96 & & & & & & & .75 \\
\hline 10. IPEI & 2.97 & 1.67 & .88 & .96 & .97 & & & & & & & \\
\hline
\end{tabular}

s Correlations equal to or greater than 0.17 are significant at $p<0.05$ or more robust level, shown in bold face. The significance test is two-tailed. They are presented in upper diagonal.

- $n=143$, for all correlations. AVE = average variance extracted and SCR = scale composite reliability. 


\section{Measurement of dependent variables, independent variables, and control}

variables. I borrowed, and modified when appropriate, all the scales for the constructs used in this dissertation research - except for the entrepreneurial identity scale, which is the dependent variable in the empirical model of this essay. I developed an entrepreneurial identity scale with two dimensions - intrinsically prospected entrepreneurial identity (IPEI) and socially constructed entrepreneurial identity (SCE) and validated its psychometric properties. The items on this scale were developed taking idea from Farmer et al.'s (2011) scale of "entrepreneur identity aspiration" and Hekman, Bigley, Steensma, \& Hereford's (2009) scale of "professional identification." Note that the identity scale for my study needed to capture the entrepreneurial career aspect as well as what Farmer et al. (2011) call "current self" and "future self." I distinguish between the "who am I" component of identity (which is socially constructed and past and present oriented) and the "who do I want to be" component of identity (which is intrinsically prospected and future oriented) (cf. Essay \# 1). Farmer et al. (2011) acknowledged that investigating both the "future self" and "current self" of entrepreneurial identity would provide a more nuanced understanding of entrepreneurial identity. Initially, I developed a larger scale comprised of 8 items for each intrinsically prospected entrepreneurial identity and socially constructed entrepreneurial identity, to subject it to an exploratory factor analysis. After conducting the exploratory factor analysis (Principal Component Analysis with Varimax rotation), I retained the IPEI scale with 5 items and the SCEI scale with 5 items as well. I removed the rest of the 6 items which showed significantly high crossloadings. Then, this instrument, with prospected and constructed entrepreneurial identities, was subjected to confirmatory factor analysis (CFA) for further confirmation. 
The modification indexes as well as the model fit indexes suggested that I needed to discard one item from the IPEI scale, thus, as recommended (cf. MacKenzie, Podsakoff, \& Podsakoff, 2011), I discarded that item. I retained the final scales with 4 intrinsically prospected entrepreneurial identity items and 5 socially constructed entrepreneurial identity items, as the CFA model showed an excellent fit $(\mathrm{NC}[X 2 /$ d.f. $]=1.68, p<.05$; $\mathrm{CFI}=.99, \mathrm{NNFI}=.99, \mathrm{RMSEA}=.07, \mathrm{SRMR}=.02)($ Hair et al., $2005 ;$ Kline, 2005).

I measured intrinsically prospected entrepreneurial identity by asking respondents to what degree they agreed or disagreed with the four scale items on a 1-7 Likert scale (1 $=$ strongly disagree and $7=$ strongly agree). For a sample, an indicator of this scale reads: "The term 'entrepreneur' reinforces your sense of who you want to be." All the indicators of the scale assess "who they want to be" to capture the intrinsic prospection of entrepreneurial identity. I measured socially constructed entrepreneurial identity using the same scale anchor with five indicators. For a sample, an indicator of this scale reads:

"Others' perception of you as an entrepreneur enhances your sense of who you are." All the indicators of the scale assess "who they are" in order to capture the social construction of entrepreneurial identity. The complete items of IPEI and SCEI scales are presented in the Appendix.

There are five latent independent variables in this study/model - imagination, extraversion, entrepreneurial family background, job meaningfulness valence, and creativity valence. Entrepreneurial family background is dummy-coded $(1=$ presence of entrepreneurial family background and $0=$ absence of entrepreneurial family background). For the two personality characteristics variables, imagination and extraversion, I used well-validated Goldberg (1992) scales. Both of these scales have 10 
indicators and are assessed on a 1-7 Likert scale ( $1=$ strongly disagree and $7=$ strongly agree). The anchor for these two scales reads: "For the following set of questions, describe yourself as you generally are now, not as you wish to be in the future using the following 1-7 scale." For a sample, an indicator of extraversion scale reads: "I am the life of the party." Similarly, a sample indicator of imagination scale reads: "I spend time reflecting on things." To measure how much value the respondents attached to job meaningfulness, I borrowed the scale developed by Kemelgor \& Poudel (2009) based on Hackman \& Oldham (1976). The anchor for this scale reads: "Please rate how much value you attach to the following factors using the $1-7$ scale." $(1=$ no value at all, and $7=$ very high value). For a sample, an indicator of job meaningfulness valence scale reads: "Ability to do skillful and interesting jobs rather than simple and repetitive jobs." To measure how much value the respondents attached to creativity in a work and career context (i.e., creativity valence), I borrowed the scale developed by Kemelgor \& Poudel (2009). This scale has the same anchor as the job meaningfulness valence scale does. A sample indicator for this scale is: "Ability to generate new ideas on how to optimize knowledge and skills." The complete items of these independent variable scales are presented in the Appendix.

I used only theoretically relevant control variables in the structural regression models and applied parsimony, rather than a blanket application of controls (cf. Becker, 2005). From the literature review, it was clear that demographic factors are related to identity, thus, I controlled for the age and gender of the respondents. In addition, since the respondents are the potential entrepreneurs currently in the paid-employment, it was 
necessary to control for their tenure in the current organization. Also, recall the discussion in the literature review section on the necessity to control this variable.

\section{Data analysis (analytical tool and approach, construct reliability, construct} validity, and common method variance). I use Structural Equation Modeling (SEM) for testing hypotheses as well as for documenting important psychometric properties. SEM has been considered to be one of the most significant methodological advances (Shook, Ketchen, Hult, \& Kacmar, 2004). One of the central features and major advantage of the SEM is its ability to model the observed/measured and latent variables simultaneously. The concurrent testing of various relationships of variables controlling for other effects of these variables is the distinct advantage of SEM over traditional methods like regression (Kline, 2005). Since both of the theorized models in the dissertation consist of a host of latent variables and since many hypotheses compare the effect sizes, SEM is an appropriate analytical tool. As recommended by method experts (e.g. Kline, 2005; Anderson \& Gerbing, 1988), I conduct structural equation modeling in two stages - by running measurement models and structural models separately. I used LISREL 8.8 with maximum likelihood estimator for the measurement models as well as structural regression models (of both Essay \# 2 \& 3). The latent variable scales used in this essay as well as the following essay are reflective scales. Because of a relatively small sample size ( $\mathrm{n}=143$ ), I utilized parceling technique, widely used in such analysis (cf. Kirkman et al., 2009; Little et al., 2002). Observe that the empirical models tested in this dissertation are fairly complex and a lot of parameters are estimated. Thus, to get a more accurate analysis, parceling of indicators for some of the scales was desirable. Since IPEI and SCEI concepts were introduced in this dissertation, I did not parcel them. In the case of 
other latent variables, I created 2 or more parcels if a scale contained 5 or more indicators. Following the guidance of Little et al. (2002), I created parcels based on both empirical and theoretical grounds. In this study, I am regarding all the independent variables (job meaningfulness valence, creativity valence, extraversion and imagination) as uni-dimensional theory-wise; therefore, I created parcels using a random approach rather than a domain-representative approach. As recommended, I set the error variances of the single-indicator factors (note that entrepreneurial family background and control variables are single-indicator variables) to zero (cf. Jöreskog \& Sörbom, 1996). I assessed the fit of measurement models and structural models using multiple indexes, both in the case of the models of this essay as well as the models of the next essay. I followed convention and took into account the fit indexes which are relatively more robust/less sensitive than others to sample size issues. Therefore, I report the ratio of chi-square to degrees of freedom, called the normed chi-square (NC), comparative fit index (CFI), nonnormed fit index (NNFI), root mean square error of approximation (RMSEA), and standardized root mean square residual (SRMR) (Jöreskog, \& Sörbom, 1996; Kline, 2005). The measurement model of Essay \# 2, which comprised of all the variables in the model, demonstrated an excellent overall fit $(\mathrm{NC}[X 2 /$ d.f. $]=1.33, p<.01 ; \mathrm{CFI}=.97$, NNFI $=.97$, RMSEA $=.05$, SRMR = .05) (Hair et al., 2005; Kline, 2005). The indicators or indicator parcels loaded well in their specified latent constructs. For this model, the standardized factor loadings ranged from .73 to .98 except for one item which loaded .56 (for imagination).

I assessed construct reliability using traditional Cronbach's alpha as well as scale composite reliability (SCR), as suggested by method experts (MacKenzie et al., 2011) 
because an alpha measure may have constraints (Raykov, 1997). The Cronbach's alpha for the constructs were all greater than .70, the suggested minimum threshold (Nunnally, 1978): .96 for socially constructed entrepreneurial identity, .97 for intrinsically prospected entrepreneurial identity, .91 for extraversion, .81 for imagination, .95 for creativity valence, and .88 for job meaningfulness valence). I calculated the SCR using the Fornell and Larcker's formula (1981: p 45). The scale composite reliability for all the constructs was very strong, reflecting the alpha measures, well above the acceptable minimum threshold of .70 (Lukas, Tan, \& Hult, 2001): .95 for SCEI, .96 for IPEI, .90 for extraversion, .81 for imagination, .94 for creativity valence, and .88 for job meaningfulness valence. The SCRs for all the constructs are also presented in Table 2.

I assessed construct validity by evaluating both convergent validity and discriminant validity among the constructs. Regarding convergent validity, first I examined the " $t$ " values of the factor loadings in the measurement models. For the measurement model of this essay, it ranged from 6.54 (for an item of imagination) to 27.23 (for an item of prospected entrepreneurial identity) suggesting a convergent validity (Netemeyer et al., 1990). Second, as suggested by method experts (cf. MacKenzie et al., 2011; Netemeyer et al., 1990), I calculated the average variance extracted (AVE) by each construct (which means, the amount of average variance captured by the construct relative to the variance due to measurement error) using Fornell and Larcker's formula (1981: p 46). The AVEs for all the constructs were quite good, ranging from .60 to .88 , more than the minimum threshold of .50 (cf. Fornell and Larcker, 1981; Netemeyer et al., 1990). The AVEs for all the constructs are presented in Table 2. Finally, to assess the overall construct validity, convergent and divergent 
validity simultaneously, I constrained the measurement model by treating all plausible pairs of latent constructs as single factor, turn by turn. These constrained models, M1 (IPEI and SCEI treated as single construct), M2 ( extraversion and imagination treated as a single construct), and M3 (creativity valence and job meaningfulness valence treated as a single construct) are poor fitting relative to the theorized measurement model (see

Table 3), which suggests an overall construct validity (cf. Netemeyer et al., 1990: 152). As recommended (cf. MacKenzie et al., 2011), I additionally assessed the discriminant validity on an even more stringent criterion. The AVEs for the constructs are greater than the squared correlation between any pair of latent constructs (see Table 2) suggesting discriminant validity (Fornell and Larcker, 1981; MacKenzie et al., 2011).

Table 3

Fit Statistics for Theorized Measurement Models. Constrained Measurement Models for Testing Psychometric Properties and Robustness Check. and Theorized Structural Model ${ }^{c}$

\begin{tabular}{|c|c|c|c|c|c|}
\hline & \multicolumn{5}{|c|}{ Fit statistics } \\
\hline & $\mathrm{NC}\left(X^{2} / d . f\right)^{d}$ & NNFI & $\mathrm{CFI}$ & RMSEA & SRMR \\
\hline Theorized measurement model & $1.33(343.73 / 258)$ & .97 & .97 & .05 & .05 \\
\hline M1: IPEI and SCEI treated as one factor & $3.67(978.90 / 267)$ & .89 & .91 & .14 & .06 \\
\hline $\begin{array}{l}\text { M2: Extraversion and imagination treated as one } \\
\text { factor }\end{array}$ & $1.92(514.92 / 267)$ & .93 & .94 & .08 & .08 \\
\hline $\begin{array}{l}\text { M3: Creativity valence and job meaningfulness } \\
\text { valence treated as one factor }\end{array}$ & $1.87(500.34 / 267)$ & .93 & .94 & .08 & .07 \\
\hline Theorized structural model & $1.62(422.49 / 260)$ & .94 & .95 & .07 & .13 \\
\hline
\end{tabular}


For common method variance (CMV) issue, I used both a priori and post hoc methods. The questionnaire is designed to minimize CMV a priori. For example, I used a diverse set of anchors when possible to minimize item characteristic effects, such as common scale anchor producing common variance. I also conducted a post hoc common method variance test, the Harman's single factor test. For the model of this essay, only $29.2 \%$ variance was explained by a single factor, less than the 50\% threshold (Podsakoff et al., 2003). This suggests that common method variance is not an issue.

Results of hypothesis tests. The results of SEM on Essay \# 2 model are presented in Figure 4. The SEM model exhibited a good overall fit as $(\mathrm{NC}[X 2 /$ d.f. $]=1.62, p<.01$; $\mathrm{CFI}=.95, \mathrm{NNFI}=.94, \mathrm{RMSEA}=.07, \mathrm{SRMR}=.13)($ Hair et al., 2005; Kline, 2005), except for SRMR measure, which is greater than .10. Since model fit indexes should always be interpreted in concert, rather than stand-alone (Kline, 2005), this is an acceptable model fit. Hypothesis "H1a" stated that the value attached by an individual to job meaningfulness would positively influence both IPEI and SCEI. This hypothesis is partially supported as the impact of job meaningfulness valence was significant for IPEI (.24). It was not significant for SCEI, although it was positive as I predicted (.14). "H1b" hypothesis stated that the effect of job meaningfulness would be greater on IPEI relative to its effect on SCEI. Therefore, this can be considered as a partially supported hypothesis. Since the value attached to creativity did not have any influence on IPEI and SCEI, both "H2a" and "H2b" hypotheses were rejected. Hypothesis "H3" predicted that entrepreneurial family background would positively influence socially constructed entrepreneurial identity. This effect was also not significant. I predicted that extraversion would positively impact IPEI (.18) and SCEI (.26), "H4a", but the impact would be 132 
higher for SCEI, "H4b". Both of these hypotheses were supported. "H5a" hypothesis, which predicted that imagination would positively influence both IPEI and SCEI, was supported. As anticipated, the positive influence of imagination on IPEI was greater than its positive impact on SCEI as $.24>.19$. Therefore, hypothesis "H5b" was also supported.

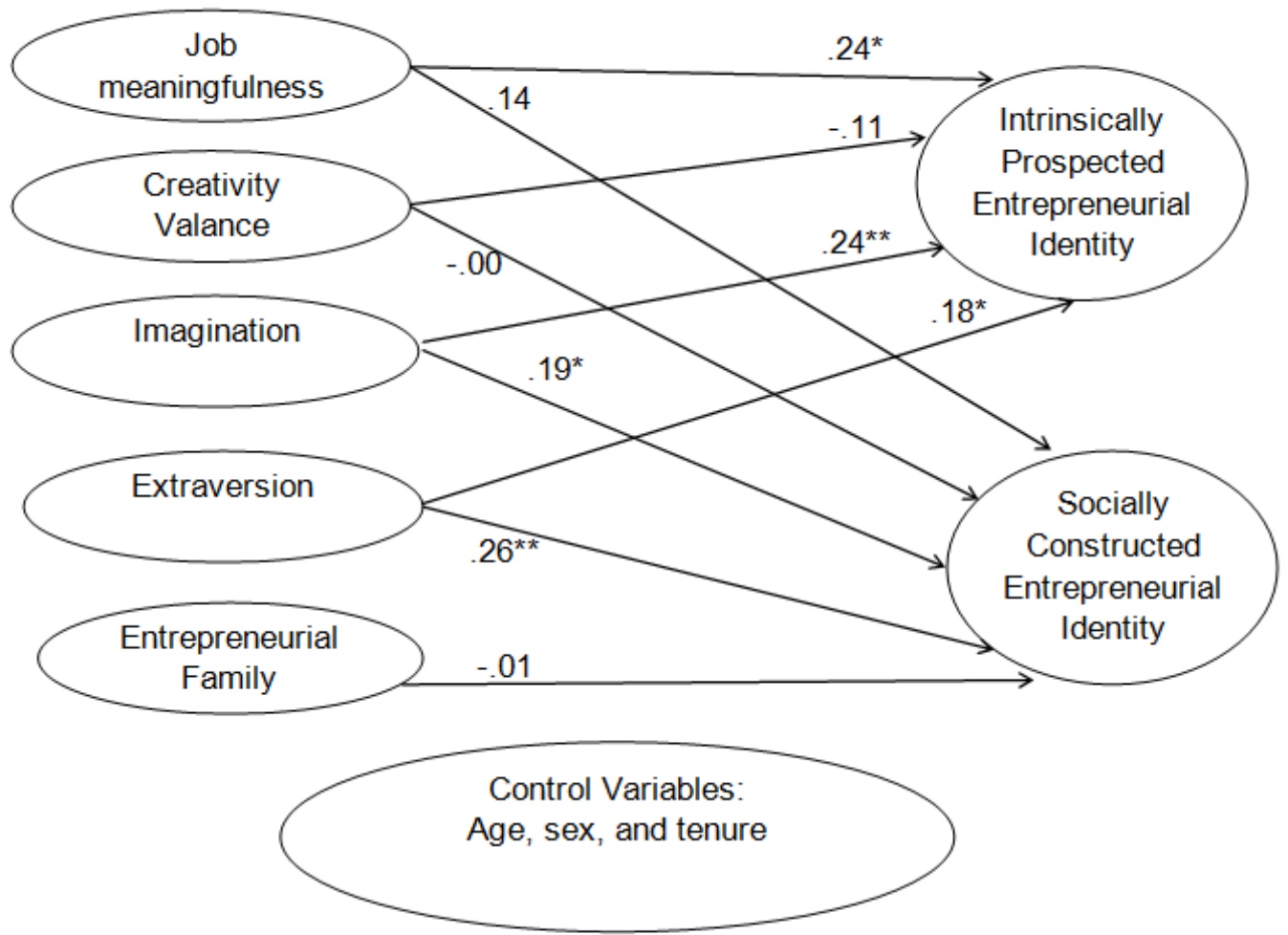

Figure 4. SEM Results for the Determinants of Entrepreneurial Identity a $b c$

a The regression coefficients reported are standardized. Control effects and factor loadings are not shown for aesthetic reasons.

$b$ The Fit index for the SEM: $(\mathrm{NC}[X 2 /$ d.f. $]=1.62, p<.01 ; \mathrm{CFI}=.95, \mathrm{NNFI}=.94$, RMSEA $=.07$, $\operatorname{SRMR}=.13$ )

c All factor loadings reported are significant at $p<.001$ level

${ }^{*} \mathrm{p}<0.05$

${ }^{* *} \mathrm{p}<0.01$ 
Tests of robustness. First, the robustness of the measurement model was tested by comparing the fit indexes of the measurement model with some plausible alternative (constrained) models. As demonstrated in Table 3, the fit indexes of the measurement model are better than those of all three constrained models, M1-M3 (cf. the discussion earlier on how they were constrained). Second, for the structural model, as IPEI and SCEI are likely to impact each other (an issue not investigated in this dissertation), I examined if allowing these endogenous variables, IPEI and SCEI, to correlate would result in any change in the results of my hypothesis tests. Whereas the model fit improved in so doing, as expected, and there were slight changes in the effect size of some of the parameters, the model did not show any different relationships than the theorized relationships. In other words, the results were similar to those of the theorized structural model. Additionally, I also checked if allowing entrepreneurial family background to relate to IPEI shows any different results. Allowing this relationship, in the theorized model, also did not change the results. In other words, neither the model fit nor the parameter estimates changed. Thus, I believe these results are relatively robust.

\section{Conclusion}

The hypotheses about the impact of career attitudes, creativity valence and job meaningfulness valence, on entrepreneurial identity received mixed support. Job meaningfulness valence was positively associated with both IPEI and SCEI but was significant only for IPEI. This highlights the significance of job meaningfulness valence when entrepreneurial identity is intrinsically prospected. However, the impact of creativity valence on entrepreneurial identity was not significant. This lack of support for 
the attitude towards creativity and entrepreneurial identity relationship might be the result of the constraints in my study sample. Note that I tested these hypotheses among the employees in an accounting firm. Since an accounting firm would generally be what I referred to as an SEP type enterprise, the respondents might have been the self-selected individuals with a lower/similar valence to creativity. A study that overcomes the limitations of the present study, sampling the potential entrepreneurs with likely equal representation from three types of entrepreneur pools (for example, sampling the employees of one innovative high-tech type firm, one imitator type firm, and one SEP type firm) can shed more conclusive light on the effect.

The hypotheses about the influence of personality characteristics on entrepreneurial identity tested the following, in summary: (a) extraversion and imagination are positively related to entrepreneurial identity and, (b) these personality characteristics have differential impacts on IPEI and SCEI. These hypotheses were supported. With the results of my study, I observe that the problem with the "personalityentrepreneurship" connection is perhaps a brave claim to predict or define entrepreneurship solely/exclusively on the basis of the direct effects of personality characteristics (personality theory). However, consistent with other researchers (Zhao \& Seibert, 2006; Zhao et al., 2010), I reason that it will be equally erroneous to claim that personality characteristics do not explain various criterion variables of entrepreneurship. Thus, personality characteristics, and their impact on entrepreneurship through the entrepreneurial identity, as documented in this research, must be regarded as one piece of the big entrepreneurship puzzle. 
Finally, the theorized effect of family background on socially constructed entrepreneurial identity was not significant. One possible explanation is the following. Rather than the simple presence or absence of family background (dummy coded in the operationalization), some other constructs which capture the more meaningful aspects of an entrepreneurial family background might be the actual predictor of entrepreneurial identity. For instance, I cited earlier a study which found an achievement orientation in the family to be a significant predictor of vocational identity (Hargrove et al., 2002: p 194). The other possibility is that the presence or absence of entrepreneurial family background is, rather, a moderating variable. In any event, this result calls for further investigation on the likely effect of entrepreneurial family background on entrepreneurial identity.

\section{Entrepreneurial Identity: The Missing Link in Nascent Entrepreneurship” (Essay 3)}

\section{Introduction}

To reiterate, 'why particular individuals, and not others, engage in entrepreneurial pursuits' is one of the central questions in the entrepreneurship discipline in general and the nascent entrepreneurship research domain in particular (Davidsson, 2006; Shane \& Venkataraman, 2000; Wilson et al., 2007). Regarding entrepreneurship as a career choice, this question can be reframed as such: Why do certain individuals, and not others, choose an entrepreneurial career? Entrepreneurship researchers have been examining this phenomenon looking at many individual level factors, such as underlying needs and motivations, personality characteristics, and cognitive factors, among others (Davidsson, 2006; Dobrev \& Barnett, 2005; Douglas \& Shepherd, 2002; Grégoire \& Shepherd, 2012; 
Shane et al., 2003; Wilson et al., 2007). Accordingly, research in the last two decades or so has provided us with a fairly good understanding of the entrepreneurship phenomenon. Inter alia, for instance, on the one hand we know that: the motivations for entrepreneurial pursuits are wide and diverse (Davidsson, 2006); the individual attributes do explain variations in entrepreneurship (Shane et al., 2003; Zhao \& Seibert, 2006; Zhao et al., 2010); identifying and exploiting entrepreneurial opportunities involves both causal and effectual approaches (Sarasvathy, 2001); entrepreneurs use different processes for information acquisition (Patel \& Fiet, 2009); and entrepreneurs engage in cognitive biases and use heuristics in decision making (Busenitz \& Barney, 1997). On the other hand, we do not yet fully know the embedded mechanisms and many of the causal factors which impact and/or facilitate an individual's transition to entrepreneurship (Markman, Balkin, \& Baron, 2002; Zhao, Seibert, \& Hills, 2005). One of these mechanisms, entrepreneurial identity, has just begun to receive attention from entrepreneurship researchers (Cardon et al., 2009; Farmer et al., 2011; Fauchart \& Gruber, 2011; Hoang \& Gimeno, 2010; Murnieks \& Mosakowski, 2007; Shepherd \& Haynie, 2009b). Understandably, the research on this topic is at the early stages of conceptual development. The research so far has only touched on few aspects of entrepreneurial identity. In other words, there is much to be understood about the role of "identity" in answering entrepreneurship questions.

Although the focus of Essay \# 2 was to shed light on theory and to test the antecedents of entrepreneurial identity, consistent with the extant literature, I offered substantive arguments to suggest that entrepreneurial identity is the missing link in the nascent entrepreneurship research domain. More particularly, I argued that the 
inconclusive findings in connecting personality attributes with entrepreneurship might have been because of this particular lacuna. The empirical findings in Essay \# 2 largely corroborated the theory insight I posited. In this essay, I take that conversation one step further by providing theoretical insights on why and how entrepreneurial identity is crucially linked with entrepreneurial actions. Taken together, Essay \# 2 and 3 will provide adequate evidence of the critical role of entrepreneurial identity in entrepreneurship.

Conceptual and empirical investigations establish that the entrepreneurial intention of a potential entrepreneur is a good predictor of realized/acted upon entrepreneurship (Krueger \& Carsrud, 1993; Obschonka et al., 2012; Souitaris et al., 2007). In addition, entrepreneurship researchers assert that intentionality is the most proximal predictor of the decision to pursue entrepreneurship, and it is often the distinguishing factor among otherwise equally disposed and competent individuals for the transition to entrepreneurship (Bird, 1988; Krueger, Reilly, \& Carsrud, 2000; Obschonka et al., 2012). Another concept that has been equally researched to predict the decision of an individual to engage in entrepreneurial pursuits is entrepreneurial self-efficacy (Chen, Greene, \& Crick, 1998; Krueger et al., 2000; Wilson et al., 2007). Hence, to assess the significance of the influence of entrepreneurial identity on entrepreneurial actions and behaviors, it is necessary to theorize and test the impact of entrepreneurial identity on entrepreneurial intentions and entrepreneurial self-efficacy. Also, recall the theory in the earlier essays which documented that an identity is crucial because it prompts a selfregulatory process that leads to certain behaviors. In addition, given the distinctions of prospected entrepreneurial identity and constructed entrepreneurial identity theorized in 
this dissertation, it is equally important to examine the possible differential influence of IPEI and SCEI on entrepreneurial intentions and entrepreneurial self-efficacy to get a more complete understanding. The conceptual model is presented in Figure 5.

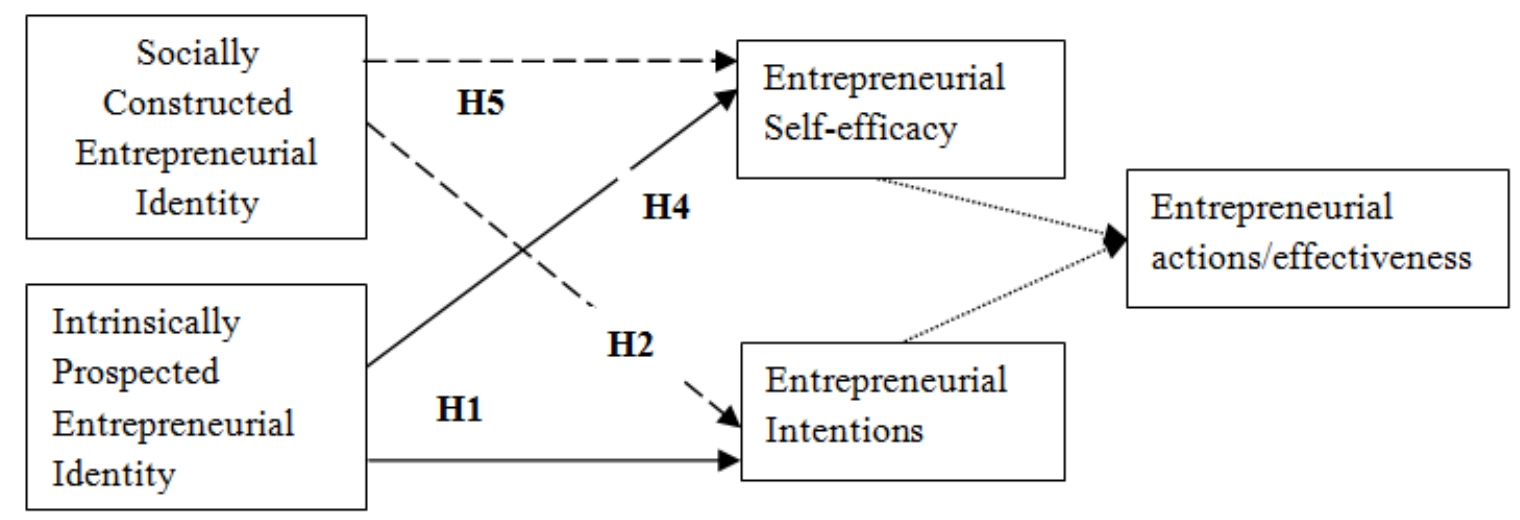

Figure 5. An Entrepreneurial Identity Centered Model of Nascent Entrepreneurship Notes:

(a) Solid arrows represent a strong effect

(b) Dashed arrows represent a weak effect

(c) Dotted arrows represent the relationships that are not hypothesized/tested in this study

(d) H3 and H6 are effect size comparison hypotheses, hence, not shown in the figure

\section{Entrepreneurial identity and entrepreneurial intentions}

In the literature review section, I provided a detailed account of how identities in general have bearings on intentionality, ranging from cooperative intentions (Boezeman \& Ellemers, 2007) to turnover intentions to withdrawal intentions (Das et al., 2008). However, because "entrepreneurial identity" is a new avenue of research for entrepreneurship researchers, limited theory and evidence exists to shed light on the effects of entrepreneurial identity on intentionality. To my knowledge, no study has yet tested "if and how" entrepreneurial identity has a bearing on the intentions of individuals to engage in entrepreneurial ventures. Therefore, I look at some other determinants of 
entrepreneurial intentions - theorized and tested - such as personality characteristics, attitude to work, and attitude to risk (Douglas \& Shepherd, 2002; Kruger et al., 2000; Zhao et al., 2005; Zhao et al., 2010) that may offer insights for the discourse in the present research. The literature refers to an entrepreneurial intention as an individual's intent to start a new business (cf. Shook, Priem, \& McGee, 2003).

First, the personality characteristic determinants on entrepreneurial intentions have been well documented (Zhao et al., 2010). The broad identity literature suggests that an identity forms the basis of intentionality (Boezeman \& Ellemers, 2007; Das et al., 2008). Therefore, it is possible to conceive that there might be some logical relation among personality characteristics, entrepreneurial identity, and entrepreneurial intentions. The literature has established that personality characteristics and identities are correlates (Brown, 2001; Ryder et al., 2000; Sheldon et al., 1997). I provided theoretical insights in Essay \# 2 that personality characteristics are the predictors of entrepreneurial identity, which empirical findings validated. As such, the logical connection is the following: entrepreneurial identity, which is influenced by personality characteristics, must be, in part, responsible for the corresponding intentionality (i.e., entrepreneurial intentions). Hence, we can expect entrepreneurial identity to positively influence entrepreneurial intentions.

Second, Cardon et al. (2009) proposed that entrepreneurial passion embedded by certain identities would lead to entrepreneurial performance. One of the insights they offer is: when the inventor identity is dominant/salient, entrepreneurial passion leads to effective opportunity recognition, whereas when the founder identity is salient, entrepreneurial passion leads to effective venture creation. Accordingly, Dobrev \& 
Barnett (2005) argued that "the founder role identity" is one of the reasons founders become repeat entrepreneurs. Similarly, the conceptual work by Hoang \& Gimeno (2010) illuminates the impact of entrepreneurial identity on the organizational emergence process. These conceptual and empirical works collectively suggest that an entrepreneurial identity gives rise to entrepreneurial actions. However, both scientific research (Bird 1988; Shook et al., 2003) and common sense hold that any actions must be preceded by a conscious state of mind which directs an individual towards actions. That is, an intention precedes the corresponding action. In fact, multiple studies have already established that entrepreneurial actions are the functions of entrepreneurial intentions (Obschonka et al., 2012; Shook et al., 2003; Souitaris et al., 2007). Taking all these pieces together, in other words, entrepreneurial intentions must be the missing link between "entrepreneurial identity and entrepreneurial actions." Therefore, the entrepreneurial identity of individuals must have a bearing on their entrepreneurial intentions.

The relationships argued in the preceding two paragraphs offer a clear big picture of "personality characteristics $\rightarrow$ entrepreneurial identity $\rightarrow$ entrepreneurial intentions $\rightarrow$ entrepreneurial actions/effectiveness" linkages. Notice that the last link of the chain is well established in the literature as invoked above. The first link was theorized and established in Essay \# 2 of this dissertation. The preceding arguments suggest the middle link. With that clarification established, I further attempt to deduce that the association between IPEI and entrepreneurial intentions and the connection between SCEI and entrepreneurial intentions vary in terms of their strength. 
Honeycutt \& Rosen (1997) examined how identities influenced people's attraction to organizations in terms of career paths. They theorized and found evidence that organizations and career paths that support individuals' salient identities are attractive to them. For example, someone with a family identity salience is more attracted towards organizations that offer flexible career paths. Drawing on this insight, it can be argued that people with an entrepreneurial identity must have developed entrepreneurial identity precisely because of their attraction to various attributes of entrepreneurship as a career (such as independence, autonomy, and self-actualization etc.). The identity development owing to the attractions of the attributes of entrepreneurship as a career is more likely to be true for an identity that is prospected by the individuals rather than an identity which is socially constructed and conferred upon them. Indeed, a qualitative study by O'Neil \& Ucbasaran (2010) furnished evidence that individuals switched to an entrepreneurial career from other career choices because the entrepreneurial career allowed them to express and integrate their personal values into the career. It allowed them to retain an authentic identity. By most accounts, this must be a prospected entrepreneurial identity. This discussion leads to the following hypotheses:

H1: Intrinsically prospected entrepreneurial identity will be positively related to entrepreneurial intentions.

H2: Socially constructed entrepreneurial identity will be positively related to entrepreneurial intentions.

H3: The positive impact of intrinsically prospected entrepreneurial identity on entrepreneurial intentions will be stronger than the positive impact of socially constructed entrepreneurial identity on entrepreneurial intentions. 


\section{Entrepreneurial identity and entrepreneurial self-efficacy}

Self-efficacy in the literature is generally referred to as the perception and/or belief in oneself as being able to do and succeed in certain acts/behaviors (Bandura, 1982; Gianakos, 1995). In other words, it is the self-confidence of individuals, based on the awareness of their own skills and abilities, to act successfully in certain tasks or domains (Bandura, 1997; Wilson et al., 2007). It is even argued that affective states and behaviors are largely the function of perceived self-efficacy, which propels individuals to act, rather than their objective abilities (Markman et al., 2002; Wilson et al., 2007). Consistent with the literature (Bandura, 1997; Chen et al., 1998; Markman et al. 2002; Kickul, Gundry, Barbosa, \& Whitcanack, 2009; Wilson et al., 2007), in this dissertation, I refer to entrepreneurial self-efficacy as the self-confidence individuals have regarding their ability to successfully engage in an entrepreneurial career. Because of the exploratory nature of the present research, and due to the lack of research on the influence of entrepreneurial identity on entrepreneurial self-efficacy, I draw from diverse literatures to make my case. I offer multiple insights on the probability and criticality of entrepreneurial identity as a precursor of entrepreneurial self-efficacy.

To start with, identity theories provide insights on why a certain identity might lead to the self-efficacy related with the typical behavioral actions of the focal identity. Identity control theory (Burke, 1991) maintains that "identities are powerful motivators because they fulfill the human need for self-verification ${ }^{12}$ (Swann, Pelham \& Krull, 1989), which then contributes to a sense of efficacy (Erez \& Earley 1993)" (cited in Murnieks \& Mosakowski, 2007: p 3). Note that the need to preserve a coherent self-

\footnotetext{
${ }^{12}$ Self-verification represents the desire for individuals to preserve self-conceptions (Burke, 2004).
} 143 
concept (self-verification) (Burke, 2004) is arguably even more crucial for entrepreneurs and potential entrepreneurs relative to most people who are engaged in other career pursuits. Recall the "jack of all trade" nature of an entrepreneurial career and "the number and diversity" of the stakeholders an active or potential entrepreneur has to engage with. Thus, because of the wide range of social interactions entrepreneurs and potential entrepreneurs have to successfully manage, in addition to the multiple roles they have to successfully perform, preserving one's self-conception is critical in entrepreneurial pursuits. And, as the literature suggests (Murnieks \& Mosakowski, 2007), doing so will lead to entrepreneurial self-efficacy. Therefore, we can expect that an entrepreneurial identity leads to entrepreneurial self-efficacy.

Second, I reason that entrepreneurial identity strengthens entrepreneurial selfefficacy because entrepreneurial identity enhances an individual's entrepreneurial careerrelated self-esteem and psychological well-being (generally assessed as the level of anxiety, happiness, stress, and overall satisfaction, cf. Brook et al., 2008). It is important to note here that self-efficacy is not "an actual objective ability"; it is, rather, "a cognitive state" of mind by virtue of which individuals perceive their competencies are good for certain actions. Therefore, irrespective of the (active or potential) entrepreneurs' actual abilities, it is reasonable to argue that developing such positive state of mind, i.e., selfefficacy, requires individuals to hold self-esteem associated with their chosen entrepreneurial career, in addition to being in a good psychological state. Because entrepreneurial career is often characterized as being fraught with "work-role overload" and "work-family conflict", self-esteem and psychological well-being is critical to the development of self-efficacy. In fact, career researchers have already studied and found 
evidence that these factors impact the psychological well-being of entrepreneurs (cf. Parasuraman, Purohit, Godshalk, \& Beutell, 1996). And, as the identity research informs us, identity does bestow individuals with career-related self-esteem and psychological well-being.

Identity researchers have extensively studied the impact of identity on the psychological well-being of individuals (cf. Brook et al., 2008). Particularly, the harmony of various identities is likely to generate higher psychological well-being (Brook et al., 2008). Recall that entrepreneurial identity is a meta-identity that, as I theorized in Essay \# 1, provides a coherence of meaning and harmonizes the multiple micro identities of the individuals who are pursuing an entrepreneurial career. Therefore, taken together, it is reasonable to argue that entrepreneurial identity might improve an active or potential entrepreneur's psychological well-being. The finding of Briscoe et al. (2012) that "individuals with self-directed protean career attitude (interchangeable with an entrepreneurial career for the present research purpose) are more likely to develop identity awareness, and thereby, psychological well-being" provides empirical evidence for the preceding argument. Just like psychological well-being, career related self-esteem has been documented as the function of identity as well (cf. Grote \& Raeder, 2009; McArdle, Waters, Briscoe, \& Hall, 2007). In a study of unemployed Australian adults testing the concept of "employability", McArdle et al. (2007) argued that a career identity was central in determining the level of self-esteem during unemployment which was related to eventual re-employment. In light of the foregoing discussion, it is conceivable that entrepreneurial identity augments psychological well-being and self-esteem, which in turn positively influence entrepreneurial self-efficacy. 
Third, the entrepreneurial career is characterized by risk \& uncertainty (Knight, 1957; Shane \& Venkataraman, 2000; Schumpeter, 1934), and thus has a high probability of failure (Shepherd 2004; Zacharakis, Meyer \& DeCastro, 1999). Research shows that many entrepreneurs enter an entrepreneurial career despite their knowledge of the high probability of failure because it provides them with a meaningful career identity and authenticity in their identity (O'Neil \& Ucbasaran, 2010). Plausibly, the identity that provides authenticity, despite the high probability of failure in the domain, must also enhance their self-efficacy, which is the basis of their actions (Bandura, 1997; Markman et al. 2002; Wilson et al., 2007).

Finally, the research in career domains has already documented the influence of various identities on relevant self-efficacies. For instance, Gianakos (1995) found that sex-role identities account in part for the difference in career decision making selfefficacy among individuals. Similarly, the ethnic identity of individuals has been found to influence their career decision making self-efficacy, and thereby, the outcome expectations as well (Gushue, 2006). If sex-role identities and ethnic identities have bearing on career-related self-efficacy, then entrepreneurial identity arguably should influence entrepreneurial self-efficacy, especially if we consider that entrepreneurial identity is a career identity. In fact, this assertion is supported by the results of Tierney, \& Farmer's (2011) study. They found that creative role identity and a change in creative role identity directly and positively influenced creative self-efficacy in a work context.

In the arguments proffered in the earlier paragraphs (also refer to the overall position of an entrepreneurial identity being a missing link), I established the following. Entrepreneurial identity is instrumental in enhancing entrepreneurial self-efficacy in 
many ways. Entrepreneurial identity provides: an authenticity in the expression of personal values and the integration of these values into a career; a sense of psychological well-being and self-esteem; coherence and stability of the self; and an overarching meaning to individuals' various career-related micro identities. For the following two reasons, intrinsically prospected entrepreneurial identity is likely to enhance entrepreneurial self-efficacy more strongly than socially constructed entrepreneurial identity does. First, recall the "internal regulators vis-à-vis external regulators" insight comprehensively derived in Essay \# 1. It is not difficult to observe that an identity which an individual engineers himself/herself based on " internal regulators" such as values, abilities, belief-systems and, more importantly, the self-reflective assessment of these factors, is likely to stimulate self-esteem and to inject these values and beliefs into the corresponding career strongly. Similarly, for the same reason, it is likely to offer a coherent narrative for the individual, providing them with a positive cognitive framework within which to engage in career related actions, thereby enhancing self-efficacy. Second, an identity which is promotion focused (refer to the discussion in Essay \# 1), such as intrinsically prospected entrepreneurial identity, is naturally better positioned to enhance self-efficacy more than a prevention focused identity, such as socially constructed entrepreneurial identity. That is because intrinsically prospected entrepreneurial identity is oriented to maximize gains and achievements, and manifests itself in ideal, aspirational goals (cf. Carver \& Scheier, 1998; Johnson et al., 2010). Therefore, I expect the influence of intrinsically prospected entrepreneurial identity on entrepreneurial self-efficacy to be stronger than the impact of socially constructed entrepreneurial identity on entrepreneurial self-efficacy. The discussion leads to the following hypotheses: 
H4: Intrinsically prospected entrepreneurial identity will be positively related with entrepreneurial self-efficacy.

H5: Socially constructed entrepreneurial identity will be positively related with entrepreneurial self-efficacy.

H6: The positive impact of intrinsically prospected entrepreneurial identity on entrepreneurial self-efficacy will be stronger than the positive impact of socially constructed entrepreneurial identity on entrepreneurial self-efficacy.

\section{Method}

Because the same data set is used to evaluate the models of Essay \# 2 and Essay $\# 3$, many method subsections which are common across these two essays are not repeated in this essay. As such, for the research design, pilot study, survey instrument development, study sample discussion, sampling rationale, and analytical tool and approach, refer to the "method section" of Essay \# 2. In addition, even in the method subsections that I report in this essay (for example, the measurement subsection), I do not repeat the explanations and discussions that I already provided in Essay \# 2 (for example, the discussion of IPEI and SCEI measurement scales) to avoid redundancy. The descriptive statistics for this essay, which includes the zero-order correlations of the variables in this study, Cronbach's alpha, scale composite reliability (SCR), and the average variance extracted by latent constructs (AVE), is presented in Table 4. 
Table 4

Descriptive Statistics.Zero-Order Correlations. AVE. SCR and Cronbach's Alpha a

\begin{tabular}{|c|c|c|c|c|c|c|c|c|c|c|c|}
\hline Variables & Mean & S.D. & 1 & 2 & 3 & 4 & 5 & 6 & 7 & 8 & 9 \\
\hline 1. Sex & & & & -.09 & -.05 & .07 & .16 & .16 & .24 & .17 & .24 \\
\hline 2. Family background & & & & & .13 & .07 & -.03 & .00 & .03 & .030 & .06 \\
\hline 3. Age & 39.00 & 10.82 & & & & .39 & .18 & .08 & .29 & .16 & .15 \\
\hline 4. Tenure & 6.80 & 6.30 & AVE & SCR & Alpha & & .03 & .23 & .29 & .29 & .26 \\
\hline 5. Risk attitude valence & 4.63 & .88 & .53 & .77 & .76 & & & .18 & .18 & .15 & .17 \\
\hline 6. ENT. intention & 2.26 & 1.33 & .90 & .96 & .96 & & & & .37 & .66 & .76 \\
\hline 7. ENT. self-efficacy & 4.28 & 1.33 & .92 & .96 & .96 & & & & & .40 & .47 \\
\hline 8. SCEI & 2.43 & 1.31 & .82 & .96 & .96 & & & & & & .75 \\
\hline 9. IPEI & 2.97 & 1.67 & .88 & .97 & .97 & & & & & & \\
\hline
\end{tabular}

a Correlations equal to or greater than 0.17 are significant at $p<0.05$ or more robust level, shown in bold face. The significance test is two-tailed. They are presented in upper diagonal.

- $n=143$, for all correlations. AVE = average variance extracted and SCR $=$ scale composite reliability

\section{Measurement of dependent variables, independent variables, and control}

variables. For the two dependent variables of this essay, entrepreneurial intentions and entrepreneurial self-efficacy, I adopted the scales from other studies. I adopted the entrepreneurial intentions scale from Liñán \& Chen (2009). I measured entrepreneurial intentions requesting the respondents to assess to what degree they agreed or disagreed with the six indicators measured on a 1-7 Likert scale $(1=$ strongly disagree, and $7=$ strongly agree). A sample indicator of this scale reads: "You have seriously thought about creating your own business in the new future." I adopted the entrepreneurial self-efficacy scale from Zhao et al. (2005) to capture the entrepreneurial task-related self-confidence of the respondents. I used the following anchor for this scale: "The following statements measure your self-efficacy in entrepreneurship; please rate your confidence in the following activities using the 1-7 scale provided below." In this Likert scale, 1 equals 
"not confident at all" and 7 equals "highly confident." For the scale measurements of two independent variables, IPEI and SCEI, refer to the measurement subsection of Essay \# 2. In addition to controlling for age, sex and tenure, which may influence entrepreneurial self-efficacy and entrepreneurial intentions, I controlled for the entrepreneurial family background and risk attitude of the respondents. Refer to the discussion throughout this dissertation on "risk and uncertainty" being at the crux of entrepreneurial pursuits (which I refrain from discussing here for brevity reasons). While objectively measuring/controlling for the attitude towards risk is tricky, I controlled for it by asking the respondents how much they cared about being able to take risk. To paraphrase, I asked the value they placed on those risk taking behaviors. For a sample, an indicator of this scale reads: "Ability to make bold decisions in uncertain situations without fear of losing your job." I borrowed this scale from Kemelgor \& Poudel (2009). The complete indicators of all the latent constructs are presented in the Appendix.

\section{Data analysis (constructs reliability, construct validity, and common method}

variance). The measurement model for this essay demonstrated an excellent overall fit $(\mathrm{NC}[X 2 /$ d.f. $]=1.43, p<.01 ; \mathrm{CFI}=.99, \mathrm{NNFI}=.98, \mathrm{RMSEA}=.06, \mathrm{SRMR}=.05)($ Hair et al., 2005; Kline, 2005). I included all the variables in the model, independent, dependent and control variables, and I created parcels for entrepreneurial self-efficacy and entrepreneurial intentions (refer to the method section of Essay \# 2 for explanation). The indicators or indicator parcels loaded very well in their specified latent constructs. The standardized factor loadings ranged from .69 to .98 except for one indicator which loaded .6 (for risk tolerance valence). 
I evaluated construct reliability with both Cronbach's alpha and scale composite reliability (SCR) as recommended (MacKenzie et al., 2011; Nunnally, 1978; Raykov, 1997). Alpha measures ranged from .76 for risk attitude valence to .97 for intrinsically prospected entrepreneurial identity. SCR measures ranged from .77 for risk attitude valence to .97 for intrinsically prospected entrepreneurial identity, almost mirroring the alpha measures. These reliability measures are quite solid as they are well above the recommended minimum threshold of .70. All the measures appear in Table 4.

I assessed construct validity in the same way as in Essay \# 2 analysis - that is, by evaluating both convergent validity and discriminant validity among the constructs. The " $t$ " values of the factor loadings in the measurement model of this essay ranged from 5.90 (for an item of risk attitude valence) to 28.62 (for an item of entrepreneurial intentions) suggesting a convergent validity (Netemeyer et al., 1990). Second, The AVEs for all the constructs were good, ranging from .53 (for risk attitude valence) to .92 (for entrepreneurial self-efficacy), more than the minimum threshold of .50 (cf. Fornell and Larcker, 1981; Netemeyer et al., 1990). The AVEs for all the constructs are presented in Table 4. Third, I constrained the measurement model to assess the overall construct validity. Models were constrained conjecturing the theoretical possibility of conceptual overlap: M1 = IPEI and SCEI treated as a single construct; M2 = IPEI and entrepreneurial intentions treated as one factor; and M3 = IPEI and entrepreneurial selfefficacy treated as one factor. As presented in Table 5, the measurement model is better fitting compared all the constrained models which documents the overall construct validity as strong. Moreover, following the experts' suggestion of a more stringent assessment of discriminant validity (cf. MacKenzie et al., 2011), I examined the AVEs 
for all the constructs relative to the squared correlation between a pair of latent constructs. As we can see in Table 4, AVEs are greater than the squared correlation for any pair which documents the discriminant validity. For example, the AVEs for intrinsically prospected entrepreneurial identity and entrepreneurial intentions (.88 and .90 respectively) are greater than the squared correlation .58 (calculated as $.76^{*} .76$ ) (Fornell and Larcker, 1981; MacKenzie et al., 2011).

\begin{tabular}{|c|c|c|c|c|c|}
\hline & \multicolumn{5}{|c|}{ Fit statistics } \\
\hline & $\mathrm{NC}\left(X^{2} / d . f\right)^{d}$ & NNFI & $\mathrm{CFI}$ & RMSEA & SRMR \\
\hline Theorized measurement model & $1.43(224.24 / 157)$ & .98 & .99 & .06 & .06 \\
\hline M1: IPEI and SCEI treated as one factor & $4.98(821.48 / 165)$ & .91 & .93 & .17 & .07 \\
\hline $\begin{array}{l}\text { M2: IPEI and entrepreneurial intentions treated } \\
\text { as one factor }\end{array}$ & $2.92(481.61 / 165)$ & .92 & .94 & .12 & .07 \\
\hline $\begin{array}{l}\text { M3: IPEI and entrepreneurial self-efficacy } \\
\text { treated as one factor }\end{array}$ & $2.30(381.29 / 165)$ & .93 & .94 & .10 & .08 \\
\hline Theorized structural model & $1.42(224.20 / 158)$ & .98 & .99 & .05 & .06 \\
\hline
\end{tabular}

c $n=143$, for all the models.

d $p<0.001$ for all the models.

In addition to the design of the questionnaire to ex ante reduce common method variance (CMV) (refer to the method section of Essay \# 2), the Harman's single factor test showed that CMV was not an issue for this study because only $28.68 \%$ variance was explained by a single factor, which is less than the 50\% threshold (Podsakoff et al., 2003). 
Results of hypothesis tests. The results of SEM on Essay \# 3 model are depicted in Figure 6. The SEM model showed an excellent overall fit (NC $[X 2 /$ d.f. $]=1.42, p<$ $.01 ; \mathrm{CFI}=.99, \mathrm{NNFI}=.98, \mathrm{RMSEA}=.05, \mathrm{SRMR}=.06)($ Hair et al., 2005; Kline, 2005). Hypotheses "H1" and "H 2" stated that intrinsically prospected entrepreneurial identity and socially constructed identity entrepreneurial identity both would positively influence entrepreneurial intentions, respectively. Both of these effects were positive and significant (.60 and .19), thus, these hypotheses were supported. "H3" hypothesis predicted that the influence of IPEI on entrepreneurial intentions would be stronger than the influence of SCEI. This hypothesis was also supported as the regression coefficients were: $.60>.19$. I predicted that both IPEI and SCEI would positively influence entrepreneurial self-efficacy, hypotheses "H4" and "H5" respectively. However, only "H4" was supported (.39). The effect of SCEI on entrepreneurial self-efficacy, although positive, was too small and not significant. Since "H6" hypothesis stated that the impact of IPEI on entrepreneurial self-efficacy would be greater than the impact of SCEI, it could be considered as a partially supported hypothesis. 


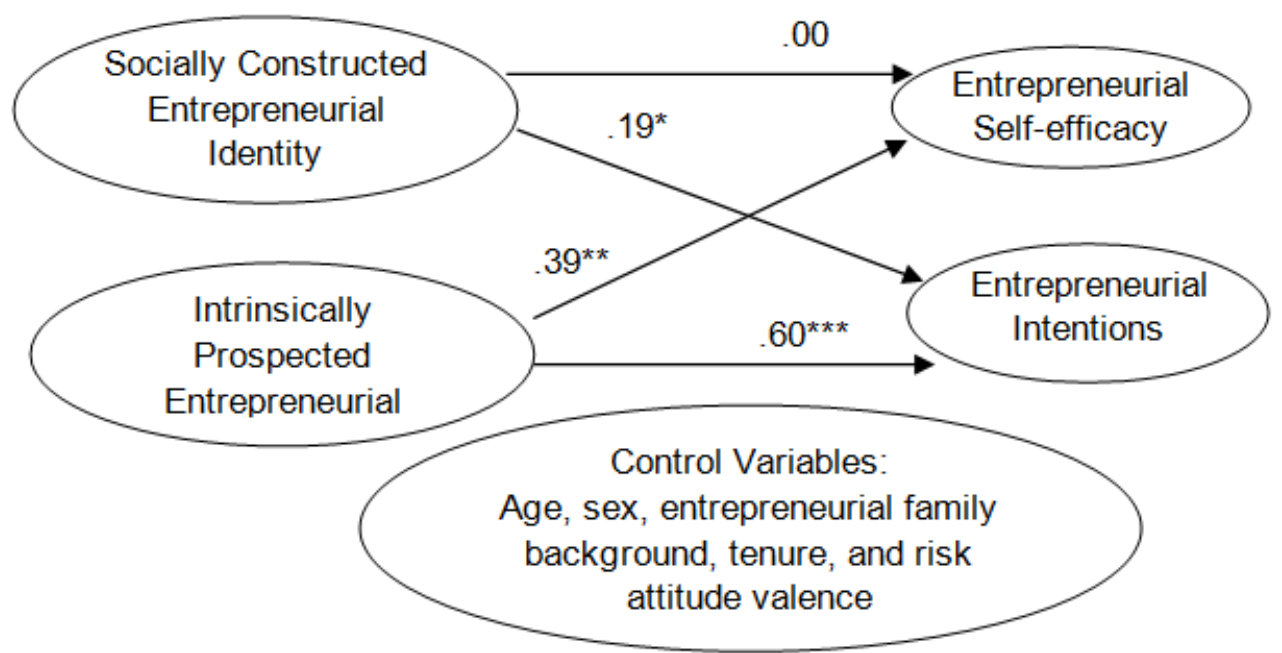

Figure 6. SEM Results for the Entrepreneurial Identity Centered Model of Nascent Entrepreneurship ${ }^{a b c}$

a The regression coefficients reported are standardized. Control effects and factor loadings are not shown for aesthetic reasons.

$b$ The Fit index for the SEM: $(\mathrm{NC}[X 2 /$ d.f. $]=1.42, p<.01 ; \mathrm{CFI}=.99, \mathrm{NNFI}=.98, \mathrm{RMSEA}=.05$, SRMR $=.06$ )

c All factor loadings reported are significant at $p<.001$ level

${ }^{*} \mathrm{p}<0.10$

${ }^{* *} p<0.01$

$* * \star \mathrm{D}<0.001$

Tests of robustness. Given the new constructs introduced in this dissertation research, I additionally needed to test the robustness of both the measurement model and structural regression model of this essay too. As explained in an earlier paragraph, I ran the alternate models (constrained models) looking at possible conceptual similarity. Because the measurement model is a much better fitting model than the rest of the alternative models, it was justified to proceed to the structural regression model. In the case of the theorized structural regression model, note that it is plausible that entrepreneurial self-efficacy might lead to entrepreneurial intentions. Thus, as a part of robustness check, I added "entrepreneurial self-efficacy $\rightarrow$ entrepreneurial intentions" 
link in the theorized structural model. The addition of this linkage in the structural model did not bring any significant change in the parameter estimates and their significance; that is, they were similar to the estimates demonstrated in Figure 6. Moreover, this added linkage was not significant.

\section{Conclusion}

In this essay, I hypothesized that entrepreneurial identity is one of the predictors, out of other possible predictors, of two constructs-entrepreneurial intentions and entrepreneurial self-efficacy-that are crucial in predicting entrepreneurial actions and effectiveness. Confirming the insights of this theory, I found the following evidence. Entrepreneurial identity enhances entrepreneurial intentions, and the positive impact of intrinsically prospected entrepreneurial identity on entrepreneurial intentions is stronger relative to the influence of socially constructed entrepreneurial identity. In the case of entrepreneurial self-efficacy also, the general insight was supported. However, some caveats remain. As theorized, intrinsically prospected entrepreneurial identity positively influenced entrepreneurial self-efficacy. However, the effect of socially constructed entrepreneurial identity on entrepreneurial self-efficacy, although positive, was not significant. This still supports the overall insight that entrepreneurial identity is a precursor of entrepreneurial self-efficacy.

Consistent with the very first study which directly introduced the concept of entrepreneurial identity (Murnieks \& Mosakowski, 2007), I argued that entrepreneurial identity is a missing link in the nascent entrepreneurship literature. The major thrust of my theory is that a career identity (such as entrepreneurial identity) precedes 
intentionality and self-efficacy that, in turn, lead to expected behavioral outcomes (such as founding a venture). As summoned and discussed earlier, whereas the literature adequately documented the effects of entrepreneurial intentions and entrepreneurial selfefficacy on entrepreneurial actions and effectiveness, there was a conspicuous void in our understanding of the factors that lead to these two proximal predictors of entrepreneurial activities in the first place. The theory advanced, and the supporting evidence presented in this essay, fill that particular gap by establishing that entrepreneurial identity is one such predictor of both entrepreneurial self-efficacy and entrepreneurial intentions. 


\section{DISCUSSION}

Contribution to the dialogues in the general identity literature. This dissertation research aimed at two primary contributions: one directed towards the general identity literature and the other directed towards the entrepreneurial identity literature. The contribution to the broad identity literature was accomplished by articulating, theorizing, and testing a distinct process of identity development - the intrinsic prospection of identity. This process was compared and contrasted with the social construction of identity, which is the predominant understanding of identity development in the extant literature (Alvesson, 2010; Ashforth et al., 2008; Ashforth 1993; Brown, 2001; Chreim, 2005; Creed et al., 2002; Day et al., 1999; Gouldner, 1957; Zimmermann \& Ravishankar, 2011). Particularly, in the theory development in Essay \# 1, the following was accomplished to advance a dual-process model of identity development. I detailed the rationale for the dual-process identity development; provided the premises of the conversations and defined the concepts; shed light on the distinctions of the two identities that develop from these distinct processes; and clarified the novelty of the construct relative to other similar concepts in the literature. In Essays \# 2 and 3, I theorized and empirically tested the dual-process identity development concept in the context of a particular identity-entrepreneurial identity. Because I theorized, empirically tested, and found evidence for two distinct types of identity, I conclude that the dual-process of identity development can be true in the case of other individual level identities as well. 
The theory I advanced is empirically substantiated on two counts: (a) the antecedents differentially impacted IPI and SCI, and (b) IPI and SCI differentially predicted criterion variables. As such, I hope this conversation of the dual-process of identity development encourages other researchers in the broad identity research domain to look for the nuances in the particular identities of their interest.

For the advancement of the dual-process identity development theory, I drew on multiple disciplines and various theories which in some form either argued or implied the intrinsic prospection of identity, without explicitly articulating it as such (Alvesson, 2010, Beech, 2008; Brown, 2001; Burke \& Reitzes, 1991; Clarke et al., 2009; Flum \& Blustein, 2000; Marco et al., 2003; Markus \& Nurius, 1986; Markus \& Nurius, 1987). Identity scholars have unambiguously noted that despite the multiple pieces of the puzzle needed to examine the identity development process, the identity research and theories often imply rather than focus on these identity development processes, leaving a void in the theory (Ibarra, 1999; Pratt et al., 2006). Therefore, by focusing on the two distinct processes of identity development, my theory offers a significant contribution to the general identity literature. The following excerpt from Kosmala \& Herrbach's (2006) paper, referring to the nature of professional identity (and generally the case for any identity) in a post-modern context, elegantly summarizes the need for these dialogues in the broader identity literature:

...we refer to the post-modern condition as one in which reality becomes ideological (Žižek, 1989), enabling individuals to construct and strategize their identity as an amalgam of attributes, values and life choices. In other words, individual identity is no longer 'passively' derived from one's position in the social space; rather it is the responsibility of each individual to reflect upon how they choose to exist in a historically and culturally specific time (p 1394). 
Contribution to the dialogues in the entrepreneurial identity literature. On the basis of the literature review and the three essays developed in this dissertation, and in congruence with other researchers (Ireland \& Webb, 2007), I arrive at the following conclusions. In spite of the richness and the breadth of the general identity literature, entrepreneurial identity remains an under-researched area with a tremendous potential to inform multiple social sciences. This dissertation significantly contributes to the justinitiated discourse on entrepreneurial identity.

First, I provided a comprehensive conceptualization of entrepreneurial identity by defining it as a meta-identity/superordinate identity. The literature referred to entrepreneurial identity in a wide array of interpretations, with such disparate conceptualizations as role identities (Cardon et al., 2009; Hoang \& Gimeno, 2010), social identities (Fauchart \& Gruber, 2011), career identity (Dobrev \& Barnett, 2005; O’Neil \& Ucbasaran, 2010), and personal identity (Nielsen \& Lassen, 2012; Sarasvathy, 2001). Connecting the thread among these identities and providing a clearer picture of entrepreneurial identity was one of the challenges of this dissertation research. Using pertinent criteria (identity centrality and identity salience across contexts), and on the basis of evidence and insights in the extant literature, I provided a relatively coherent and comprehensive picture of entrepreneurial identity-as a composite of multiple micro identities. This should substantially help further research in the entrepreneurial identity domain because it provides conceptual clarity for future researchers. Drawing from diverse literatures, I articulated why such a superordinate entrepreneurial identity is actually an advantage to active and potential entrepreneurs. The main insight I provided 
to that end is the following. Entrepreneurs and potential entrepreneurs need all the micro identities of entrepreneurial identity composite to navigate complex (social, economic, and other) systems. Furthermore, entrepreneurial identity provides an overarching theme to create a harmony, synergy, and coherence among these constituent identities. Because of the "jack of all trades" nature of an entrepreneurial career, such a synergized metaidentity is strongly advantageous.

With a detailed grounding in the broader identity theories, other relevant theories, and the theory advanced in this research, I offered another insight on the nature of entrepreneurial identity: different types of entrepreneurs (innovators, imitators, and selfemployed professionals) have different make-ups (in terms of the centrality and salience of micro identities) of their entrepreneurial identity composite. I showed that, owing to the differential strength of intrinsically prospected and socially constructed identities, there will be some similarities and some distinctions among the entrepreneurial identities of the three broad categories of entrepreneurs. The same reasoning explains the possible within-group variation (e.g., the variation among imitators) of entrepreneurial identity as well. This theorizing, I hope, opens the door for multiple conversations on the entrepreneurial identity topic.

Next, drawing insights from across academic traditions, I theorized and tested three different categories of antecedents of entrepreneurial identity - career attitude related antecedents (job meaningfulness and creativity), personality characteristics related antecedents (extraversion and imagination), and contextual antecedents (family background). Examining the antecedents of entrepreneurial identity has remained a more or less uncharted territory so far. Thus, the contribution of this research should be 
meaningful in providing future researchers some clear avenues for research in that direction (further discussion on this follows).

Similarly, the present research, I hope, filled a very important gap in nascent entrepreneurship research. Despite the importance of entrepreneurial self-efficacy and entrepreneurial intentions in this research domain (Chen, et al., 1998; Krueger \& Carsrud, 1993; Krueger et al., 2000; Obschonka et al., 2012; Souitaris et al., 2007; Wilson et al., 2007), there were limitations in our understanding of what factors contribute to entrepreneurial self-efficacy and entrepreneurial intentions. The linkage of both intrinsically prospected entrepreneurial identity and socially constructed entrepreneurial identity with those constructs enhanced that understanding. It is reasonable to conclude that entrepreneurial identity is one such significant link in predicting entrepreneurial pursuits.

Opportunities for further theory development on entrepreneurial identity. Given the complexities of the influence of entrepreneurial identity on various entrepreneurial behaviors, it will be significant to assess the change in entrepreneurial identity as an individual switches to entrepreneurship from some other career. A fine grained analysis of prospected and constructed entrepreneurial identities, and their relationships (harmonizing or conflicting) with the constituent micro identities during the transition process, will be interesting research. It will not only be an extension of the theoretical work of this dissertation, but also an excellent opportunity to complement the "identity complexity structure" research of Brook et al. (2008) and colleagues in an entrepreneurial context. 
Another theoretically important avenue to be explored in the entrepreneurial identity research domain is of identity foreclosure which, in career contexts, refers to the idea that an individual might commit to a career without engaging in the required exploratory behaviors (Brown et al., 2000). The examination of the harmony and conflict between entrepreneurial identity and other identities of active and potential entrepreneurs, and the consequences to entrepreneurship, will also fill a significant gap in the entrepreneurial identity literature. For instance, an individual might have various entrepreneurial competencies and might hold an entrepreneurial identity. However, other identities might be in direct conflict with one's entrepreneurial identity. As a result, a person who is capable of making a greater impact in society through entrepreneurial pursuits might engage in other socio-economically less influential career pursuits.

Similarly, given the highly exacting nature of an entrepreneurship career, individuals with lower "critical consciousness" (the ability of individuals to assess and overcome socio-political barriers) might refrain from exploring entrepreneurship as a career. Literature has already suggested that critical consciousness and career development are linked, and career identity plays a crucial role in career development (Diemer \& Blustein, 2006). A study that looks at critical consciousness, the relative strength of entrepreneurial identity compared to other identities of an individual, and the influence of these identities on the hazard of entrepreneurship (i.e., if someone will choose an entrepreneurial career) and entrepreneurial success will therefore constitute important theoretical work.

Another theoretically interesting, yet relatively uncharted territory of research, also relevant to practice, is the identity dynamics that involves the identities of various 
stakeholders in an entrepreneurial firm. In particular, we have very little, if any, understanding about the interplay of the organizational identity of employees, the organizational identity of the entrepreneur who founded the organization, and the other micro identities that constitute an entrepreneurial identity. It is reasonable to think that this dynamics will have a specific impact on both performance and business survival. Such a study will substantively and simultaneously complement the present dissertation research and the work of Dobrev \& Barnett, (2005), Drori et al. (2009) and Obschonka et al. (2012).

Note that the organizational identity of entrepreneurs is also part of the composite identity referred to as entrepreneurial identity. Research has already documented that leadership that identifies with followers, the prototypical leadership, is evaluated more positively on leadership effectiveness despite possible failure in reaching the maximal goal because of identity commonality (cf. Giessner et al., 2008). On the other hand, the failure research in the entrepreneurship literature documents the persistence of entrepreneurs despite the looming chances to fail (Shepherd 2003; Zacharakis et al., 1999). In this background, it will be interesting to see to what extent organizational identity, leader role identity, and possibly other identities which are not part of entrepreneurial identity composite (such as the gender identity of an entrepreneur) influence each other. More importantly, it will be interesting to know how their interactions shape the various constructs investigated in the entrepreneurial failure research domain (such as the escalation of commitment and persistence).

Given that a significant number of new ventures are started by founding teams rather than sole entrepreneurs (Shane, 2003) and given the complicated structure and 
dynamics within founding teams (Clarysse \& Moray, 2004; Ruef, Aldrich, \& Carter, 2003; Ucbasaran, Lockett, Wright, \& Westhead, 2003), examining the influence of identity on founding team dynamics will be very stimulating research. The research on founding teams has so far focused primarily on the competencies and capabilities of the founding teams. The founding team members' performance, and the subsequent performance of the organization, could be at least partly explained by the alignments and conflicts of identities among the entrepreneurs. In fact, Randel \& Jaussi's (2003) study provides a clue in this direction. They found that the variance in performance of individual members working in cross-functional teams was significantly explained by the personal and social functional background identities of the employees. Further studies which examine the conflicting and complementing impacts of personal and social identities of entrepreneurial founding teams on their performance will fill an important gap in the entrepreneurship research domain.

Opportunities for further empirical research on entrepreneurial identity. The research initiated in this dissertation opens several further empirical research opportunities as well. The replication and additional validation of the entrepreneurial identity scales developed in this study in different geographic contexts will have significance in the entrepreneurial identity research domain. So will the replication in a sample of currently active entrepreneurs. Empirical testing of the propositions developed in the theoretical essay of the dissertation (Essay \#1) provides another opportunity for significant contribution to the entrepreneurship field. This study looked at some contextual, personality-related, and career attitude related antecedents of entrepreneurial identity. Investigation of other contextual variables, career attitude related variables, and 
cognitive variables in relation to entrepreneurial identity will constitute another important contribution to the field. The examination of subtle impacts, such as the interactions among these variables, will be particularly interesting.

Similar to entrepreneurial self-efficacy and entrepreneurial intentions, entrepreneurial identity might impact other cognitive constructs considered important in entrepreneurial studies, such as the locus of control and the level of optimism, among others. A longitudinal, multilevel study that tracks the changes in the strength of IPEI and SCEI and their impact on various factors (e.g., self-efficacy, optimism) when a potential entrepreneur transforms to an active entrepreneur will constitute a meaningful research both theoretically and empirically.

Previous research suggested that entrepreneurial self-efficacy and entrepreneurial intentions matter in the likelihood of transitioning from a potential entrepreneur to an active entrepreneur (cf. earlier discussions). The present research found that entrepreneurial identity predicts both entrepreneurial self-efficacy and entrepreneurial intentions. Therefore, a hazard analysis that looks at the "transition possibility" by examining the direct effects of entrepreneurial identity and its indirect effects through entrepreneurial intentions and entrepreneurial self-efficacy will provide significant insights to further advance the dialogues in the nascent entrepreneurship research domain.

In the literature review section of this dissertation, I documented that having a strong sense of organizational identity lowers the turnover intentions among employees at different levels of the organizational hierarchy. The empirical findings from the third essay of the dissertation suggest that individuals who have a strong entrepreneurial identity are likely to have greater entrepreneurial intentions. Taking these findings 
together, it is logical to conclude that the strength of entrepreneurial identity among active entrepreneurs might impact not only their success, but also their intentions to hold on to the organization in the face of imminent failure. It will be thought-provoking to see, both theoretically and empirically, how entrepreneurial identity influences entrepreneurial persistence and failure.

\section{Implications for practice (for potential and active entrepreneurs, managers and}

investors). We know that entrepreneurs and their ventures face a multitude of problems in achieving entrepreneurial effectiveness - such as the liability of newness, legitimacy issues, the liability of smallness, and resource constraints, among others (Aldrich \& Fiol, 1994; Lounsbury \& Glynn, 2001; Shane \& Venkataraman, 2000; Stinchcombe, 1965). However, our knowledge of the likelihood of someone transitioning to an entrepreneurial career from other careers is still relatively limited. In light of the discussion in the preceding sections, it can be concluded that the organizational level identity of entrepreneurial firms and the entrepreneurial identity of individuals (including that of the founders) are critical in understanding the effectiveness of entrepreneurial firms as well as an individual's transition to an entrepreneurial career (Cardon et al., 2009; Dobrev \& Barnett, 2005; Farmer et al., 2011; Fauchart \& Gruber, 2011; Hoang \& Gimeno, 2010; Lounsbury \& Glynn, 2001; O’Neil \& Ucbasaran 2010). Given this general assertion, I discuss some of the more immediate and critical implications of entrepreneurial identity for active and potential entrepreneurs, for managers, and for the investors.

First, the theory insights and the empirical findings in the dissertation suggest that entrepreneurial identity, as a superordinate identity with constituent micro identities, can assist entrepreneurs and potential entrepreneurs in better managing the uncertainties 
associated with identifying and exploiting entrepreneurial opportunities. Entrepreneurial identity infuses meanings and authenticity in the entrepreneurial career. The possible synergistic effects of micro-identities further helps entrepreneurs meet the challenges of the socioeconomic systems they find themselves in. Second, while it is important to effectively balance the perception of uniqueness (personal identity) and the affiliation and identification with social units and context-specific roles (social and role identities) in any career context, this is arguably even more critical in an entrepreneurial career. Complementing some other research (e.g., Shepherd \& Haynie, 2009b), my research suggests that entrepreneurial identity provides the overarching structure for the various micro identities of active and potential entrepreneurs. It helps them to acquire a personalization and depersonalization balance (cf. Kreiner et al., 2006) of their selfconcept providing a healthy psychological state, self-esteem, and therein the entrepreneurial career related self-efficacy. Finally, throughout the dissertation, I also emphasized how identity awareness and identity commitment, in general, translates into enhanced psychological well-being, self-efficacy, and effectiveness in various goaloriented behaviors. When entrepreneurs and potential entrepreneurs are aware of the nature of their identities, the insights of this research suggest, they can better manage their entrepreneurial, goal-oriented actions.

Entrepreneurs found and manage organizations. The vast literature in "organizational structure" and "organizational control" invariably suggests that for organizations to function, a structured, controlled system is necessary - no matter the oldschool/modernist control system or the so called post-modern control system (cf. Gabriel, 1999). Understanding entrepreneurial identity will therefore have a direct bearing both on 
how entrepreneurs self-regulate themselves and on how they, in the capacity of top executives of their firm, work to effectively design and implement the organizational control systems in their organizations in order to regulate the work behaviors of others. Understanding the difference between intrinsic prospection and the social construction of identity could be a particularly important "soft-tool" in the control system of an organization. For example, imagine a business organization with a significant number of professional staffs. The top management might try to enhance the organizational identity of its general and professional employees in order to enhance the citizenship behaviors, and thereby improve performance. However, creating and promoting narratives to enhance organizational identity requires tact. The organizational identity of employees is, after all, the social construction of their identity. If the professional identity of these employees has already been strongly developed through intrinsic prospection, however, and the narratives, discourses, and symbols created for the organizational identity are in conflict with the narratives, discourses, and symbols representative of their professional identity, the employees will face an identity conflict. In that event, the effort of the top management team could even be counterproductive because professional employees might prefer to strengthen their intrinsically prospected professional identity relative to their socially constructed organizational identity. Therefore, entrepreneur executives and top managers should devise the discourses, narratives, and symbols to promote organizational identity by making sure that the other intrinsically prospected identities of employees, including personal and professional identities, are not in direct conflict with their organizational identity. 
Investors and entrepreneurship researchers alike face two fundamental questions regarding entrepreneurial investment. Are the factors related with an entrepreneur more important or the factors related to entrepreneurial opportunity? This is an ongoing conversation and concern (cf. Kaplan, Sensoy, \& Strömberg, 2009; Mitteness, Baucus, \& Sudek, 2012). The study of Mitteness et al. (2009) documented that, at least at the initial stage of investing, the entrepreneur matters the most. What attributes of an entrepreneur can the investor assess in order to predict the eventual success or failure of the venture? The literature tells us that many factors, such as startup experience and industry experience (Shane, 2003; Parker 2009), matter. The findings of this research, along with the insights of other preliminary work on entrepreneurial identity, suggest that entrepreneurial identity could be one such tool for investors to assess the intentionality, self-efficacy, and thereby predict the entrepreneurial success and effectiveness of an entrepreneur.

Implications for policy making. A state or a country invests resources in the infrastructure for entrepreneurship development and encourages individuals to become entrepreneurs because entrepreneurship is crucial for job creation and economic growth (cf. van Stel, Carree, Thurik, 2005; Wong, Ho, \& Autio, 2005). In a policy context, the high failure rate of entrepreneurs (cf. discussion earlier in the dissertation) equates to the underutilization of the resources of the government, which is nevertheless scarce to begin with. Thus, from the macro level research perspective, there is an important question to be answered: Do we need more entrepreneurs, or simply the right type of entrepreneurs (cf. Parker, 2009)? Just as investors are concerned with their particular investment with an entrepreneur, the policy makers also have the challenge of encouraging individuals 
with an entrepreneurial aptitude, competencies, and disposition for entrepreneurial pursuits. Assessing entrepreneurial identity might be one of the instruments they can use to decide where to invest resources when supporting potential entrepreneurs. To explain further, it is possible that some entrepreneurs, who are struggling to succeed, might have become entrepreneurs due to identity foreclosure (committing to a particular career/work without considering other careers seriously). Conversely, other individuals who could have proven to be competent entrepreneurs might choose other career options out of identity foreclosure.

Implications for entrepreneurship education. Reflecting the common perception and general reports (cf. World Economic Forum Report, 2011), scientific research also concludes that entrepreneurship education makes a difference because it fosters an entrepreneurial ecosystem (cf. Fayolle, Gailly, \& Lassas-Clerc, 2006; Souitaris et al., 2007; Von Graevenitz, Harhoff, \& Weber, 2010). More particularly, Von Graevenitz and colleagues found that prospective entrepreneurs "receive informative signals and learn about their entrepreneurial aptitude" during this education. From the theory insights generated throughout the dissertation on the impact of entrepreneurial identity, and particularly from the finding that entrepreneurial identity leads to entrepreneurial intentions and entrepreneurial self-efficacy, it is logical to conclude that "entrepreneurial identity" is one critical element of the entrepreneurial aptitude repertoire. Thus, the implications of entrepreneurial identity research on entrepreneurship education cannot be overstated. 
Limitations. There are several limitations, both theoretical and method-related, of this dissertation research - and therefore, the results should be interpreted cautiously. First, although I used one of the advanced statistical analytical tools, SEM, to analyze the data, and conducted robustness checks, methodological limitations still remain. First, it was a cross-sectional survey, not a longitudinal study; therefore, the causality claims made in my dissertation are of only suggestive nature, not conclusive. Second, I employed purposive sampling technique to collect my data, which is a non-random sampling. As I quoted earlier, although non-random sample is widely accepted in social science research, and should be reasonable for an exploratory investigation such as this dissertation research, the generalizability (external validity) of findings is weak for this type of sampling. Third, despite the ex ante and ex post measures taken for the common method variance issue, the present research may not have been free from CMV. Finally, even though my study sample is heterogeneous in terms of personal demographics, it was nearly homogenous in terms of race of the respondents. Since identity and race are related (cf. review section), it further constrains the findings, particularly the possibility of generalizing across races. There may be some theoretical limitation to this study as well. I proposed a dual-process framework of identity development and argued that every identity develops through both social construction and intrinsic prospection. I articulated the distinctions of IPI and SCI in relation to other identity-related constructs as well. That being said, one premise of this research may have constraints. One of the premises of the research was that "who am I" is the basic anchor question of the socially constructed identity and "who do I want to be" is the basic anchor question of intrinsically prospected identity. Operationalization of the constructs in this research was done based on this basic 
premise. Although the answer for "who do I want to be" is searched through internal regulators, discussed throughout the dissertation, I acknowledge that it cannot function in a social vacuum. Therefore, one could argue that the conceptual demarcation between "self-constitution of an identity within social systems" (i.e., intrinsic prospection) and "the influence of social systems on this identity" (i.e., the impact of external regulators) might be thin. And, this would constitute a valid contention. Therefore, some alternative operationalization of these two forms of identity, capturing the degree of influence of "internal regulators" and "external regulators" on an identity, rather than simply anchoring to "who am I" and "who do I want to be", will make the IPI and SCI distinction more conclusive.

Concluding remarks. In the broad, pragmatic scheme of things, entrepreneurship (creation and growth of ventures and organizations) constitutes the most important force of socio-economic development (Dobrev \& Barnett, 2005). It is critical to understand entrepreneurs' and potential entrepreneurs' identities-not only because they influence the effectiveness of entrepreneurship, but also because they shape the identities of the organizations they found, which has immediate implications on various aspects of the society at large (Cardon et al., 2009; Dobrev \& Barnett, 2005).

Organizations and individuals have reciprocal relationships and influences (Burke \& Reitzes, 1991; Stryker \& Burke, 2000). Obviously, in the similar fashion, as organizational scholars (Aldrich \& Ruef, 2006) have asserted, organizations and the further larger social units have that reciprocal relationships and influences. In this way, one could argue that the persistent, individual actions of the entrepreneurs that create and operate these organizations ultimately contribute to the building blocks of the prosperity 
of a particular society. Social psychologists argue that "an active self" is necessary for these persistent individual behaviors, and we know that an active self in turn requires "an identity" and the individual's full commitment to that identity (Burke \& Reitzes, 1991). Endorsing these broad insights, the theory and empirical findings in the present research suggested that entrepreneurial identity plays a crucial role in engendering entrepreneurial actions and entrepreneurial effectiveness through entrepreneurial intentions and entrepreneurial self-efficacy. After all, to reiterate, entrepreneurial actions determine the success or failure of organizations which, eventually, translates into social goods and prosperity. 


\section{REFERENCES}

Abrams, D., Ando, K., \& Hinkle, S. (1998). Psychological attachment to the group: cross-cultural differences in organizational identification and subjective norms as predictors of workers' turnover intentions. Personality and Social Psychology Bulletin, 24(10), 1027-1039.

Agarwal, R., Echambadi, R., Franco, A. M., \& Sarkar, M. (2004). Knowledge transfer through inheritance: Spin-out generation, development, and survival. Academy of Management Journal, 47(4), 501-522.

Albert, S., \& Whetten, D. A. (1985). Organizational identity. In L. L. Cummings \& B. M. Staw (Eds.), Research in organizational behavior, 7, 263-295. Greenwich, CT: JAI Press.

Aldrich, H. E., \& Fiol, C. M. (1994). Fools rush in? The institutional context of industry creation. Academy of Management Review, 19(4), 645-670.

Aldrich, H. E., \& Kenworthy, A. (1999). The accidental entrepreneur: Campbellian antinomies and organizational foundings. In: Baum,J. A. C.; McKelvey, B. (eds.). Variations in Organization Science: In Honor of Donald T. Campbell, 19-33. CA: Sage.

Aldrich, H. E., \& Ruef, M. (2006). Organizations evolving, (2 ${ }^{\text {nd }}$ edition), CA: Sage. Alvesson, M. (2001). Knowledge work: Ambiguity, image and identity. Human Relations, 54(7), 863-886. 
Alvesson, M. (2010). Self-doubters, strugglers, storytellers, surfers and others: Images of self-identities in organization studies. Human Relations, 63(2), 193-217.

Alvesson, M., \& Kärreman, D. (2007). Unraveling HRM: Identity, Ceremony, and Control in a Management Consulting Firm. Organization Science, 18(4), 711-723.

Alvesson, M., \& Willmott, H. (2002). Identity regulation as organizational control: producing the appropriate individual. Journal of Management Studies, 39(5), 619644.

Amabile, T. M. (1996). Creativity and innovation in organizations (5), Boston: Harvard Business School.

Amason, A. C., Shrader, R. C., \& Tompson, G. H. (2006). Newness and novelty: Relating top management team composition to new venture performance. Journal of Business Venturing, 21(1), 125-148.

Andersen, S. M., \& Chen, S. (2002). The relational self: an interpersonal social-cognitive theory. Psychological Review, 109(4), 619-645.

Anderson, J. C., \& Gerbing, D. W. 1988. Structural Equation Modeling in Practice: A Review and Recommended Two-Step Approach. Psychological Bulletin, 103(3), 411-423.

Anteby, M. (2008). Identity incentives as an engaging form of control: Revisiting leniencies in an aeronautic plant. Organization Science, 19(2), 202-220.

Aquino, K., \& Douglas, S. (2003). Identity threat and antisocial behavior in organizations: The moderating effects of individual differences, aggressive modeling, and hierarchical status. Organizational Behavior and Human Decision Processes, 90(1), 195-208. 
Arthur, M. B., Khapova, S. N., \& Wilderom, C. P. (2005). Career success in a boundaryless career world. Journal of Organizational Behavior, 26(2), 177-202.

Aryee, S., \& Luk, V. (1996). Work and nonwork influences on the career satisfaction of dual-earner couples. Journal of Vocational Behavior, 49(1), 38-52.

Ashforth, B. E. (1993). Emotional labor in service roles: the influence of identity. Academy of Management Review, 18(1), 88-115.

Ashforth, B. E., Harrison, S. H., \& Corley, K. G. (2008). Identification in organizations: An examination of four fundamental questions. Journal of Management, 34(3), $325-374$

Ashforth, B. E., \& Kreiner, G. E. (1999). "How can you do it?": Dirty work and the challenge of constructing a positive identity. Academy of Management Review, 24(3), 413-434.

Ashforth, B. E., \& Mael, F. (1989). Social identity theory and the organization. Academy of Management Review, 14(1), 20-39.

Bagozzi, R. P., Bergami, M., Marzocchi, G. L., \& Morandin, G. (2012). Customerorganization relationships: Development and test of a theory of extended identities. Journal of Applied Psychology, 97(1), 63-76.

Bandura, A. (1989). Human agency in social cognitive theory. American Psychologist, 44(9), 1175-1184.

Bandura, A. (1997). Self-efficacy: The exercise of control. New York: Freeman.

Bandura, A. (1999). Moral disengagement in the perpetration of inhumanities. Personality and Social Psychology Review, 3(3), 193-209.

Bartel, C. A. (2001). Social comparisons in boundary-spanning work: effects of 
community outreach on members' organizational identity and identification. Administrative Science Quarterly, 46(3), 379-414.

Bartels, J., Pruyn, A., De Jong, M., \& Joustra, I. (2007). Multiple organizational identification levels and the impact of perceived external prestige and communication climate. Journal of Organizational Behavior, 28(2), 173-190.

Baum, J. R. (1994). The relation of traits, competencies, vision, motivation, and strategy to venture growth. Unpublished doctoral dissertation, University of Maryland, College Park, DC.

Becker, T. E. (2005). Potential problems in the statistical control of variables in organizational research: A qualitative analysis with recommendations. Organizational Research Methods, 8(3), 274-289.

Beech, N. (2008). On the nature of dialogic identity work. Organization, 15(1), 51-74.

Bergami, M., \& Bagozzi, R. P. (2000). Self-categorization, affective commitment and group self-esteem as distinct aspects of social identity in the organization. British Journal of Social Psychology, 39(4), 555-577.

Beyer, J. M., \& Hannah, D. R. (2002). Building on the past: enacting established personal identities in a new work setting. Organization Science, 13(6), 636-652.

Bird, B. (1988). Implementing entrepreneurial ideas: The case for intention. Academy of Management Review, 13(3), 442-453.

Blader, S. L., \& Tyler, T. R. (2009). Testing and extending the group engagement model: linkages between social identity, procedural justice, economic outcomes, and extrarole behavior. Journal of Applied Psychology, 94(2), 445-464.

Blake, R. J., \& Sackett, S. A. (1999). Holland's typology and the five-factor model: A 
rational-empirical analysis. Journal of Career Assessment, 7(3), 249-279.

Boezeman, E. J., \& Ellemers, N. (2007). Volunteering for charity: pride, respect, and the commitment of volunteers. Journal of Applied Psychology, 92(3), 771-785.

Brewer, M. B. (1991). The social self: On being the same and different at the same time. Personality and Social Psychology Bulletin, 17(5), 475-482.

Brewer, M. B., \& Gardner, W. (1996). Who is this " We"? Levels of collective identity and self representations. Journal of Personality and Social Psychology, 71(1), 83.

Brewer, M. B., \& Pierce, K. P. (2005). Social identity complexity and outgroup tolerance. Personality and Social Psychology Bulletin, 31(3), 428-437.

Brickson, S. (2000). The impact of identity orientation on individual and organizational outcomes in demographically diverse settings. Academy of Management Review, 25(1), 82-101.

Briscoe, J. P., Henagan, S. C., Burton, J. P., \& Murphy, W. M. (2012). Coping with an insecure employment environment: The differing roles of protean and boundaryless career orientations. Journal of Vocational Behavior, 80(2), 308-316.

Brockner, J., Houser, R., Birnbaum, G., Lloyd, K., Deitcher, J., Nathanson, S., \& Rubin, J. Z. (1986). Escalation of commitment to an ineffective course of action: the effect of feedback having negative implications for self-identity. Administrative Science Quarterly, 31(1), 109-126.

Brook, A. T., Garcia, J., \& Fleming, M. A. (2008). The effects of multiple identities on psychological well-being. Personality and Social Psychology Bulletin, 34(12), $1588-1600$.

Brooks, L., Cornelius, A., Greenfield, E., \& Joseph, R. (1995). The relation of career- 
related work or internship experiences to the career development of college seniors. Journal of Vocational Behavior, 46(3), 332-349.

Brower, R. S., \& Abolafia, M. Y. (1997). Bureaucratic politics: The view from below. Journal of Public Administration Research and Theory, 7(2), 305-331.

Brown, A. D. (1997). Narcissism, identity, and legitimacy. Academy of Management Review, 22(3), 643-686.

Brown, A. D. (2001). Organization studies and identity: towards a research agenda. Human Relations, 54(1), 113-121.

Brown, A. D., \& Starkey, K. (2000). Organizational identity and learning: a psychodynamic perspective. Academy of Management Review, 25(1), 102-120.

Brown, C., Glastetter-Fender, C., \& Shelton, M. (2000). Psychosocial identity and career control in college student-athletes. Journal of Vocational Behavior, 56(1), 53-62.

Burke, P. J. (2003). Relationships among multiple identities. In P. J. Burke, T. J. Owens, R. T. Serpe, \& P. A. Thoits (Eds.), Advances in identity theory and research, 195214. New York: Kluwer Academic/Plenum.

Burke, P. J. (2004). Identities and social structure: The 2003 Cooley-Mead award address. Social Psychology Quarterly, 67(1), 5-15.

Burke, P. J., \& Reitzes, D. C. (1991). An identity theory approach to commitment. Social Psychology Quarterly, 53(3), 239-251.

Busenitz, L. W., \& Barney, J. B. (1997). Differences between entrepreneurs and managers in large organizations: Biases and heuristics in strategic decisionmaking. Journal of Business Venturing, 12(1), 9-30.

Busenitz, L. W., West, G. P., Shepherd, D., Nelson, T., Chandler, G. N., \& Zacharakis, 
A. (2003). Entrepreneurship research in emergence: Past trends and future directions. Journal of Management, 29(3), 285-308.

Callero, P. L. (1985). Role-identity salience. Social Psychology Quarterly, 48(3), 203215.

Cardon, M. S., Wincent, J., Singh, J., \& Drnovsek, M. (2009). The nature and experience of entrepreneurial passion. Academy of Management Review, 34(3), 511-532.

Cardon, M. S., Zietsma, C., Saparito, P., Matherne, B. P., \& Davis, C. (2005). A tale of passion: New insights into entrepreneurship from a parenthood metaphor. Journal of Business Venturing, 20(1), 23-45.

Carter, N. M., Gartner, W. B., Shaver, K. G., \& Gatewood, E. J. (2003). The career reasons of nascent entrepreneurs. Journal of Business Venturing, 18(1), 13-39.

Carver, C. S., \& Scheier, M. F. (1998). On the self-regulation of behavior. Cambridge: Cambridge University Press.

Cheek, C., \& Jones, R. M. (2001). Identity style and employment histories among women receiving public assistance. Journal of Vocational Behavior, 59(1), 76-88.

Chen, C. C., Greene, P. G., \& Crick, A. (1998). Does entrepreneurial self-efficacy distinguish entrepreneurs from managers? Journal of Business Venturing, 13(4), 295-316.

Chreim, S. (2005). The continuity--change duality in narrative texts of organizational identity. Journal of Management Studies, 42(3), 567-593.

Chreim, S., Williams, B. E., \& Hinings, C. R. (2007). Interlevel influences on the reconstruction of professional role identity. Academy of management Journal, 50(6), 1515-1539. 
Clair, J. A., Beatty, J. E., \& MacLean, T. L. (2005). Out of sight but not out of mind: managing invisible social identities in the workplace. Academy of Management Review, 30(1), 78-95.

Clark, S. M., Gioia, D. A., Ketchen, D. J., \& B. Thomas, J. (2010). Transitional identity as a facilitator of organizational identity change during a merger. Administrative Science Quarterly, 55, 397-438.

Clarke, C. A., Brown, A. D., \& Hailey, V. H. (2009). Working identities? Antagonistic discursive resources and managerial identity. Human Relations, 62(3), 323-352.

Clarysse, B., \& Moray, N. (2004). A process study of entrepreneurial team formation: the case of a research-based spin-off. Journal of Business Venturing, 19(1), 55-79.

Cole, M. S., \& Bruch, H. (2006). Organizational identity strength, identification, and commitment and their relationships to turnover intention: does organizational hierarchy matter? Journal of Organizational Behavior, 27(5), 585-605.

Collins, O. F., \& Moore, D. G. (1964). The enterprising man, (1) Michigan: Michigan State University Press.

Conger, J. A., Kanungo, R. N., \& Menon, S. T. (2000). Charismatic leadership and follower effects. Journal of Organizational Behavior, 21(7), 747-767. .

Cooper, D., \& Thatcher, S. M. B. (2010). Identification in organizations: the role of selfconcept orientations and identification motives. Academy of Management Review, 35(4), 516-538.

Crant, J. M. (2000). Proactive behavior in organizations. Journal of Management, 26(3), $435-462$.

Creed, W. E. D., Dejordy, R., \& Lok, J. (2010). Being the change: resolving institutional 
contradiction through identity work. Academy of management Journal, 53(6), 1336-1364.

Creed, W. E. D., Scully, M. A., \& Austin, J. R. (2002). Clothes make the person? The tailoring of legitimating accounts and the social construction of identity. Organization Science, 13(5), 475-496.

Das, D., Dharwadkar, R., \& Brandes, P. (2008). The importance of being 'Indian': Identity centrality and work outcomes in an off-shored call center in India. Human Relations, 61(11), 1499-1530.

Davidsson, P. (2006). Nascent entrepreneurship: empirical studies and developments. Foundations and Trends in Entrepreneurship, 2(1), 1-76.

Day, D. V., Cross Jr, W. E., Ringseis, E. L., \& Williams, T. L. (1999). Selfcategorization and identity construction associated with managing diversity. Journal of Vocational Behavior, 54(1), 188-195.

Delmestri, G. (2006). Streams of inconsistent institutional influences: Middle managers as carriers of multiple identities. Human Relations, 59(11), 1515-1541.

Detert, J. R., Treviño, L. K., \& Sweitzer, V. L. (2008). Moral disengagement in ethical decision making: A study of antecedents and outcomes. Journal of Applied Psychology, 93(2), 374-391.

Dick, P., \& Nadin, S. (2006). Reproducing gender inequalities? A critique of realist assumptions underpinning personnel selection research and practice. Journal of Occupational and Organizational Psychology, 79(3), 481-498.

Diemer, M. A., \& Blustein, D. L. (2006). Critical consciousness and career development among urban youth. Journal of Vocational Behavior, 68(2), 220-232. 
Dobrev, S. D., \& Barnett, W. P. (2005). Organizational roles and transition to entrepreneurship. Academy of Management Journal, 48(3), 433-449.

Dobrow, S. R., Chandler, D. E., Murphy, W. M., \& Kram, K. E. (2012). A review of developmental networks incorporating a mutuality perspective. Journal of Management, 38(1), 210-242.

Dobrow, S. R., \& Higgins, M. C. (2005). Developmental networks and professional identity: A longitudinal study. Career Development International, 10 (6/7), 567583.

Douglas, E. J., \& Shepherd, D. A. (2002). Self-employment as a career choice: attitudes, entrepreneurial intentions, and utility maximization. Entrepreneurship Theory and Practice, 26(3), 81-90.

Down, S., \& Reveley, J. (2009). Between narration and interaction: Situating first-line supervisor identity work. Human Relations, 62(3), 379-401.

Downing, S. (2005). The social construction of entrepreneurship: Narrative and dramatic processes in the coproduction of organizations and identities. Entrepreneurship Theory and Practice, 29(2), 185-204.

Drori, I., Honig, B., \& Sheaffer, Z. (2009). The life cycle of an internet firm: Scripts, legitimacy, and identity. Entrepreneurship Theory and Practice, 33(3), 715-738.

Dukerich, J. M., Golden, B. R., \& Shortell, S. M. (2002). Beauty is in the eye of the beholder: the impact of organizational identification, identity, and image on the cooperative behaviors of physicians. Administrative Science Quarterly, 47(3), $507-533$.

Dutton, J., Roberts, L. M., \& Bednar, J. (2011). Using a positive lens to complicate the 
positive in identity research. Academy of Management Review, 36(2), 427-431.

Dutton, J. E., \& Dukerich, J. M. (1991). Keeping an eye on the mirror: image and identity in organizational adaptation. Academy of management Journal, 34(3), 517-554.

Dutton, J. E., Dukerich, J. M., \& Harquail, C. V. (1994). Organizational images and member identification. Administrative Science Quarterly, 39 (2), 239-263.

Dutton, J. E., Roberts, L. M., \& Bednar, J. (2010). Pathways for positive identity construction at work: Four types of positive identity and the building of social resources. Academy of Management Review, 35(2), 265-293.

Dyer, J. H., \& Nobeoka, K. (2000). Creating and managing a high-performance knowledge-sharing network: The Toyota case. Strategic Management Journal, 21(3), 345-367.

Dyer, W. G., \& Handler, W. (1994). Entrepreneurship and family business: Exploring the connections. Entrepreneurship Theory and Practice, 19(1), 71-83.

Eddleston, K. A., \& Powell, G. N. (2008). The role of gender identity in explaining sex differences in business owners' career satisfier preferences. Journal of Business Venturing, 23(2), 244-256.

Elsbach, K. D. (2003). Relating physical environment to self-categorizations: Identity threat and affirmation in a non-territorial office space. Administrative Science Quarterly, 48(4), 622-654.

Epitropaki, O. (2013). A multi-level investigation of psychological contract breach and organizational identification through the lens of perceived organizational membership: Testing a moderated-mediated model. Journal of Organizational Behavior, 34(1), 65-86. 
Erikson, E. H. (1959). Identity and the life cycle. Psychological Issues, 1, 1-171.

Ethier, K. A., \& Deaux, K. (1994). Negotiating social identity when contexts change: Maintaining identification and responding to threat. Journal of Personality and Social Psychology, 67(2), 243-251.

Farmer, S. M., \& Aguinis, H. (2005). Accounting for subordinate perceptions of supervisor power: An identity-dependence model. Journal of Applied Psychology, 90(6), 1069-1083.

Farmer, S. M., Tierney, P., \& Kung-McIntyre, K. (2003). Employee creativity in Taiwan: an application of role identity theory. Academy of management Journal, 46(5), 618-630.

Farmer, S. M., \& Van Dyne, L. (2010). The idealized self and the situated self as predictors of employee work behaviors. Journal of Applied Psychology, 95(3), 503-516.

Farmer, S. M., Yao, X., \& Kung-Mcintyre, K. (2011). The behavioral impact of entrepreneur identity aspiration and prior entrepreneurial experience. Entrepreneurship Theory and Practice, 35(2), 245-273.

Fauchart, E., \& Gruber, M. (2011). Darwinians, communitarians, and missionaries: the role of founder identity in entrepreneurship. Academy of Management Journal, 54(5), 935-957.

Fayolle, A., Gailly, B., \& Lassas-Clerc, N. (2006). Effect and counter-effect of entrepreneurship education and social context on student's intentions. Estudios de Economía Aplicada, 24(2), 509-524.

Fearon, J. D., \& Laitin, D. D. (2000). Violence and the social construction of ethnic 
identity. International Organization, 54(4), 845-877.

Feldman, S. D. 1979. Nested identities. In N. K. Denzin (Ed.), Studies in symbolic interaction, (2), 399-418. Greenwich, CT: JAI Press.

Fillis, I., \& Rentschler, R. (2010). The role of creativity in entrepreneurship. Journal of Enterprising Culture, 18(01), 49-81.

Flum, H., \& Blustein, D. L. (2000). Reinvigorating the study of vocational exploration: A framework for research. Journal of Vocational Behavior, 56(3), 380-404.

Flum, H., \& Kaplan, A. (2006). Exploratory orientation as an educational goal. Educational Psychologist, 41(2), 99-110.

Fornell, C., \& Larcker, D. F. (1981). Evaluating structural equation models with unobservable variables and measurement error. Journal of Marketing Research, 18, 39-50.

Fugate, M., Kinicki, A. J., \& Ashforth, B. E. (2004). Employability: A psycho-social construct, its dimensions, and applications. Journal of Vocational Behavior, 65(1), 14-38.

Gabriel, Y. (1999). Beyond happy families: A critical reevaluation of the controlresistance-identity triangle. Human Relations, 52(2), 179-203.

Gartner, W. B. (1988). "Who is an entrepreneur?" is the wrong question. American Journal of Small Business, 12(4), 11-32.

Gelfand, M. J., Major, V. S., Raver, J. L., Nishii, L. H., \& O'Brien, K. (2006). Negotiating relationally: The dynamics of the relational self in negotiations. Academy of Management Review, 31(2), 427-451.

Gianakos, I. (1995). The relation of sex role identity to career decision-making self- 
efficacy. Journal of Vocational Behavior, 46(2), 131-143.

Giddens, A. (1991). Modernity and self-identity. Oxford: Polity Press.

Giessner, S. R., \& van Knippenberg, D. (2008). "License to fail": Goal definition, leader group prototypicality, and perceptions of leadership effectiveness after leader failure. Organizational Behavior and Human Decision Processes, 105(1), 14-35.

Gino, F., Schweitzer, M. E., Mead, N. L., \& Ariely, D. (2011). Unable to resist temptation: How self-control depletion promotes unethical behavior. Organizational Behavior and Human Decision Processes, 115(2), 191-203.

Gioia, D. A., Price, K. N., Hamilton, A. L., \& Thomas, J. B. (2010). Forging an identity: An insider-outsider study of processes involved in the formation of organizational identity. Administrative Science Quarterly, 55(1), 1-46.

Gioia, D. A., \& Thomas, J. B. (1996). Identity, image, and issue interpretation: Sensemaking during strategic change in academia. Administrative Science Quarterly, 41(3), 370-403.

Goldberg, C. B., Riordan, C., \& Schaffer, B. S. (2010). Does social identity theory underlie relational demography? A test of the moderating effects of uncertainty reduction and status enhancement on similarity effects. Human Relations, 63(7), 903-926.

Goldberg, L. R. (1990). An alternative" description of personality": the big-five factor structure. Journal of Personality and Social Psychology, 59(6), 1216-1229.

Goldberg, L. R. (1992). The development of markers for the Big-Five factor structure. Psychological Assessment, 4(1), 26-42.

Golden-Biddle, K., \& Rao, H. (1997). Breaches in the boardroom: Organizational 
identity and conflicts of commitment in a nonprofit organization. Organization Science, 8(6), 593-611.

Gonzalez, J. A., \& Denisi, A. S. (2009). Cross-level effects of demography and diversity climate on organizational attachment and firm effectiveness. Journal of Organizational Behavior, 30(1), 21-40.

Gore, J. S., Cross, S. E., \& Kanagawa, C. (2009). Acting in our interests: Relational selfconstrual and goal motivation across cultures. Motivation and Emotion, 33(1), 7587.

Gouldner, A. W. (1957). Cosmopolitans and locals: toward an analysis of latent social roles. Administrative Science Quarterly, 281-306.

Grant, A. M., Dutton, J. E., \& Rosso, B. D. (2008). Giving commitment: employee support programs and the prosocial sensemaking process. Academy of management Journal, 51(5), 898-918.

Greenhaus, J. H., Peng, A. C., \& Allen, T. D. (2012). Relations of work identity, family identity, situational demands, and sex with employee work hours. Journal of Vocational Behavior, 80(1), 27-37.

Grégoire, D., \& Shepherd, D. (2012). Technology-market combinations and the identification of entrepreneurial opportunities: An investigation of the opportunity-individual nexus. Academy of management Journal, 55(4), 753-785.

Grégoire, D. A., Noel, M. X., Déry, R., \& Béchard, J. P. (2006). Is there conceptual convergence in entrepreneurship research? A co-citation analysis of frontiers of entrepreneurship research, 1981-2004. Entrepreneurship Theory and Practice, 30(3), 333-373. 
Griepentrog, B. K., Harold, C. M., Holtz, B. C., Klimoski, R. J., \& Marsh, S. M. (2012). Integrating social identity and the theory of planned behavior: predicting withdrawal from an organizational recruitment process. Personnel Psychology, 65(4), 723-753.

Grote, G., \& Raeder, S. (2009). Careers and identity in flexible working: Do flexible identities fare better? Human Relations, 62(2), 219-244.

Grube, J. A., \& Piliavin, J. A. (2000). Role identity, organizational experiences, and volunteer performance. Personality and Social Psychology Bulletin, 26(9), 11081119.

Gushue, G. V. (2006). The relationship of ethnic identity, career decision-making selfefficacy and outcome expectations among Latino/a high school students. Journal of Vocational Behavior, 68(1), 85-95.

Hackman, J. R., \& Oldham, G. R. (1976). Motivation through the Design of Work: Test of a Theory. Organizational Behavior \& Human Performance, 16, 250-279.

Hair Jr, J., Anderson, R. E., Tatham, R. L., \& Black, W. (2005). Multivariate data analysis, (2 $2^{\text {nd }}$ Indian reprint). Delhi: Pearson.

Hargrove, B. K., Creagh, M. G., \& Burgess, B. L. (2002). Family interaction patterns as predictors of vocational identity and career decision-making self-efficacy. Journal of Vocational Behavior, 61(2), 185-201.

Haslam, S. A., \& Ellemers, N. (2005). Social identity in industrial and organizational psychology: Concepts, controversies and contributions. International Review of Industrial and Organizational Psychology, 20(1), 39-118.

Haslam, S. A., \& Platow, M. J. (2001). The link between leadership and followership: 
How affirming social identity translates vision into action. Personality and Social Psychology Bulletin, 27(11), 1469-1479.

Haslam, S. A., \& Reicher, S. (2006). Stressing the group: Social identity and the unfolding dynamics of responses to stress. Journal of Applied Psychology, 91(5), 1037-1052.

Hekman, D. R., Bigley, G. A., Steensma, H. K., \& Hereford, J. F. (2009). Combined effects of organizational and professional identification on the reciprocity dynamic for professional employees. Academy of Management Journal, 52(3), 506-526.

Higgins, E. T. (1998). Promotion and prevention: Regulatory focus as a motivational principle. Advances in Experimental Social Psychology, 30, 1-46.

Hirst, G., Van Dick, R., \& Van Knippenberg, D. (2009). A social identity perspective on leadership and employee creativity. Journal of Organizational Behavior, 30(7), 963-982.

Hitlin, S. (2003). Values as the core of personal identity: Drawing links between two theories of self. Social Psychology Quarterly, 66(2)118-137.

Hoang, H., \& Gimeno, J. (2010). Becoming a founder: How founder role identity affects entrepreneurial transitions and persistence in founding. Journal of Business Venturing, 25(1), 41-53.

Hoekstra, H. A. (2011). A career roles model of career development. Journal of Vocational Behavior, 78(2), 159-173.

Hogan, R., \& Blake, R. (1999). John Holland's vocational typology and personality theory. Journal of Vocational Behavior, 55(1), 41-56. 
Hogg, M. A., \& Terry, D. J. (2000). The beauty of and barriers to organizational theories of identity. Academy of Management Review, 25(1), 141-143.

Hogg, M. A., Terry, D. J., \& White, K. M. (1995). A tale of two theories: A critical comparison of identity theory with social identity theory. Social Psychology Quarterly, 58(4), 255-269.

Holland, J. L., Gottfredson, D. C., \& Power, P. G. (1980). Some diagnostic scales for research in decision making and personality: Identity, information, and barriers. Journal of Personality and Social Psychology, 39, 1191-1200.

Holmvall, C. M., \& Bobocel, D. R. (2008). What fair procedures say about me: Selfconstruals and reactions to procedural fairness. Organizational Behavior and Human Decision Processes, 105(2), 147-168.

Honeycutt, T. L., \& Rosen, B. (1997). Family friendly human resource policies, salary levels, and salient identity as predictors of organizational attraction. Journal of Vocational Behavior, 50(2), 271-290.

Hyytinen, A., \& Maliranta, M. (2008). When Do Employees Leave Their Job for Entrepreneurship? The Scandinavian Journal of Economics, 110(1), 1-21.

Ibarra, H. (1999). Provisional selves: experimenting with image and identity in professional adaptation. Administrative Science Quarterly, 44(4), 764-791.

Ireland, R. D., \& Webb, J. W. (2007). A cross-disciplinary exploration of entrepreneurship research. Journal of Management, 33(6), 891-927.

Jackson, C. C., \& Neville, H. A. (1998). Influence of racial identity attitudes on African American college students' vocational identity and hope. Journal of Vocational Behavior, 53(1), 97-113. 
Jehn, K. A., \& Bezrukova, K. (2010). The faultline activation process and the effects of activated faultlines on coalition formation, conflict, and group outcomes. Organizational Behavior and Human Decision Processes, 112(1), 24-42.

Jensen, S. M., \& Luthans, F. (2006). Entrepreneurs as authentic leaders: impact on employees' attitudes. Leadership \& Organization Development Journal, 27(8), 646-666.

Johnson, M. D., Morgeson, F. P., \& Hekman, D. R. (2012). Cognitive and affective identification: Exploring the links between different forms of social identification and personality with work attitudes and behavior. Journal of Organizational Behavior, 33(8), 1142-1167.

Johnson, R. E., Venus, M., Lanaj, K., Mao, C., \& Chang, C.-H. (2012). Leader identity as an antecedent of the frequency and consistency of transformational, consideration, and abusive leadership behaviors. Journal of Applied Psychology, 97(6), 1262.

Johnson, R. E., Chang, C.-H., \& Yang, L.-Q. (2010). Commitment and motivation at work: The relevance of employee identity and regulatory focus. Academy of Management Review, 35(2), 226-245.

Johnson, R. E., \& Lord, R. G. (2010). Implicit effects of justice on self-identity. Journal of Applied Psychology, 95(4), 681-695.

Jones, C., \& Volpe, E. H. (2011). Organizational identification: Extending our understanding of social identities through social networks. Journal of Organizational Behavior, 32(3), 413-434.

Jöreskog, K. G., \& Sörbom, D. (1996). LISREL 8 user's reference guide. Chicago: Scientific Software International Inc. 
Lieblich, A., \& Josselson, R. (1997). The narrative study of lives. Newbury Park, CA: Sage.

Kaplan, S. N., Sensoy, B. A., \& Strömberg, P. (2009). Should investors bet on the jockey or the horse? Evidence from the evolution of firms from early business plans to public companies. The Journal of Finance, 64(1), 75-115.

Keenoy, T., Ybema, S., Oswick, C., Sabelis, I., Ellis, N., \& Beverungen, A. (2007). Human Relations special issue call for papers: Constructing identity in organizations. Human Relations,60(2), 395-397.

Kemelgor, B., \& Poudel, K. (2009). Do you care about anything else other than how much you get? A look at the employee valence factor for non-financial and financially unconvertible rewards in entrepreneurial and non entrepreneurial firms. Frontiers of Entrepreneurship Research, 29(10), 1.

Kickul, J., Gundry, L. K., Barbosa, S. D., \& Whitcanack, L. (2009). Intuition versus analysis? testing differential models of cognitive style on entrepreneurial Self-Efficacy and the new venture creation process. Entrepreneurship Theory and Practice, 33(2), 439-453.

Kirkman B.L., Chen G., Farh J.L., Chen Z. X., Lowe K.B. (2009). Individual power distance orientation and follower reactions to transformational leaders: A crosslevel, cross-cultural examination. Academy of Management Journal, 52(4), $744-764$.

Kirzner, I. M. (1999). Creativity and/or alertness: A reconsideration of the Schumpeterian entrepreneur. The Review of Austrian Economics, 11(1), 5-17.

Kirzner, I. M. (2009). The alert and creative entrepreneur: a clarification. Small Business 
Economics, 32(2), 145-152.

Klein, S. B. (2008). Commentary and Extension: Moderating the Outcome of Identity Confirmation in Family Firms. Entrepreneurship Theory and Practice, 32(6), 1083-1088.

Klepper, S., \& Sleeper, S. (2005). Entry by spinoffs. Management Science, 51(8), 12911306.

Kline, R. B. (2005). Principles and practice of structural equation modeling. New York: Guilford.

Knight, F. H. (1957). Risk, uncertainty and profit. New York: Kelley \& Millman.

Kornberger, M., \& Brown, A. D. (2007). `Ethics' as a discursive resource for identity work. Human Relations, 60(3), 497-518.

Kosmala, K., \& Herrbach, O. (2006). The ambivalence of professional identity: On cynicism and jouissance in audit firms. Human Relations, 59(10), 1393-1428.

Kreiner, G. E., \& Ashforth, B. E. (2004). Evidence toward an expanded model of organizational identification. Journal of Organizational Behavior, 25(1), 1-27.

Kreiner, G. E., Ashforth, B. E., \& Sluss, D. M. (2006). Identity Dynamics in Occupational Dirty Work: Integrating Social Identity and System Justification Perspectives. Organization Science, 17(5), 619-636.

Kreiner, G. E., Hollensbe, E. C., \& Sheep, M. L. (2006). On the edge of identity: Boundary dynamics at the interface of individual and organizational identities. Human Relations, 59(10), 1315-1341.

Krueger Jr, N. F., Reilly, M. D., \& Carsrud, A. L. (2000). Competing models of entrepreneurial intentions. Journal of Business Venturing, 15(5), 411-432. 
Krueger, N. F., \& Carsrud, A. L. (1993). Entrepreneurial intentions: applying the theory of planned behaviour. Entrepreneurship \& Regional Development, 5(4), 315-330.

Kunda, G. (2009). Engineering culture: Control and commitment in a high-tech corporation. Philadelphia: Temple University Press.

Lang, J. C., \& Lee, C. H. (2005). Identity accumulation, others' acceptance, job-search self-efficacy, and stress. Journal of Organizational Behavior, 26(3), 293-312.

Lazear, EP (2005), 'Entrepreneurship', Journal of Labor Economics, 23(4), 649-680.

LeBoeuf, R. A., Shafir, E., \& Bayuk, J. B. (2010). The conflicting choices of alternating selves. Organizational Behavior and Human Decision Processes, 111(1), 48-61.

Leech, N. L., \& Onwuegbuzie, A. J. (2002, November). A call for greater use of nonparametric statistics. Paper presented at the annual meeting of the Mid-South Educational Research Association, Chattanooga, TN.

Leonard, N. H., Beauvais, L. L., \& Scholl, R. W. (1999). Work motivation: The incorporation of self-concept-based processes. Human Relations, 52(8), 969-998.

Liñán, F., \& Chen, Y. W. (2009). Development and Cross-Cultural application of a specific instrument to measure entrepreneurial intentions. Entrepreneurship Theory and Practice, 33(3), 593-617.

Little, T. D., Cunningham, W. A., Shahar, G., \& Widaman, K. F. (2002). To parcel or not to parcel: Exploring the question, weighing the merits. Structural Equation Modeling, 9, 151-173.

Lobel, S. A., \& St. Clair, L. (1992). Research notes. Effects of family responsibilities, gender, and career identity salience on performance outcomes. Academy of management Journal, 35(5), 1057-1069. 
London, M. (1993). Relationships between career motivation, empowerment and support for career development. Journal of Occupational and Organizational Psychology, 66(1), 55-69.

Lounsbury, M., \& Glynn, M. A. (2001). Cultural entrepreneurship: Stories, legitimacy, and the acquisition of resources. Strategic Management Journal, 22(6), 545-564.

Lukas B.A., Tan J.J., Hult G.T.M. (2001). Strategic fit in transitional economies: The case of China's electronics industry. Journal of Management, 27(4), 409-429.

MacKenzie, S. B., Podsakoff, P. M., \& Podsakoff, N. P. (2011). Construct measurement and validation procedures in MIS and behavioral research: Integrating new and existing techniques. MIS Quarterly, 35(2), 293-334.

Mael, F., \& Ashforth, B. E. (1992). Alumni and their alma mater: A partial test of the reformulated model of organizational identification. Journal of Organizational Behavior, 13(2), 103-123.

March, J. G., \& Simon, H. A. (1958). Organizations. New York: Wiley

Marco, C. D., Hartung, P. J., Newman, I., \& Parr, P. (2003). Validity of the decisional process inventory. Journal of Vocational Behavior, 63(1), 1-19.

Markman, G. D., Balkin, D. B., \& Baron, R. A. (2002). Inventors and new venture formation: The effects of general self-efficacy and regretful thinking. Entrepreneurship Theory and Practice, 27(2), 149-165.

Markman, G. D., \& Baron, R. A. (2003). Person-entrepreneurship fit: why some people are more successful as entrepreneurs than others. Human Resource Management Review, 13(2), 281-301.

Markus, H., \& Nurius, P. (1986). Possible selves. American Psychologist, 41(9), 954. 
Markus, H. \& Nurius, P. (1987). Possible selves: The interface between motivation and the self-concept. In K. Yardley \& T. Honess (Eds.), Self and identity: Psychosocial perspectives, 157-172. New York: Wiley.

Markus, H., \& Wurf, E. (1987). The dynamic self-concept: A social psychological perspective. Annual Review of Psychology, 38(1), 299-337.

Martens, M. L., Jennings, J. E., \& Jennings, P. D. (2007). Do the stories they tell get them the money they need? The role of entrepreneurial narratives in resource acquisition. Academy of Management Journal, 50(5), 1107-1132.

Mayer, D. M., Greenbaum, R. L., Shteynberg, G., \& Kuenzi, M. (2009). When do fair procedures not matter? A test of the identity violation effect. Journal of Applied Psychology, 94(1), 142-161.

McArdle, S., Waters, L., Briscoe, J. P., \& Hall, D. T. (2007). Employability during unemployment: Adaptability, career identity and human and social capital. Journal of Vocational Behavior, 71(2), 247-264.

McMullen, J. S., \& Shepherd, D. A. (2006). Entrepreneurial action and the role of uncertainty in the theory of the entrepreneur. Academy of Management Review, 31(1), 132-152.

Miller, D., \& Le Breton-Miller, I. (2011). Governance, social identity, and entrepreneurial orientation in closely held public companies. Entrepreneurship Theory and Practice, 35(5), 1051-1076.

Miller, T. L., \& Wesley Ii, C. L. (2010). Assessing mission and resources for social change: an organizational identity perspective on social venture capitalists' decision criteria. Entrepreneurship Theory and Practice, 34(4), 705-733. 
Milton, L. P. (2008). Unleashing the relationship power of family firms: Identity confirmation as a catalyst for performance. Entrepreneurship Theory and Practice, 32(6), 1063-1081.

Milton, L. P., \& Westphal, J. D. (2005). Identity confirmation networks and cooperation in work groups. Academy of Management Journal, 48(2), 191-212.

Mitchell, J. R., \& Shepherd, D. A. (2010). To thine own self be true: Images of self, images of opportunity, and entrepreneurial action. Journal of Business Venturing, 25(1), 138-154.

Mitteness, C. R., Baucus, M. S., \& Sudek, R. (2012). Horse vs. Jockey? How stage of funding process and industry experience affect the evaluations of angel investors. Venture Capital, 14(4), 241-267.

Moss, T. W., Short, J. C., Payne, G. T., \& Lumpkin, G. T. (2011). Dual identities in social ventures: An exploratory study. Entrepreneurship Theory and Practice, 35(4), 805-830.

Mullen, B., Migdal, M. J., \& Rozell, D. (2003). Self-awareness, deindividuation, and social identity: Unraveling theoretical paradoxes by filling empirical lacunae. Personality and Social Psychology Bulletin, 29(9), 1071-1081.

Murnieks, C. Y. (2007). Who am I? The quest for an entrepreneurial identity and an investigation of its relationship to entrepreneurial passion and goal-setting. Unpublished doctoral dissertation, University of Colorado, Colorado.

Murnieks, C. Y., \& Mosakowski, E. M. (2007). Who am I? Looking inside the “entrepreneurial identity”. Frontiers of Entrepreneurship Research, 27(5), 5.

Nanda, R., \& Sørensen, J. B. (2010). Workplace peers and entrepreneurship. 
Management Science, 56(7), 1116-1126.

Navis, C., \& Glynn, M. A. (2010). How new market categories emerge: Temporal dynamics of legitimacy, identity, and entrepreneurship in satellite radio, 19902005. Administrative Science Quarterly, 55(3), 439.

Navis, C., \& Glynn, M. A. (2011). Legitimate distinctiveness and the entrepreneurial identity: Influence on investor judgments of new venture plausibility. Academy of Management Review, 36(3), 479-499.

Netemeyer, R. G., Johnston, M. W., \& Burton, S. (1990). Analysis of role conflict and role ambiguity in a structural equations framework. Journal of Applied Psychology, 75(2), 148-157.

Nielsen, S. L., \& Lassen, A. H. (2012). Identity in entrepreneurship effectuation theory: a supplementary framework. International Entrepreneurship and Management Journal, 8(3), 373-389.

Nunnally, J. C. (1978). Psychometric theory. New York: McGraw-Hill.

Obschonka, M., Goethner, M., Silbereisen, R. K., \& Cantner, U. (2012). Social identity and the transition to entrepreneurship: The role of group identification with workplace peers. Journal of Vocational Behavior, 80(1), 137-147.

Olkkonen, M.-E., \& Lipponen, J. (2006). Relationships between organizational justice, identification with organization and work unit, and group-related outcomes. Organizational Behavior and Human Decision Processes, 100(2), 202-215.

O'Neil, I., \& Ucbasaran, D. (2010). Individual identity and sustainable entrepreneurship: The role of authenticity. Paper presented at the London Institute of Small Business \& Entrepreneurship Conference. 
Onwuegbuzie, A. J., \& Collins, K. M. (2007). A Typology of Mixed Methods Sampling Designs in Social Science Research. Qualitative Report, 12(2), 281-316.

Parker, S. C. (2009). The economics of entrepreneurship. Cambridge: Cambridge University Press.

Parasuraman, S., Purohit, Y. S., Godshalk, V. M., \& Beutell, N. J. (1996). Work and family variables, entrepreneurial career success, and psychological well-being. Journal of Vocational Behavior, 48(3), 275-300.

Patel, P. C., \& Fiet, J. O. (2009). Systematic search and its relationship to firm founding. Entrepreneurship Theory and Practice, 33(2), 501-526.

Pessar, P. R. (1995). The elusive enclave: Ethnicity, class, and nationality among Latino entrepreneurs in greater Washington, DC. Human Organization, 54(4), 383-392.

Podsakoff, P. M., MacKenzie, S. B., Lee, J. Y., \& Podsakoff, N. P. (2003). Common method biases in behavioral research: A critical review of the literature and recommended remedies. Journal of Applied Psychology, 88(5), 879-903.

Postmes, T., \& Jetten, J. (2006). Reconciling individuality and the group. In T. Postmes \& J. Jetten (Eds.), Individuality and the group: Advances in social identity, 258269. London: Sage.

Poudel, K. P., Carter, R., \& Lonial, S. (2012). The process aspect of entrepreneurial orientation-performance relationship: Uncovering the mediating roles of technological capabilities, innovation and firm growth. Frontiers of Entrepreneurship Research, 32(12), 3.

Pratt, M. G., \& Foreman, P. O. (2000). Classifying managerial responses to multiple organizational identities. Academy of Management Review, 25(1), 18-42. 
Pratt, M. G., Rockmann, K. W., \& Kaufmann, J. B. (2006). Constructing professional identity: the role of work and identity learning cycles in the customization of identity among medical residents. Academy of management Journal, 49(2), 235262.

Randel, A. E., \& Jaussi, K. S. (2003). Functional background identity, diversity, and individual performance in cross-functional teams. Academy of management Journal, 46(6), 763-774.

Raykov, T. (1997). Scale reliability, Cronbach's coefficient alpha, and violations of essential tau-equivalence with fixed congeneric components. Multivariate Behavioral Research, 32(4), 329-353.

Reynolds, S. J., \& Ceranic, T. L. (2007). The effects of moral judgment and moral identity on moral behavior: An empirical examination of the moral individual. Journal of Applied Psychology, 92(6), 1610-1624.

Richardson, M. S., Meade, P., Rosbruch, N., Vescio, C., Price, L., \& Cordero, A. (2009). Intentional and identity processes: A social constructionist investigation using student journals. Journal of Vocational Behavior, 74(1), 63-74.

Richter, A. W., West, M. A., Van Dick, R., \& Dawson, J. F. (2006). Boundary spanners' identification, intergroup contact, and effective intergroup relations. Academy of Management Journal, 49(6), 1252-1269.

Roberts, B. W., \& DelVecchio, W. F. (2000). The rank-order consistency of personality traits from childhood to old age: a quantitative review of longitudinal studies. Psychological Bulletin, 126(1), 3.

Roccas, S., \& Brewer, M. B. (2002). Social identity complexity. Personality and Social 
Psychology Review, 6(2), 88-106.

Rothbard, N. P., \& Edwards, J. R. (2003). Investment in work and family roles: A test of identity and utilitarian motives. Personnel Psychology, 56(3), 699-729.

Ruef, M., Aldrich, H. E., \& Carter, N. M. (2003). The structure of founding teams: Homophily, strong ties, and isolation among US entrepreneurs. American Sociological Review, 68(2), 195-222.

Ryder, A. G., Alden, L. E., \& Paulhus, D. L. (2000). Is acculturation unidimensional or bidimensional? A head-to-head comparison in the prediction of personality, selfidentity, and adjustment. Journal of Personality and Social Psychology, 79(1), 49.

Sarasvathy, S. D. (2001). Causation and effectuation: Toward a theoretical shift from economic inevitability to entrepreneurial contingency. Academy of Management Review, 26(2), 243.

Savickas, M. L., Nota, L., Rossier, J., Dauwalder, J.-P., Duarte, M. E., Guichard, J., Soresi, S., Esbroeck, R. V., van Vianen, A. E. M. (2009). Life designing: A paradigm for career construction in the 21st century. Journal of Vocational Behavior, 75(3), 239-250.

Schmitt-Rodermund, E., \& Vondracek, F. W. (1999). Breadth of interests, exploration, and identity development in adolescence. Journal of Vocational Behavior, 55(3), 298-317.

Schumpeter, J. A. (1934). The theory of economic development: An inquiry into profits, capital, credit, interest, and the business cycle. Cambridge, MA: Harvard University Press.

Shane, S., Locke, E. A., \& Collins, C. J. (2003). Entrepreneurial motivation. Human 
Resource Management Review, 13(2), 257-279.

Shane, S., \& Venkataraman, S. (2000). The promise of entrepreneurship as a field of research. Academy of Management Review, 25(1), 217-226.

Shane, S. A. (2003). A general theory of entrepreneurship: The individual-opportunity nexus. MA: Edward Elgar Publishing.

Sheldon, K. M., Ryan, R. M., Rawsthorne, L. J., \& Ilardi, B. (1997). Trait self and true self: Cross-role variation in the Big-Five personality traits and its relations with psychological authenticity and subjective well-being. Journal of Personality and Social Psychology, 73(6), 1380.

Shepherd, D. A. (2003). Learning from business failure: Propositions of grief recovery for the self-employed. Academy of Management Review, 28(2), 318-328.

Shepherd, D. A. (2004). Educating entrepreneurship students about emotion and learning from failure. Academy of Management Learning \& Education, 3(3), 274-287.

Shepherd, D., \& Haynie, J. M. (2009). Family business, identity conflict, and an expedited entrepreneurial process: A process of resolving identity conflict. Entrepreneurship Theory and Practice, 33(6), 1245-1264.

Shepherd, D., \& Haynie, J. M. (2009). Birds of a feather don't always flock together: Identity management in entrepreneurship. Journal of Business Venturing, 24(4), 316-337.

Shepherd, D. A., Wiklund, J., \& Haynie, J. M. (2009). Moving forward: Balancing the financial and emotional costs of business failure. Journal of Business Venturing, 24(2), 134-148.

Shook, C. L., Ketchen, D. J., Hult, G. T. M., \& Kacmar, K. M. (2004). An assessment of 203 
the use of structural equation modeling in strategic management research. Strategic Management Journal, 25(4), 397-404.

Shook, C. L., Priem, R. L., \& McGee, J. E. (2003). Venture creation and the enterprising individual: a review and synthesis. Journal of Management, 29(3), 379-399.

Silva, O. (2007). The Jack-of-All-Trades entrepreneur: Innate talent or acquired skill? Economics Letters, 97(2), 118-123.

Singelis, T. M. (1994). The measurement of independent and interdependent selfconstruals. Personality and Social Psychology Bulletin, 20(5), 580-591.

Souitaris, V., Zerbinati, S., \& Al-Laham, A. (2007). Do entrepreneurship programmes raise entrepreneurial intention of science and engineering students? The effect of learning, inspiration and resources. Journal of Business Venturing, 22(4), 566591.

Stam, W., \& Elfring, T. (2008). Entrepreneurial orientation and new venture performance: the moderating role of intra- and extraindustry social capital. Academy of Management Journal, 51(1), 97-111.

Stets, J. E., \& Burke, P. J. (2000). Identity theory and social identity theory. Social Psychology Quarterly, 26(3), 224-237.

Stinchcombe, A. 1965. Social structure and organizations. In J. March (Ed.), Handbook of organizations, 260-290. Chicago: Rand McNally.

Stryker, S. (2007). Identity theory and personality theory: Mutual relevance. Journal of Personality, 75(6), 1083-1102.

Stryker, S., \& Burke, P. J. (2000). The past, present, and future of an identity theory. Social Psychology Quarterly, 63(3), 284-297. 
Stryker, S., \& Serpe, R. (1982). Commitment, identity salience, and role behavior: Theory and research example. In W. Ickers \& E. Knowles (Eds.), Personality, roles and social behavior, 199-219. New York: Springer-Verlag.

Sundaramurthy, C., \& Kreiner, G. E. (2008). Governing by managing identity boundaries: The case of family businesses. Entrepreneurship Theory and Practice, 32(3), 415-436.

Sveningsson, S., \& Alvesson, M. (2003). Managing managerial identities: Organizational fragmentation, discourse and identity struggle. Human Relations, 56(10), 11631193.

Swann Jr, W. B., Gómez, A., Seyle, D. C., Morales, J., \& Huici, C. (2009). Identity fusion: The interplay of personal and social identities in extreme group behavior. Journal of Personality and Social Psychology, 96(5), 995-1011.

Tajfel, H. 1978. Social categorization, social identity and social comparison. In H. Tajfel (Ed.), Differentiation between social groups: Studies in the social psychology of intergroup relations, 61-76. London: Academic Press.

Tajfel, H. (2010). Social identity and intergroup relations (Vol. 7) Cambridge: Cambridge University Press.

Tajfel, H., \& Turner, J. C. (1979). An integrative theory of intergroup conflict. In W. G. Austin \& S. Worchel (Eds.), The social psychology of group relations, 33-47. Monterey, CA: Brooks-Cole.

Tajfel, H., \& Turner, J. C. 1986. The social identity theory of intergroup behavior. In S. Worchel \& W. G. Austin (Eds.), Psychology of intergroup relations, ( $2^{\text {nd }}$ edition), 7-24. Chicago: Nelson-Hall. 
Thatcher, S. M. B., \& Zhu, X. (2006). Changing identities in a changing workplace: identification, identity enactment, self-verification, and telecommuting. Academy of Management Review, 31(4), 1076-1088.

Thompson, M. N., \& Dahling, J. J. (2010). Image theory and career aspirations: Indirect and interactive effects of status-related variables. Journal of Vocational Behavior, 77(1), 21-29.

Thornborrow, T., \& Brown, A. D. (2009). 'Being regimented': Aspiration, discipline and identity work in the British parachute regiment. Organization Studies, 30(4), 355376.

Tiedeman, D. V. (1961). Decision and vocational development: A paradigm and its implications. Personnel and Guidance Journal, 40, 15-21

Tierney, P., \& Farmer, S. M. (2011). Creative self-efficacy development and creative performance over time. Journal of Applied Psychology, 96(2), 277-293.

Ucbasaran, D., Lockett, A., Wright, M., \& Westhead, P. (2003). Entrepreneurial founder teams: Factors associated with member entry and exit. Entrepreneurship Theory and Practice, 28(2), 107-128.

van Dick, R., van Knippenberg, D., Kerschreiter, R., Hertel, G., \& Wieseke, J. (2008). Interactive effects of work group and organizational identification on job satisfaction and extra-role behavior. Journal of Vocational Behavior, 72(3), 388399.

Van Knippenberg, B., Martin, L., \& Tyler, T. (2006). Process-orientation versus outcome-orientation during organizational change: the role of organizational identification. Journal of Organizational Behavior, 27(6), 685-704. 
Van Stel, A., Carree, M., \& Thurik, R. (2005). The effect of entrepreneurial activity on national economic growth. Small Business Economics, 24(3), 311-321.

Vondracek, F. W., Schulenberg, J., Skorikov, V, Gillespie, L. K., \& Wahlheim, C. (1995). The relationship of identity status to career indecision during adolescence. Journal of Adolescence, 18, 17-29.

Von Graevenitz, G., Harhoff, D., \& Weber, R. (2010). The effects of entrepreneurship education. Journal of Economic Behavior \& Organization, 76(1), 90-112.

Waterman, A. S., \& Waterman, C. K. (1976). Factors related to vocational identity after extensive work experience. Journal of Applied Psychology, 61(3), 336-340.

Whetten, D. A. (1989). What constitutes a theoretical contribution? Academy of Management Review, 14(4), 490-495.

Whitbourne, S. K. (1986). Openness to experience, identity flexibility, and life change in adults. Journal of Personality and Social Psychology, 50(1), 163-168.

Wilson, F., Kickul, J., \& Marlino, D. (2007). Gender, entrepreneurial Self-Efficacy, and entrepreneurial career intentions: Implications for entrepreneurship Education1. Entrepreneurship Theory and Practice, 31(3), 387-406.

Wong, P. K., Ho, Y. P., \& Autio, E. (2005). Entrepreneurship, innovation and economic growth: Evidence from GEM data. Small Business Economics, 24(3), 335-350.

World Economic Forum. (2011). Unlocking Entrepreneurial Capabilities to Meet the Global Challenges of the 21st Century (A report). Retrieved from http://www3.weforum.org/docs/WEF_GEI_UnlockingEntrepreneurialCapabilities _Report_2011.pdf

Worthington, R. L., \& Whittaker, T. A. (2006). Scale Development Research: A Content 
Analysis and Recommendations for Best Practices. The Counseling Psychologist, 34(6), 806-838.

Wright, M., Robbie, K., \& Ennew, C. (1997). Serial entrepreneurs. British Journal of Management, 8(3), 251-268.

Zacharakis, A. L., Meyer, G. D., \& De Castro, J. (1999). Differing perceptions of new venture failure: a matched exploratory study of venture capitalists and entrepreneurs. Journal of Small Business Management, 37(3), 1-14.

Zellweger, T. M., Nason, R. S., Nordqvist, M., \& Brush, C. G. (2013). Why do family firms strive for nonfinancial goals? An organizational identity perspective. Entrepreneurship Theory and Practice, 37(2), 229-248.

Zhao, H., \& Seibert, S. E. (2006). The big five personality dimensions and entrepreneurial status: a meta-analytical review. Journal of Applied Psychology, 91(2), 259-271.

Zhao, H., Seibert, S. E., \& Hills, G. E. (2005). The mediating role of self-efficacy in the development of entrepreneurial intentions. Journal of Applied Psychology, 90(6), $1265-1272$.

Zhao, H., Seibert, S. E., \& Lumpkin, G. T. (2010). The relationship of personality to entrepreneurial intentions and performance: A meta-analytic review. Journal of Management, 36(2), 381-404.

Zimmermann, A., \& Ravishankar, M. N. (2011). Collaborative IT offshoring relationships and professional role identities: Reflections from a field study. Journal of Vocational Behavior, 78(3), 351-360. 


\section{APPENDIX}

\section{Extraversion}

For the following set of questions, describe yourself as you generally are now, not as you wish to be in the future using the following 1-5 scale.

a. I am the life of the party.

b. I don't talk a lot.

c. I feel comfortable around people.

d. I keep in the background.

e. I start conversations.

f. I have little to say.

g. I talk to a lot of different people at parties.

h. I don't like to draw attention to myself.

i. I don't mind being the center of attention.

$\mathrm{k}$. I am quiet around strangers.

\section{Imagination}

For the following set of questions, describe yourself as you generally are now, not as you wish to be in the future using the following 1-5 scale.

a. I have a rich vocabulary.

b. I have difficulty understanding abstract ideas.

c. I have a vivid imagination.

d. I am not interested in abstract ideas.

e. I have excellent ideas.

f. I do not have a good imagination.

g. I am quick to understand things.

h. I use difficult words.

i. I spend time reflecting on things.

$\mathrm{k}$. I am full of ideas. 


\section{Creativity valence}

Please rate how much value you attach to the following factors using the 1-7 scale.

A. Opportunities to generate ideas for improving or renewing products and services in the organization.

B. Ability to generate new ideas on how to optimize knowledge and skills.

C. Encouragement to use your creativity in solving problems related to work.

D. Support from your supervisors and colleagues when you come up with a new idea in your job.

\section{Job meaningfulness valence}

Please rate how much value you attach to the following factors using the 1-7 scale.

A. Doing a variety of tasks using different skills and talents.

B. Ability to complete a project that you have started.

C. Significance of your work to the overall goals of the organization.

D. The difference your work makes in the well-being of your organization and its coworkers.

E. Ability to do a task from start to finish.

F. Ability to do skillful and interesting jobs rather than simple and repetitive jobs.

G. Feeling proud of the work you do in your job.

\section{Socially constructed entrepreneurial identity}

Please answer the extent to which you agree or disagree with the following statements using the 1-7 scale provided below.

A. Others' perception of you as an entrepreneur enhances your sense of who you are.

B. Other entrepreneurs' failures hurt your sense of who you are.

C. When someone praises entrepreneurs, it enhances your self-identity.

D. When talking about entrepreneurs, you say "we" rather than "they" because that is who you are.

E. Your ties with the entrepreneurial community strengthen your self-image.

\section{Intrinsically prospected entrepreneurial identity}

Please answer the extent to which you agree or disagree with the following statements using the 1-7 scale provided below.

A. An entrepreneur has always been part of who you want to be.

B. You are proud that you want to be an entrepreneur.

C. The term "entrepreneur" reinforces your sense of who you want to be.

D. Other entrepreneurs' successes confirm your sense of who you want to be. 


\section{Entrepreneurial intentions}

Please answer the extent to which you agree or disagree with the following statements using the 1-7 scale provided below.

You will start a new business in the near future.

You are determined to start your own business in the near future.

You have seriously thought about creating your own business in the new future.

You will make every effort to create a new business in the near future.

You intend to start a new business in the new future.

You have already started to engage in new business creation activities.

\section{Entrepreneurial self-efficacy}

The following statements measure your self-efficacy in entrepreneurship; please rate your confidence in the following activities using the 1-7 scale provided below:
A. In successfully identifying new business opportunities.
B. In creating new products/services.
C. In exploring new markets and new regions for existing products/services.
D. In commercializing new ideas/ products/services.

\section{Risk attitude valence}

Please rate how much value you attach to the following factors using the 1-7 scale.

a. work environments where you are encouraged to take risks to get results in your job

b. employer tolerance for failure when employees are trying to achieve company goals

c. ability to make bold decisions in uncertain situations without fear of losing your job 


\section{CURRICULUM VITAE}

Krishna P Poudel

30 Brandy Drive, Greensboro, North Carolina

Email: poudel.krishna1380@gmail.com

\section{Education}

Ph.D., 2014

M.P.A., 2007

M.A., 2002

B. A., 2000
Entrepreneurship, University of Louisville, KY, USA.

Public Administration, Cornell University, NY, USA.

Political Science, Tribhuvan University, Kathmandu, Nepal. (First division, top 5\% graduate).

Psychology and Political Science, Tribhuvan University, Nepal. (First division, top student at Trichandra College in major).

\section{Academic Positions}

1. $2013-2014$

3. $2004-2005$

4. $2003-2005$
Adj. Assistant Professor of Entrepreneurship School of Business and Economics North Carolina A\&T State University, NC, USA

$\underline{\text { Instructor } \& \text { Research Assistant }}$

College of Business, University of Louisville, KY, USA.

Faculty

Bachelor's of Rural Development Program, Classic International College, Kathmandu, Nepal.

Faculty

Bachelor's of Development Studies Program National College, Kathmandu, Nepal. 


\section{Research Interests}

Entrepreneurship | Entrepreneurial Identity | Firm Strategic Orientations/Entrepreneurial Orientation | Organizational Rewards | Organizational Structure | Entrepreneurial Founding Teams | New Venture Growth.

\section{Research Method Skills}

Structural Equation Modeling (including Latent Growth Curve Modeling) $\mid$ Hierarchical Linear Modeling (including Piecewise Linear Modeling and Polynomial Growth Modeling) | Multivariate (MANOVA, Repeated Measure ANOVA) | Logistic Regression | Multiple Linear Regression | Self-Organizing Maps (SOM) | Neural Networks.

\section{Publications}

1. Poudel, K. P., Carter, R., \& Lonial, S. 2012. The Process Aspect of the Entrepreneurial Orientation - Performance Relationship: Uncovering the Mediating Roles of Technological Capability, Innovation, and Firm Growth. Frontiers of Entrepreneurship Research.

2. Kemelgor, B., \& Poudel, K.P. 2009. Do You Care Anything Else Than How Much You Get? A Look at the Employee Valence Factor for Non-financial and Financially Unconvertible Rewards in Entrepreneurial and Non-Entrepreneurial Firms. Frontiers of Entrepreneurship Research.

3. Poudel, K. P., Marino, L., Lonial, S., \& Thatcher, S.M.B. 2012. Exploring Direct and Contingency Effects of Entrepreneurial Orientation, Learning Commitment, and Market-linking Capability on Performance. Frontiers of Entrepreneurship Research. [Summary].

4. Poudel, K.P. 2011. The Impact of Founders' Competencies and Commitment on New Venture Growth: A Longitudinal Analysis. Frontiers of Entrepreneurship Research. [Summary].

5. Poudel, K. P. 2010. Is the Black Box Opened Yet? A Conceptual Framework of Venture Capitalist-Entrepreneur Relationship in Social Exchange Theory Perspective. Southern Management Association Proceedings.

\section{Peer-reviewed Conference Presentations}

1. Poudel, K. P., Marino, L., Lonial, S., \& Thatcher, S.M.B. 2012. Exploring Direct and Contingency Effects of Entrepreneurial Orientation, Learning Commitment, and 
Market-linking Capability on Performance. Babson College Entrepreneurship Research Conference (BCERC). June. Texas, USA. (Co-presenter, along with L. Marino).

2. Poudel, K. P., Carter, R., \& Lonial, S. 2012. The Process Aspect of the Entrepreneurial Orientation - Performance Relationship: Uncovering the Mediating Roles of Technological Capability, Innovation, and Firm Growth. Babson College Entrepreneurship Research Conference (BCERC). June. Texas, USA. (Presenting author).

3. Poudel, K.P. 2011. The Impact of Founders' Competencies and Commitment on New Venture Growth: A Longitudinal Analysis. Babson College Entrepreneurship Research Conference (BCERC). June. Syracuse, NY, USA.

4. Poudel, K. P., \& Thatcher, S.M.B. 2010. The Case for a Knowledge Corridor of Mediation in Models of Team Effectiveness. Academy of Management Annual Meeting. August. Montreal, Canada. (Presenting author).

5. Poudel, K. P. 2010. Is the Black Box Opened Yet? A Conceptual Framework of Venture Capitalist-Entrepreneur Relationship in Social Exchange Theory Perspective. Southern Management Association Annual Meeting. October. Florida, USA.

6. Poudel, K. P., \& Thatcher, S.M.B. 2010. The Role of Entrepreneurial Organizational Structure in Opportunity Identification and Exploitation: Resolving the Paradoxes of Uncertainty \& Inertia. International Council for Small Business World Conference. June. Cincinnati, Ohio, USA. (Presenting author).

7. Kemelgor, B., \& Poudel, K.P. 2009. Do You Care Anything Else Than How Much You Get? A Look at the Employee Valence Factor for Non-financial and Financially Unconvertible Rewards in Entrepreneurial and Non-Entrepreneurial Firms. Babson College Entrepreneurship Research Conference (BCERC). June. Wellesley, MA, USA. (Presenting author - both).

\section{Honors, Awards, and Editorial Responsibilities}

1. $\quad$ Editorial Board. 2014-present. International Entrepreneurship and Management Journal, Published by Springer, New York, USA.

2. Outstanding Reviewer Award. 2010. Academy of Management, Annual Meeting (GDO Division), Montreal, Canada.

3. Sponsorship for Access to Confidential NORC Enclave Data. 2010. Kauffman Foundation, USA. [Sponsorship granted on the basis of competitive proposals from researchers globally]. 
4. $\quad$ Associate Editor. Fall 2006. The Current, Public Policy Journal Published by Cornell University, New York, USA.

5. Research Editor. Spring 2006. The Current, Public Policy Journal Published by Cornell University, New York, USA.

\section{Manuscript Ready for Submission}

1. Poudel, K. P., Carter, R., \& Lonial, S. A Multi-theoretical Approach to Entrepreneurial Orientation-Performance Relationship: The Roles of Technological Capability and Consumer Attitude.

(Journal of Business Research, tentative submission date 12/2014)

Working Papers (Organized in the order of submission priority/plan)

1. Poudel, K. P., Marino, L., Lonial, S., \&Thatcher, S.M.B. Exploring Direct and Contingency Effects of Entrepreneurial Orientation, Learning Commitment, and Market-linking Capability on Firm Performance.

(Revisions for submission to Strategic Management Journal)

2. Kemelgor, B., \& Poudel, K. P. Without Entrepreneurial Employees? Direct, Contingent, and Configurational Influence of Employees' Attitudes to Rewards on Organizational Entrepreneurship.

(Targeted at Journal of Management - data analysis complete - writing stage)

3. Poudel, K. P., \& Thatcher, S.M.B. The Role of Entrepreneurial Organizational Structure in Opportunity Identification and Exploitation: Resolving the Paradoxes of Uncertainty \& Inertia.

(Targeted at Academy of Management Review - inter-author draft revision stage)

4. Poudel, K. P. Understanding the Individual Level Entrepreneurial Identity: Identity Development, Complexity, and Variations across Entrepreneur Types.

(Targeted at Academy of Management Review - dissertation essay \# 1)

5. Poudel, K. P. Exploring the Determinants of Individual Level Entrepreneurial Identity.

(Targeted at Journal of Applied Psychology - dissertation essay \# 2)

6. Poudel, K. P. Entrepreneurial Identity: The Missing Link in the Nascent Entrepreneurship.

(Targeted at Journal of Business Venturing - dissertation essay \# 3) 
7. Poudel, K. P., \& Thatcher, S.M.B. An Integrated Model of Team Effectiveness: The Case for a Knowledge Corridor of Mediation.

(Targeted at Journal of Management - inter-author draft revision stage)

8. $\quad$ Poudel, K. P., Thatcher, S.M.B., \& Baucus, M. Organizational Compassion: The Importance of Employees' Social Comparisons \& Personal Reflections.

(Targeted at Academy of Management Review - inter-author draft revision stage)

9. Poudel, K. P. The Impact of Founders' Competencies and Commitment on New Venture Growth: A Longitudinal Analysis.

(Targeted at Entrepreneurship Theory and Practice - draft revision stage)

10. Poudel, K. P. Is the Black Box Opened Yet? A Theoretical Framework of Investor-Entrepreneur Relationship in Social Exchange Theory Perspective.

(Targeted at Administrative Science Quarterly - Theory draft complete, plans for qualitative data collection)

\section{Academic Service}

1. External Reviewer.

- Academy of Management Review. (Since 2011).

- Administrative Science Quarterly. (Since 2011).

- Journal of Management Studies. (Since 2010).

○ Journal of Business Venturing. (Since 2010).

○ Entrepreneurship Theory \& Practice. (Since 2011).

- International Entrepreneurship and Management Journal. (Since 2010).

2. $\underline{\text { Reviewer. }}$

○ Annual Meeting, Academy of Management. (2011, 2010).

(For Entrepreneurship, Organization and Management Theory, and Gender \& Diversity in Organizations divisions).

- Annual Conference, Southern Management Association. (2011, 2010, 2009).

- Annual Global Conference, International Council for Small Business. (2011, 2010).

3. Session Chair. Babson College Entrepreneurship Research Conference. (June 2011), Syracuse, USA.

4. Discussant. Annual Conference, Southern Management Association. (October 2010), St. Petersburg, Florida, USA. 
5. Coordinator. 2013. Entrepreneurship Week, coordinated various entrepreneurship related programs that benefited entrepreneurial students as well as entrepreneur community at large. North Carolina Agricultural and Technical State University, Greensboro, NC.

\section{Grants, Scholarships, Assistantships, Fellowships}

1. Travel Grant. 2012, 2011, 2010, 2009. College of Business, University of Louisville. (For various conferences).

2. Travel Grant. 2011. Kauffman Foundation. (For Babson Conference, Syracuse).

3. Graduate Student Scholarship Travel Grant. 2010. University of Louisville. (For Academy Meeting).

4. Assistantship. 2008-2012. College of Business, University of Louisville, USA.

5. Tuition Fellowship. 2005- 2007. Cornell Institute for Public Affairs, Cornell University, USA.

6. Tuition Scholarship. 1997- 2000. Trichandra College, Kathmandu, Nepal.

\section{Teaching Experience}

1. 2014, Spring: Entrepreneurship (MGMT 425). School of Business \& Economics, North Carolina Agricultural \& Technical State University, NC, USA. [2 sections].

2. 2013, Fall: Entrepreneurship (MGMT 425). School of Business \& Economics, North Carolina Agricultural \& Technical State University, NC, USA.

3. 2013, Fall: Management Concepts (MGMT 422). School of Business \& Economics, North Carolina Agricultural \& Technical State University, NC, USA.

4. 2012, Fall: Operations Management (MGMT 401). College of Business, University of Louisville, KY, USA.

5. 2012, Spring: Operations Management (MGMT 401). [2 sections]. College of Business, University of Louisville, KY, USA.

6. 2011, Spring: Management \& Organizational Behavior (MGMT 301). [2 sections]. College of Business, University of Louisville, KY, USA.

7. 2010, Fall: Management \& Organizational Behavior (MGMT 301). [2 sections]. College of Business, University of Louisville, KY, USA.

8. 2010, Spring: Business Statistics (MGMT 201, co-taught, part of Teaching Practicum).

College of Business, University of Louisville, KY, USA. 
9. 2003-2005: Political and Constitutional Development in Nepal. [Multiple sections]. National College, Kathmandu, Nepal.

10. 2004-2005: Rural Economics.

Classic International College, Kathmandu, Nepal.

\section{Teaching Evaluations}

(Most recently taught five classes at University of Louisville and four classes at North Carolina Agricultural \&Technological State University)

Among the top (quartile) instructors in the department for Spring 2011, Spring 2012 \& Fall 2012 at University of Louisville.

1. Accessibility: "The instructor has been accessible to you outside of class". (1-5 scale)

\begin{tabular}{|l|l|l|l|l|}
\hline & University & Mean & Median & Mode \\
\hline Entrepreneurship (425) Spring 2014 [002 Section ] & NCAT & 4.08 & 4.5 & 5 \\
\hline Entrepreneurship (425) Spring 2014 [003 Section ] & NCAT & 3.83 & 3.5 & 3 \\
\hline Entrepreneurship (425) Fall 2013 [004 Section ] & NCAT & 4 & 4 & 4 \\
\hline Management Concepts (422) Fall 2013 [004 Section ] & NCAT & 3.88 & 4 & 3 \\
\hline Operations Management (401) Fall 2012 [02 Section] & U of L & 4.03 & 4 & 5 \\
\hline Operations Management (401) Spring 2012 [01 Section] & U of L & 4.13 & 4 & 4 \\
\hline Operations Management (401) Spring 2012 [03 Section] & U of L & 3.96 & 4 & 5 \\
\hline Management and OB (301) Spring 2011[77 Section] & U of L & 3.75 & 3.5 & 3 \\
\hline Management and OB (301) Spring 2011[03 Section] & U of L & 4 & 4 & 5 \\
\hline
\end{tabular}

2. Effectiveness: "Considering both the limitations and possibilities of the subject matter and course, how would you rate the overall teaching effectiveness of the instructor?" (1-5 scale)

\begin{tabular}{|l|l|l|l|l|}
\hline & University & Mean & Median & Mode \\
\hline Operations Management (401) Fall 2012 [02 Section] & U of L & 3.63 & 4 & 4 \\
\hline Operations Management (401) Spring 2012 [01 Section] & U of L & 3.81 & 4 & 3,4 \\
\hline Operations Management (401) Spring 2012 [03 Section] & U of L & 3.54 & 4 & 4 \\
\hline Management and OB (301) Spring 2011[77 Section] & U of L & 3.63 & 3 & 3 \\
\hline Management and OB (301) Spring 2011[03 Section] & U of L & 3.31 & 3 & 3 \\
\hline
\end{tabular}

3. Organization: "The instructor was organized in class". (1-5 scale)

\begin{tabular}{|l|l|l|l|l|}
\hline & University & Mean & Median & Mode \\
\hline Entrepreneurship (425) Spring 2014 [002 Section ] & NCAT & 3.83 & 4 & 5 \\
\hline Entrepreneurship (425) Spring 2014 [003 Section ] & NCAT & 3.83 & 4 & 4 \\
\hline Entrepreneurship (425) Fall 2013 [004 Section ] & NCAT & 3.89 & 4 & 4 \\
\hline Management Concepts (422) Fall 2013 [004 Section ] & NCAT & 3.88 & 4 & 4 \\
\hline
\end{tabular}


4. Preparedness: "The instructor was well prepared for class." (1-5 scale)

\begin{tabular}{|l|l|l|l|l|}
\hline & University & Mean & Median & Mode \\
\hline Entrepreneurship (425) Spring 2014 [002 Section ] & NCAT & 4 & 4.5 & 5 \\
\hline Entrepreneurship (425) Spring 2014 [003 Section ] & NCAT & 3.83 & 4 & 4 \\
\hline Entrepreneurship (425) Fall 2013 [004 Section ] & NCAT & 4.22 & 4 & $5 / 4$ \\
\hline Management Concepts (422) Fall 2013 [004 Section] & NCAT & 4.06 & 4 & 5 \\
\hline
\end{tabular}

5. Erudition: "The instructor was knowledgeable about the subject matter." (1-5 scale)

\begin{tabular}{|l|l|l|l|l|}
\hline & University & Mean & Median & Mode \\
\hline Entrepreneurship (425) Spring 2014 [002 Section ] & NCAT & 3.82 & 4 & 5 \\
\hline Entrepreneurship (425) Spring 2014 [003 Section ] & NCAT & 4 & 4 & 4 \\
\hline Entrepreneurship (425) Fall 2013 [004 Section ] & NCAT & 4.22 & 4 & $5 / 4$ \\
\hline Management Concepts (422) Fall 2013 [004 Section] & NCAT & 3.75 & 4 & $5 / 3$ \\
\hline
\end{tabular}

\section{Sample Student Comments from the Teaching Evaluation Reports (Verbatim)}

- Most of the content in this course is a refresher for me. I will say the critical thinking aspect was worthwhile. I welcome and enjoy this new approach to learning. I always felt that Kentucky schools only taught us to memorize content rather than learn and apply. Thanks for the change. [MGMT. 301].

- He made us think. He didn't just lecture and talk "at us", he got us involved in the discussion. [MGMT. 301].

- Powerpoints would be helpful before going over material not after. He tends to talk very fast and it is hard to understand it all/grasp all the information. [MGMT. 401].

- The instructor was very fair and respectful to the students in the class. Knowledgeable about the material. He obviously enjoys teaching and doing great for his first time teaching this class. Got better as the semester went along. [MGMT. 401].

- The whole course was great. The way it was taught and how the materials where covered in the exams and quizzes was all very relevant. I really enjoyed the course and the enthusiasm of the instructor. [MGMT. 401].

- Class discussions could be too long and drawn out. I know he was trying to engage discussions but sometimes we had to cover difficult material too quickly because we spent too much time on soliciting answers from the class. Needs more balance there. [MGMT. 401].

- I really enjoyed this course! It was organized very effectively, and the lectures were very beneficial (for those students that paid attention, at least!!!). The structure of the course helped me learn the material so well, and it is material that I feel like I will be able to retain for a very long time. Which is something that I cannot always say about courses 
here at $U$ of L. I also enjoyed incorporation of The Goal into the class. In addition, I thought the textbook was a great choice as well. [MGMT. 401].

- Although he is fairly new to teaching, Mr. Poudel did a fantastic job teaching this course. His passion and excitement for the material, as well as teaching, are very evident every day in class. He was always extremely prepared and organized in his approach. [MGMT. 401].

- Prof is very helpful and truly cares about his students but may need to evaluate his method of teaching as it is not always engaging to the students. [MGMT. 401].

\section{Affiliations}

○ Member, Academy of Management (2009 - 2014).

- Member, Southern Management Association (2010 - 2011).

- Executive Member, Nepal Association at Cornell (2005 - 2007), NY.

- Life Member, Nepal Red Cross Society (Since 2004).

- Member, Amnesty International Nepal (2004-2006).

\section{Master's Degree Thesis and Research Reports}

- 2007: Professional Report, Cornell University. Strategic market research done on behalf of Live Systems Technology SA (LSTSA), Colombia, attempting to penetrate US biopesticides market. (Supervisors - Prof. Randy Allen \& Prof. Norman Uphoff).

○ 2004: Academic Research Report, Tribhuvan University. Impact Evaluation of Tourism on Indigenous Tharu People.

- 2002: Thesis, Tribhuvan University. The SAARC Social Charter: Will It Be a Breakthrough in South Asian Regionalism? (Supervisor - Prof. Ram Kumar Dahal).

\section{Conference Consortia}

- Selected Participant. 2011. Doctoral Student Consortium. Babson College Entrepreneurship Research Conference, Syracuse, NY, USA.

○ Selected Participant. 2010. Entrepreneurship Doctoral Consortium. Academy of Management, Annual Meeting, Montreal, Canada.

○ Selected Participant. 2010. Doctoral Consortium. Southern Management Association, Annual Meeting, Florida, USA.

- Participant. 2009. New Doctoral Student Consortium. Academy of Management, Annual Meeting, Chicago, USA. 


\section{Non-academic Employment}

○ 2007 - 2008: Linguist. L3 Communications (A fortune 500 company) Virginia, USA.

○ 2002 - 2004: Consultant (Contract work). National Association of Village Development Committees in Nepal (NAVIN), Kathmandu, Nepal.

○ 1999 - 2000: Associate. Radisson Hotel (Privilege Plus project), Kathmandu, Nepal.

- 1996 - 2001: Language Trainer. Alpha-Beta Institute, Orchid Institute and IBM institute, Kathmandu, Nepal.

Ph.D. Coursework [* Denotes visiting faculty]

$\underline{\text { Methods }}$

○ Research Design

- Linear Statistics

- Multivariate Statistics

- Structural Equation Modeling

- Hierarchical Linear Modeling

○ Data Mining

- Quantitative Approach to Entrepreneurship

$\begin{array}{ll}- & \text { Dr. James O. Fiet } \\ - & \text { Dr. Richard Germain } \\ - & \text { Dr. Joseph Petrosko } \\ \text { - } & \text { Dr. Richard Germain } \\ - & \text { Dr. Jill Adelson } \\ - & \text { Dr. M. Kandtarzic } \\ \text { - } & \text { Dr. Per Davidsson* }\end{array}$

Theory

○ Venture Capital

- Sociological Foundations of Entrepreneurship

- Strategy and Entrepreneurship

○ Psychological Foundations of Entrepreneurship

- Current Topics in Entrepreneurship

- Organizational Behavior in Entrepreneurial Firms

- Economics Approach to Entrepreneurship

- Entrepreneurship Pedagogy \& Practice
- $\quad$ Dr. James O. Fiet

- Dr. Howard Aldrich*

- Dr. Jay Barney*

- Dr. Dean Shepherd*

- Dr. Scott Shane*

- Dr. Bruce Kemelgor

- Dr. Simon Parker*

- Dr. Melissa Baucus

\section{Personal}

○ Foreign Language Skills: Nepali, Hindi - native proficiency, Urdu - verbal only.

- Software: SPSS (PASW), SAS, LISREL, AMOS, \& HLM.

○ Singer/ Song Writer / Lyricist: Nepali Music, Hindi Music, \& English Music. 